\title{
Über Schreckneurosen in klinischer und unfallrechtlicher Beziehnng.
}

\author{
Von
}

\section{Dr. Paul Horn-Bonn,}

Oberarzt der intern-neurologischen Abteilung am Krankenhause der Barmherzigen Brüder (Direktor: Geheimrat Prof. Dr. Rumpf).

Bereits an anderer Stelle haben $R u m p f$ und ich die Forderung erhoben, die unter dem immer noch bäufig und gern gebrauchten, aber zweifellos klinisch vollkommen unklaren Begriff "traumatische Neurose" einhergehenden Krankbeitsbilder möglichst scharf zu differenzieren und den Namen "traumatische Neurose", der bei seiner Einführung durch Oppenheim sicher einen Fortschritt bedeutete, aber im übrigen lediglich einen Sammelbegriff darstellt, vollkommen fallen zu lassen. Auch von anderer Seite (Erben, Reichardt u. a.) ist, nachdem unsere Kenntnisse über das Wesen der "traumatischen Neu-

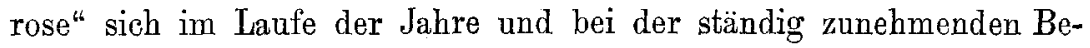
gutachtung nervöser Unfallfulgen wesentlich erweitert und unsere Anschauungen sich verschoben haben, auf das Unzweckmässige, ja für die klinische und unfallrechtliche Beurteilung geradezu Unbeilvolle dieser Bezeichnung hingewiesen worden; verleitet sie doch vielfach zu oberflächlichen Diagnosen und damit prognostisch zu vollkommen falschen Schlussfolgerungen. Fast täglich kann man aus ärztlichen Gutachten ersehen, dass nicht nur die verschiedenartigsten funktionell-nervösen Störungen, sondern auch sebr viele irrtümlich gedentete und in der Entwicklung begriffene organische Symptomenbilder mit dem bequemen und scheinbar alles deckenden Namen "traumatische Neurose" belegt werden; glaubt man sich doch damit der Mühe enthoben, das jeweils vorliegende Krankheitsbild nach Entstebung, Symptomenbild und Verlauf näher zu analysieren. So sahen wir eine typische Arthritis deformans der Wirbelsäule nach Rückenquetschung, ausgesprochene myokarditische Veränderungen nach Brustkontusion, eine Meningitis serosa nach Schädelverletzung und zahlreiche sonstige organische Erkrankungen als "traumatische Neurose" bezeichnet. Aber auch in der Benennung rein funktionell-nervöser 
Störungen besteht vielfach noch grösste Verwirrung. So werden beispielsweise nervöse Störungen nach Sehreck im selben Falle bald als Hysterie, bald als Neurasthenie oder Hypochondrie, bald als "traumatische Neurose" bezeichnet. Schuld an diesen Missständen und Unklarheiten ist sicher zum grossen Teile das Fehlen einer anerkannten, den klinischen und praktischen Bedürfnissen Rechnung tragenden Klassifikation der Unfallneurosen. Die auf rein symptomatologischen Gesichtspunkten beruhende Einteilung in traum atische Neurasthenie, Hysterie, Hypochondrie und Mischformen kann, wie auch Reichardt sehr scharf betont, sowohl in klinischer als vor allem auch in versicherungstechnischer Beziehung nicht mehr als ausreichend betrachtet werden, da sie einerseits mit viel zu unbestimmten Ausdriicken arbeitet und andererseits die gerade für die unfallrechtliche Beurteilung wichtigsten Faktoren vollkommen unberücksichtigt lässt.

Ich habe daher, besonders aus diesen praktischen Bedürfnissen heraus, geglaubt, auf einen anderen Weg hinweisen zu müssen, der die klinische und unfallirechtliche Tragweite der bei der ganzen Krankheitsgenese direkt und indirekt mitwirkenden Momente schärfer erkennen lässt, und habe bereits auf der 6. Jahresversammlung der Gesellschaft deutscher Nervenärzte (Hamburg, September 1912) eine Einteilung der Unfallnearosen nach ätiologischen Gesichtspunkten rorgeschlagen, die bei Berücksichtigung der praktisch wichtigsten Faktoren (Schreck, Contusio capilis und Commotio cerebri, allgemeine Erschütterung mit Commotio spinalis, sonstige lokale Traumen, Rentenkampf) sich folgendermassen gestalten würde:

I. Primäre Neurosen (direkte, unmittelbare Unfallfolgen).

1. Schreckneurosen.

2. Kommotionsneurosen i. w. S.,

a) cerebraler Typ (Contusio capitis und Commotio cerebri),

b) spinaler Typ (nach schwerer allgemeiner Erschütterung; speziell Commotio spinalis).

3. Neurosen nach sonstiger lokaler Kontusion.

4. Mischformen (Kombinationen von 1-3).

II. Sekundäre Neurosen (indirekte, mittelbare Unfallfolgen). Rentenkampfneurosen,

a) als Fortentwicklung von I (1-4),

b) als selbständige Krankheitsform.

Es ist ja geradezu ein Dogma geworden, der unmittelbaren Einwirkung eines Unfalles, d. h. den primären ursächlichen Momenten für die Gestaltung des Krankheitsbildes nur eine untergeordnete Be- 
deutung beizumessen. Ich muss aber demgegenüber, so sehr auch der unheilvolle Einfluss der sekundär einwirkenden Momente, der Befürchtung:s- und Begehrungsvorstellungen, der vielfachen falschen Autosuggestioneu und Suggestionen Dritter, überhaupt des ganzen Rentenkampfes anzuerkennen ist, doch darauf hinweisen, dass mindestens dieselbe krankheitsbestimmende Wirkung auch den primären ursächlichen Faktoren zukommt. Der von Nonne in der Diskussion zu meinem Vortrag u. a. geäusserten Ansicht, die Art und Schwere eines Unfalles seien für die Gestaltung des Falles ohne Belang, vermag ich jedenfalls nach unseren Erfahrungen nicht ohne weiteres beizustimmen, wenn ich auch davon überzeugt bin, dass durch die mit dem Rentenkampf einsetzende Alteration der Psyche nach hypochondrisch-querulatorischer Richtung hin sämmtliche Formen der primären Unfallneurosen eine gewisse einheitliche Färbung exhalten, eben das Gepräge der sogen. Rentenkampfneurosen, wobei sich der Charakter des ursprünglichen Grundtyps (Schreckneurose etc.) mehr oder weniger verwischt. In den Anfangsstadien, in denen noch sekundär einwirkende Schädlichkeiten fehlen, heben sich aber die Grund ty pen der primären Neurosen als ziemlich gut umschriebene Symptomenbilder mit erkennbarer, charakteristischer Schärfe voneinander ab (Schreckneurosen, Kommotionsneurosen ete.). Dabei ist es keineswegs gleichgïltig, ob es sich um ein geringfügiges oder ein schweres Trauma, um einen leichten Schrecken oder um Todesangst, um eine Kopfkontusion oder um eine schwere Gehirnerschütterung gehandelt hat. Mit Recht sagt Reichardt: "Es ist ein grosser Unterschied, ob jemand Stunden oder auch nur Minuten oder Sekunden lang in wirklicher Todesgefahr geschwebt hat und dies auch gewusst hat (wirklich begründete Todesangst), bevor er gerettet wurde, oder ob jemand, der nur leicht verletzt wird, im gleichen Augenblick, wo er überhaupt die Verletzung begreift, auch weiss, dass ihm gar nichts Ernsthaftes passiert ist." Es liegt auch, was die Eigenart des Traumas anbetrifft, klar anf der Hand, dass die rein psychische Erschütterung des Schrecks, von pathologischen Gesichtspunkten aus betrachtet, eine prinzipiell andersartige Einwirkung bedeutet als ein Kopftrauma, beispielsweise eine Gehirnerschütterung, bei der vielfach direkte anatomische Schädigungen, feinere Blutungen, Strukturveränderungen und Degenerationsherde auftreten können, ohne dass der funktionelle Charakter der Neurose als solcher in klinischer Hinsicht geändert würde. Auch die Neurosen nach sonstigen lokalen Traumen und nach schwerer allgemeiner Erschütterung mit Commotio spinalis haben ihre besonderen Eigentümlichkeiten, deren Besprechung mich aber an dieser Stelle za weit führen würde. Nur 
möchte ich bezüglich der Neurosen nach allgemeiner Frschütterung, die dem Erichsenschen Bilde• der "railway-spine" am nächsten stehen, kurz erwähnen, dass sicher in vielen derartigen Fällen trotz ihres funktionellen klinischen Charakters, pathologisch-anatomisch betrachtet, Übergangsformen zu echten Hämatomyelien, molekulare Umlagerungen, strukturelle Schädigungen der Ganglienzellen und ihrer Fortsätze, feinste Blutungen und Degenerationsherde vorliegen dürften. Auch Strümpell ist der Ansicht, dass eine allgemeine mechanische Erschütterung des Nervensystems für manche Fälle keineswegs von der Hand zu weisen ist. Dass hierbei auch die Schwere des Traumas von Bedeutung sein kann, liegt klar zutage. Andererseits ist durchaus zuzugeben, dass unter dem Einflusse sekundärer schädlicher Momente sich oft genug ein Missverhältnis zwischen direkter Unfalleinwirkung und schliesslich resultierendem Krankheitszustande herausbildet. Darans aber eine grundsätzliche Belanglosigkeit des primären Traumas schlussfolgern zu wollen, würde sicher den tatsächlichen Verhältnissen nicht entsprechen. Ich gebe auch weiterhin zu, dass die Durchführung des Finteilungsprinzipes nach ätiologischen Gesichtspunkten in vereinzelten Fällen auf Schwierigkeiten stösst, glaube aber doch, dass es wenigstens die praktisch wichtigsten Grundtypen klar hervortreten lässt. Übrigens hat Nonne unter Einschränkung seines anfänglich abweichenden Standpunktes wenigstens den Schreck- und Kommotionsneurosen in der oben erwähnten Diskussion eine gewisse Sonderstellung unter den Unfallneurosen eingeräumt. Völlige Klärung werden aber nur systematisch durchgeführte, eingehende Untersuchungen über Genese, Symptomatologie und Verlauf der einzelnen Krankheitsformen bringen können.

Als erste grosse Gruppe der Unfallneurosen habe ich die Schreckneurosen gleichmässig durchzuarbeiten begonnen und zwar habe ich, um ein möglichst reines klinisches Bild zu erhalten, zunächst nur diejenigen Fälle ins Auge gefasst, bei denen der Unfall einzig und allein in einer Schreckwirkung bestand und mit keinerlei Nebenverletzung, die das Krankheitsbild hätte beeinflussen können (Kopfrerletzung, sonstige lokale Kontusion, schwere Allgemeinerschütterung), verbunden war. Natürlich wurde damit die Zahl der zu verwertenden. Fälle, die ohne diese Einschränkung etwa das 3-4fache betragen hätte, ganz beträchtlich eingeengt. Im ganzen liegen der vorliegenden Arbeit 100 Fälle "reiner" Schreckneurosen zugrunde, von denen 16 bereits früher von mir veröffentlicht wurden. Hierzu kommen nun 80 neu beobachtete Fälle, sowie 4 Fälle, die mir in dankenswertester: Weise von der Kgl. Eisenbahndirektion Frankfurt a/Main aktenmässig zur Verfügung gestellt wurden. 
Im einzelnen verteilen sich die 80 neu beobachteten $F \ddot{a l l}$ e folgendermassen:

\begin{tabular}{l|c|c|c}
\hline & Männer & Frauen & Zusammen \\
\hline $\begin{array}{l}\text { 1. In gewerblichen (privaten und staat- } \\
\text { lichen) Betrieben angestellte Ar- } \\
\text { beiter usw. . . . . . . . . }\end{array}$ & 14 & & \\
\hline $\begin{array}{l}\text { 2. Eisenbahn- und Strassenbahnpassa- } \\
\text { giere . . . . . . . . . . }\end{array}$ & 26 & 26 & 16 \\
\hline \begin{tabular}{l} 
3. Telephonistinnen . . . . . \\
\hline
\end{tabular} & - & 12 & 12 \\
\hline
\end{tabular}

Die früher veröffentlichten 16 Fälle sowie die 4 aktenmässig mir bekannten Fälle betreffen sämtlich im Eisenbahnbetrieb zu Schaden gekommene Personen.

Auffallend ist nun zunächst die relative Seltenheit "reiner" Schreckneurosen, betrug doch die Gesamtzahl aller in den letzten 5 Jahren auf der intern-neurologisehen Abteilung begutachteten Unfallneurosen gegen 3000. Die Ursache für das nur vereinzelte Vorkommen von Schreckneurosen ist wohl in der Hauptsache darin zu suchen, dass die weitaus meisten unserer Unfallpatienten zum Kreise der gewerblichen Arbeiter gehörten. Bei diesen (siehe Gruppe 1) kommen aber eigentliche Schreckneurosen und ganz besonders absolut "reine" Fälle nur in verschwindender Zahl zur Beobachtung, obwohl. die Unfälle, die sich in Bergwerken, Fabriken oder sonstigen gewerblichen und industriellen Unternehmen ereignen, abgesehen von ibrer oft erheblichen Tragweite in körperlicher Beziehung, auch zur Hervorbringung starker psychischer Emotionen sehr wohl geeignet sind. Vielfach tritt aber die psychische Einwirkung des Unfalles, gegenüber der für die Frage der Erwerbsfähigkeit zunächst in Betracht kommenden körperlichen Schädigung im Bewusstsein des Verletzten vollkommen zurück, wobei auch eine gewisse Indolenz und Abstumpfung durch stete Tätigkeit in einem gefahrdrohenden Betrieb eine Rolle spielen mag. Jedenfalls scheinen Schreckwirkungen bei Arbeitern, falls sie überhaupt zu stärkeren Störungen führen, meist in relativ kurzer Zeit überwunden zu werden; bekommt man doch ältere Fälle von „reiner" Schreckneurose, über die 13. Woche hinaus, kaum zu Gesicht. Man könnte zur Erklärung dieser sicher auffälligen Erscheinung vielleicht noch den Umstand heranziehen, dass die Unfallrente der Arbeiter erheblich geringer ist als die unfallverletzten Privatpersonen 
gesetzlich zustehende Entschädigung; mehr in Betracht kommt aber m. E. die Tatsache, dass die Arbeiter einen heftigen Schreck ohne gleichzeitige körperliche Schädigung meist garnicht als „Unfall" empfinden und auch die Arbeitgeber ein derartiges Ereignis nicht als anmeldepflichtig zu betrachten pflegen. Immerhin trifft man vereinzelte Ausnahmen. So hat beispielsweise, um einige besonders eigenartige Fälle herauszugreifen, das R.-V.-A. Erschrecken infolge Anschreiens durch einen Vorgesetzten als Betriebsunfall angesehen. Das Anschreien war wesentlich durch die vom Kläger verschuldete Vernachlässigung der Betriebsarbeit hervorgerufen, fand also seine Veranlassung im Betrieb (Breithaupt). „Den Schreckneurosen zugerechnet und als entschädigungspflichtig hat das R.-V.-A. ferner einen Fall erklärt, bei dem ein Arbeiter beauftragt wurde, kadaverös riechendes Blut und Leichenteile eines Verunglückten mit Lysol zu übergiessen. Der Arbeiter beschuldigte eine Lysolvergiftung als Ursache der bei ihm auftretenden nervösen Störungen, während Prof. L. eine durch Schrecken hervorgerufene Störung annahm "(Rumpf). Als entschädigungspflichtiger Unfall aufgefasst wurde auch der von Placzek mitgeteilte Fall, wobei ein herzkranker Patient durch den plötzlichen Anblick eines blutüberströmten Menschen eine wesentliche Verschlimmerang seines Herzleidens erfuhr. Noch exzeptioneller liegt ein ron Flatau beobachteter Fall: Ein Bierfahrer hatte seinen Wagen kurze Zeit unbeaufsichtigt gelassen und bemerkte später, dass ein unter dem Wagen befindlicher eiserner Kasten, der $1200 \mathrm{M}$. Wechselgeld enthielt, seines Inhalts beraubt war. Die an die hierbei erlittene Schreckeinwirkung sich anschliessende nervöse Erkrankung wurde vom R.-V.-A. als entschädigungspflichtige Unfallfolge anerkannt. Ersichtlich wird damit dem Begriffe "Unfall" eine Auslegung gegeben, die zum mindesten sehr weitgehend erscheint; andererseits vermag ich Flatau nicht ganz zu folgen, der das Ansehen eines Unglücksfalles nicht auch als persönliche Unfallschädigung gelten lassen will. Ich glaube, dass in dieser Hinsicht keine generellen, sondern nur Entscheidungen von Fall zu Fall angängig sind. Zudem erfordern, nebenbei bemerkt, die Haftpflichtfälle (Eisen- und Strassenbahnunfälle) eine etwas andere Beurteilung als die gewerblichen Unfälle, da sowobl Reichshaftpflichtgesetz wie B.-G.-B. in ihren Haftpflichtbestimmungen im Gegensatz zur Reichsversicherungsordnung den $\mathrm{Be}-$ griff „Unfall" überhaupt nicht kennen, sondern ganz allgemein von einer "Verletzung des Körpers oder der Gesundheit" sprechen. Andererseits muss natürlich, darin stimme ich Reichardt vollkommen bei, die Forderung erhoben werden, ein psychisches Trauma als wesentliche Teilursache einer Erkrankung oder einer eingetretenen Ver- 
schlimmerung nur dann anzuerkennen, wenn es sich tatsächlich nm eine sehr erbebliche, aussergew öhnlich starke psychische Emotion gehandelt hat. Auch muss das Auftreten der psychisch-nervösen Störungen in engem zeitlichen. Zusammenhang mit dem angeblichen Unfallereignis stehen und die psychisch-nervösen Störungen selbst müssen einigermassen charakteristisch sein, d. b. in das Symptomenbild der Schreckneurosè hinein passen. Ist dies nicht der Fall, so besteht stets der begründete Verdacht, dass die Störungen andere Ätiologie besitzen und vielleicht schon vor dem Unfall aus endogener Veranlagung oder aus sonstigen Schädlichkeiten heraus entstanden waren. Viele Psychopathen weisen an sich schon neurasthenische, hysterische und hypochondrische Erscheinungen auf, dazu kommen abnorme Charaktereigenschaften (Reichardt), wie Energielosigkeit, Weichlichkeit, Wehleidigkeit etc. Alle diese Erscheinungen müssen natürlich bei der späteren Feststellung der Unfallfolgen mit berïcksichtigt und bei der unfallrechtlichen Würdigung der Zusammenhangsfrage von den eigentlichen Schrecksymptomen so weit wie möglich abgesondert werden.

Bei den von uns beobachteten Fällen von reinen Schreckneurosen bei Arbeitern war als Ursache des Erschreckens u. a. angegeben: plötzliches Herausschlagen einer Stichflamme aus einem Kessel (Fall 5), Anblick herabstürzender Gesteinsmassen (Fall 13), unvermutetes Hinzutreten eines Arbeitskollegen in der ansgesprochenen Absicht, den anderen zu ersehrecken (Fall 16). In einem Falle erkrankte ein Steinbrucharbeiter (Fall 4) vor Schreck darüber, dass er "beinahe" in ein Schiessloch gefallen wäre. Ein anderer bekam eine typische Schreckneurose, als er von seinem Fahrrad stürzte und gleichzeitig dicht vor sich ein herankommendes Fuhrwerk erblickte. Ein junger Fabrikarbeiter (Fall 9), der in $3 \mathrm{~m}$ Höhe auf einer Leiter stand, rutschte mit dieser aus, konnte sich zwar noch halten, erkrankte aber infolge des erlittenen Schreckens. Figenartig liegt anch der Fall eines Postschaffners (Fall 10), der eine Eisenbahnunterführung gerade in dem Augenblick passierte, als über ihm ein D-Zug entgleiste; er glaubte, die Unterführung werde einstürzen und geriet in stärkste psychische Emotion, die eine charakteristische Schreckneurose im Gefolge hatte. Wir kommen damit schon ins Gebiet der mit dem Eisenbahnbetrieb verbundenen Unfälle, ron denen zunächst diejenigen der Eisenbahnbeamten und -arbeiter, für die ja unfallrechtlich analoge Gesichtspunkte (R.-V.-O.) in Betracht kommen wie für die gewerblichen Arbeiter, kurz hervorgehoben seien. Besonders ausgesetzt Schreckwirkungen jeder Art ist das gesamte Fahrpersonal, vor allem aber die Lokomotivführer, von denen auch eine 
ganze Reihe an Schreckneurose erkranken. So begutachteten wir noch neulich einen Lokomotivführer (Fall 2), der plötzlich vor seiner Maschine einen "dunklen Schatten" auftauchen sah, der sich später als ein stehengebliebener Packwagen herausstellte. Er vermochte noch in rascher Geistesgegenwart den Zug zum Stehen zu bringen, war aber von dieser Stunde an wegen stärkster psychisch-nervöser Störungen für mehrere Monate vollkommen dienstrunfähig. Manche Bahnbeamte überstehen 2, 3, anch 4 und 5 Unfälle gut, bis dann ein erneuter Unfall eintritt, dem ihre psyehische Widerstandskraft nicht mehr gewachsen ist. Auch einen derartigen Fall (1), der einen 59 jährigen Lokomotivführer betraf, beobachtete ich noch kürzlich; erst der 6. Unfall (beim Kreuzen eines entgegenkommenden Zuges schlug eine offen stehende Tür gegen den Lokomotivführerstand) vermochte das psychische Gleichgewicht für längere Zeit zu erschüttern, während die früheren Unfälle nur kurzdauernde Folgen gezeitigt hatten. Ins Gebiet der Schreckneurose gehört auch die Erkrankung eines Schrankenwärters (Fall 11), der in der Dunkelheit beim Schliessen der Schranken einen mit seinem Wagen herankommenden Fuhrmann zunächst übersehen hatte und sich hierüber heftig erschreckte; dazu kam als weiteres Moment noch eine heftige Auseinandersetzung mit dem Fuhrmann. In einem mir aktenmässig bekannten Fall (82) sah ein Weichensteller, wie ein Blitzstrahl in der Nähe der Weiche einschlug; obwohl er selbst nicht getroffen wurde, hatte der ausgestandene Schreck eine typische Erkrankung zur Folge. Auch der Anblick eines Zugzusammenstosses, einer Entgleisung od. dergl. führt gelegentlich zu Schreckneurosen. So litt ein Weichensteller (Fall 7), der eine Zugentgleisung mitansah, längere Zeit an psychisch-nervösen Erscheinungen.

Ganz analoge Fälle finden sich bei Eisen-oder Strassenbahnpassagieren. Die Kgl. Eisenbahndirektion Frankfurt a/M. teilte mir den Fall eines Kreisschulinspektors mit (Fall 84), der bein Verlassen des Zuges auf dem Bahnsteige sah, wie andere Passagiere beinahe von einem D-Zuge überiahren wurden. Der erlittene Schreck hatte eine mehrmonatige Psychoneurose im Gefolge. Wenn, wie ans oben gegebener Tabelle ersichtlich, die weitaus meisten Schreckneurosen im Bahnbetriebe ihre Entstehung finden, so dürfte nicht zuletzt die Eigenart dieses ganzen Betriebes, die Plötzlichkeit und oft katastrophal hereinbrechende Unvermitteltheit vieler Bahnunfälle verantwortlich zu machen sein, wenngleich ich ausdrücklich hervorheben möchte, dass viele angeblichen Eisen- oder Strassenbahnunfälle, an sich betrachtet, so geringfügig waren, dass andere Passagiere in keiner Weise in Mitleidenschaft gezogen wurden. Welche Momente im einzelnen hier 
in Betracht zu ziehen sind (individuelle Disposition, Rentensucht), wird weiterhin noch näher zu erörtern sein. Hier möchte ich nur die sehr beachtenswerte Tatsache hervorheben, dass im Eisenbahndirektionsbezirke Elberfeld im Jahre 1911 unter 195 Unfallpatienten 89 (= 46 Proz.) an nervösen Beschwerden erkrankten, sicherlich ein eklatanter Gegensatz zu der geringen Zahl der bei Berufsgenossenschaften zur Anmeldung kommenden Unfallneurosen (Biss, Merzbacher, Schultze und Stursberg) und im Hinblick auf die bisher oft enormen Entschädigungsansprüche jedenfalls ein Beweis, von welch erheblicher Bedeutung gerade die nervösen Erkrankungen nach Eisenbahnunfällen in praktischer Beziehung sind. Aber auch hier kommen, obwohl das psychisch-emotionelle Moment bei den Unfallneurosen nach Eisen- und Strassenbahuunfällen mit seinen verschiedenen. Variationen und graduellen Abstufungen (Furcht vor körperlicher Schädigung, Entsetzen über den Anblick Verwundeter oder Getöteter, Todesangst bei Entgleisungen oder Zusammenstössen etc.) fast stets die ausschlaggebende Rolle spielt, "reine" Schreckneurosen nur bei dem kleineren Teil der Fälle vor; jedenfalls fanden sich unter 170 früher von mir bearbeiteten Fällen von nervösen Erkrankungen nach Eisenbahnunfällen nur etwa 10 Proz. "reine" Schreckn e u rosen. Eine der häufigsten Krankheitsursachen waren Erschrecken und protrahierte Angst bei Zugentgleisungen, während bei den Strassenbahnunfällen das psychische Trauma meist in der mit Zusammenstössen gegebenen unvermittelten Schreckeinwirkung bestand. In anderen Fällen war es nur ein plötzlicher heftiger Stoss oder ein starkes Schleudern des Wagens, das als Ursache der Erkrankung beschuldigt wurde, also an sich ziemlich harmlose Ereignisse, während in anderen Fällen es sich tatsächlich um schwere Katastrophen handelte. Ausschlaggebend war aber stets das Plötzliche, Unerwartete, Gewaltsame der psychischen Alteration, mögen nun im einzelnen optische, akustische, mechanische oder sonstige Sinnesreize das vermittelnde, reaktionsauslösende Agens gebildet haben. Fehlen derartige Reize, z. B. bei schlafenden Passagieren, so bleibt auch in der Regel die "Erschütterung des Nervensystems" aus (Erichsen).

Unerwartete akustische Reize sind es auch, die bei der 3. Gruppe unserer Patienten, den Telephonistinnen die Schreckwirkung bedingten, so dass ihre Besprechung an dieser Stelle und ibre Einbeziehung ins Gebiet der Schreckneurosen durchaus begründet erscheint. Auch Bernhardt, Eulenburg, Jakoby, Räbinger und Schuster sind übereinstimmend der Ansicht, dass die nach Telephonunfällen auftretenden nervösen Störungen fast ausnahmslos plötzlichen, unerwarteten Gehörseindrücken und der dadurch hervorgerufenen psychi- 
schen Shockwirkung zur Last zu legen sind, und zwar werden vor allem die bei starkem Wecken (mehrmaliges und schnelles Drehen der Kurbel) auftretenden knackenden Geräusche („W eckgeräusche“) sowie die bei Gelegenheit atmosphäriseher Entladungen durch Blitzschlag in die Telephonleitung entstehenden starken Knallerscheinungen als ursächliche shockauslösende Momente betrachtet. Übergang von elektrischer Energie, wie er meist von den Patientinnen behauptet wird, kommt nur in seltenen Ausnahmefällen vor (Bernhardt) und ist nur möglich, wenn die Telephonistinnen, entgegen der Dienstvorschrift, die Verbindungsschnüre nicht am isolierten Griff, sondern am metallenen Ende anfassen, während der Teilnehmer weckt (Jakoby). Aber auch dann ist eine Schädigung durch den Strom an sich, da bei der Telephonie nur Schwachströme von etwa 5 Volt verwandt werden, im allgemeinen als ausgeschlossen zu betrachten. Sicher spielt bei allen Telephonunfällen die durch gelegentliche Zeitungsherichte genährte Furcht vor schädlichen Folgen (Telephonophobie und "Gewitterfurcht", Keraunophobie) bei der Entstehung der nervösen Störungen eine grosse Rolle. Nach dieser Richtung hin sind auch die Fälle von Schuster und Dana sehr bemerkenswert, bei denen das zufällige Berühren stromloser Hochspannungsdrähte. genügt hatte, schwere nervöse Erscheinungen auszulösen. Allerdings können bei der Telephonie in seltenen Fällen auch Starkströme übergehen, nämlich dann, wenn die Telephonleitung irgendwo mit einem Starkstromkabel in Berührung kommt oder wenn sich die Beamtin gerade in dem Augénblicke in die Leitung einschaltet, während diese von einem Blitzstrahl getroffen wird. Bernhardt vermochte allerdings unter einem grossen Material von Betriebsunfällen nach Blitzschlag niemals eine direkte elektrische Einwirkung auf die Beamtin nachzuweisen. Auch die technische Prüfung der Apparate und der Leitung ergab niemals einen Anhalt für das Vorliegen einer elektrischen Schädigung. Jedenfalls ist im Hinblick auf vereinzelte gegenteilige Auffassungen (Wallbaum) daran festzuhalten, dass es sich bei den nerrösen Störungen nach Telephonunfällen in der Regel um nichts Weiteres als um Schreckneurosen handelt, wie ich auch nach unserem allerdings geringen Material (12 Fälle) nur bestätigen kann. Übrigens ist Bernhardt der Ansicht, dass zwischen den durch eine Schalleinwirkung und den durch Starkstromübergang bei Telephonistinnen entstehenden krankbaften Erscheinungen völlige Übereinstimmung bestehe, da alle Symptome auch im letzteren Falle obne Zwang als durch Sehreck und intensive unvermittelte Schalleinwirkung bedingt betrachtet werden könnten, wie auch die Untersuchungen und Beobachtungen Jellineks an schlafenden Individuen 
schlussfolgern liessen, für die ein sonst tödlich wirkender Starkstrom sich als vollkommen ungefährlich erwies. Bezüglich der Starkströme bin ich, offen gestanden, skeptischer. Jedenfalls kann dann nicht mehr von Schreckneurose gesprochen werden, wenn sich, wie es tatsächlich mitunter der Fall ist, schwere organische Nervenstörungen nachweisen lassen, z. B. Netzhautablösung (Pfahl), Erscheinungen von Bulbärparalyse und Acusticusstörungen (Finkelnburg) oder sonstige zentrale oder periphere Schädigungen. Meist handelt es sich allerdings um ein Mixtum compositum von organischen und funktionell-nerrösen Störungen (Ganser, Schmaltz), wobei bald die psychischen Störungen als wesentlichster Befund betrachtet werden (Wilms), bald dem elektrischen Strom eine spezifisch nervenschädigende Wirkung zugeschrieben wird (Hoche). So beobachtete ich selbst kürzlich einen Fall (Fernsprechteilnehmer), bei dem es infolge Blitzschlags in die Leitung sowohl zu psychischen Shockerscheinungen als auch zu einer organischen isolierten Schädigung des linken Nerv. cruralis (Neuritis mit Abmagerung und Herabsetzung der faradischen und galvanischen Erregbarkeit) gekommen war: Auch Todesfälle durch Blitzschlag in die Leitung sollen vereinzelt vorkommen, ob durch Shockwirkung mit Lähmung des Atemund Gefässzentrums oder durch spezifische elektrische Schädigung, bleibe dahingestellt.

Aber auch bei sicherem Ausscllluss elektrischen Energieüberganges liegen organische Schädigungen noch im Bereiche der Möglichkeit, die vor Stellung der Diagnose Schreckneurose zunächst noch in Erwägung zu ziehen sind, und-zwar kommen hier diejenigen Schädigungen in Betracht, die durch intensive Schalleinwirkungen das Gehörorgan selbst erleiden kann. Abgesehen von den ausserordentlich seltenen Fällen traumatischer Trommelfellruptur (Veis), die durch starkes Weckläuten oder durch elektrische Starkstromeinwirkung bedingt sein kann (nur 3 Fälle in der literatur bekannt), sind es vor allem Erschütterungen der Hörnervenausbreitung im Labyrinth, die sich zwar meist wieder ausgleichen, gelegentlich aber zu einer Degeneration der perzipierenden Elemente und damit zu einer Dauerschädigung führen. Diese kann dann ihrerseits wieder die Ursache allgemein nervöser Störungen bilden oder das Abklingen einer begleitenden Schreckneurose hintanbalten. So war in dem von mir beobachteten Falle B. durch allzu starkes Wecken eine Läsion des inneren Ohres (Labyrintherschütterung) mit Herabsetzung des Hörvermögens und subjektiven Geräuschen entstanden, daneben bestand eine Shockwirkung, die zweifellos hauptsächlich wegen der anbaltenden Hörstörung als sehr bartnäckig sich erwies. 
Im allgemeinen kann man aber Bernhardt beistimmen, dass eine Schädigung des Hörorgans, überhaupt eine organische Läsion durch Telephonunfälle nur in den seltensten Fällen zur Beobachtung kommt, und dass es sich bei den nervösen Unfallfolgen der Telephonistinnen fast ausnahmslos um charakteristische Schreckneurosen handelt. Eine Analyse der klinischen Erscheinungen wird, wie ich schon jetzt vorweg nehmen kann, diese Ansicht vollkommen bestätigen.

In klinischer Hinsicht sind ausgedehntere Beobachtungen über Schreckwirkungen zuerst von Stierlin veröffentlicht worden, der die medizinischen Folgezustände der bekannten Grubenkatastrophen ron Courrières und Ha mm (Radbod) sowie der Erdbeben von $V$ alparaiso und Messina eingehend studierte und vor allem die hierbei zutage tretenden psychischen Störungen näher beschrieben hat, aber auch bereits auf somatischem Gebiete auffallende vasomotorische Symptome als einigermassen charakteristisch hervorheben konnte. 2 grosse Gruppen von Symptomen, solche, die mehr auf psychisehem und solche die rorwiegend auf somatischem Gebiete liegen, lassen sich also von vornherein unterscheiden, wenngleich bei den innigen Wechselbeziehungen beider Gruppen diese Einteilung nur systematischen Wert beanspruchen kann.

Auf psychischem Gebiete sind es ror allem die Erscheinungen akuter Verwirrtheit, die zunächst als unmittelbarste Schreckeinwirkung in sehwereren Fällen sich bemerkbar machen und die Ähnlichkeit haben mit Dämmerzuständen nach Art der Amentia oder der Hysterie, mitunter auch wohl mit letzterer identisch sind. Zum Teil gehen sie mit amnestischen Störungen und Desorientierung für Raum, Zeit und Personen einher und können in dieser Weise Stunden, ja selbst Tage hindurch anbalten (Stierlin). Im iibrigen besteht entweder ein ausgesprochen stuporöses Verhalten: Apathie, Gleichgïltigkeit und Interesselosigkeit für alle Vorgänge der Aussenwelt, in einzelnen Fällen aber auch eine auffallende Euphorie mit völliger Situationsverkennung, oder es kommt zu starken psychischen Erregungszuständen, Verzweiflungsausbrüchen etc. mit impulsiven, z. T. ganz sinnlosen Affekthandlungen. Beim Erdbeben von Valparaiso handelte es sich um eine geradezu "unerhörte Schreckwirlsung“ (Stierlin), wirkten doch „die stärksten Sehreckmittel zusammen: das entsetzliche Getöse, die allgemeine wahnsinnige Verwirrung, das Gefühl der Möglichkeit, in jedem Moment von einem zusammenstürzenden Hause begraben zu werden, die wohlbekannte Gefahr einer Sturzwelle rom Meer, die Dunkelheit der Nacht, das anarchistische Raubgesindel" etc., kurzum psychische Traumen, wie sie in 
ihrer Konzentriernng und Brutalität kaum übertroffen werden können und daher auch zu einer grossen Reihe schwerster psychischer Störungen geführt haben. Ähnliches wird aus Courrières berichtet. Zangger beobachtete einen Patienten, der aus der Mine herausgebracht, "wie toll" umherrannte und sich zu den Leichen legen wollte. Ein anderer schlug, nach Hause gebracht, alles Geschirr entzwei in der Meinung, er sei noch unten in der Mine.

Vergleichen wir nun die Stierlinschen Beobachtungen bei Erdbeben- und Grubenkatastrophen mit den psychisch-nervösen Zuständen, wie sie in kleinerem Maßstabe in gewerblichen Betrieben, bei Eisenund Strassenbahnunfällen sowie bei Telephonunfällen vorkommen, so findet sich, dass unterschiedslos in sämtlichen Fällen generell die nämlichen Störungen immer wieder anzutreffen sind. Allerdings sind, wenn wir zunächst die Betriebsunfälle ins Auge fassen, die psychischen Erscheinungen, vor allem die Verwirrtheitszustände, entsprechend dem meist fehlenden katastrophalen Charakter des Unfalles, in der Mehrzahl der Fälle erheblich weniger ausgeprägt und hervorstechend. Von den 16 Patienten meiner Beobachtung zeigten aber alle ausnahmslos die Erscheinungen starker allgemeiner Exaltation, die besonders bei den 2 weiblichen Patientinnen einen ziemlich hohen Grad erreichte. Vor allem waren es Aufgeregtheit, Angstgefühl und Schreckhaftigkeit, allgemeine innere Unruhe, Schlafstörung, wiederholt auch ausgesprochene Depressionszustände, die im Vordergrunde der Erkrankung standen. In mehreren Fällen bestand für den Unfallhergang ein gewisser Grad von Amnesie; die Patienten wussten wohl, dass irgendetwas passiert war, vermochten aber keinerlei Einzelbeschreibung mebr zu geben, obwohl im übrigen keine Störung der Merkfähigkeit sich fand. Gelegentlich wird allerdings auch über allgemeine Vergesslichkeit geklagt. Kühne beschreibt den Fall eines älteren Lehrers, der durch Schreck infolge Ausbruchs einer Feuersbrunst u. a. das Zahlengedächtuis verlor; auch im Falle eines älteren Maurers bestanden auffallende Gedächtnisstörungen. Kühne nimmt an, dass bei den schon bejahrten, wahrscheinlich entsprechend arteriosklerotischen Patienten die Ausgleichsvorrichtungen im Gehirn infolge der durch Schreck bedingten Zirkulationsstörung im Gehirn vernichtet wurden. Überhaupt dürfte ein grosser Teil der psychischen Erscheinungen auf plötzlich einsetzenden vasomotorischen Störungen beruhen. Wiederholt wurde von unseren Patienten angegeben, sie seien "total verwirrt", „benommen" oder "wie von sich" gewesen, mehrmals waren Ohnmachtsanwandlungen beobachtet worden. Dabei fand sich fast stets eine auffallende Blässe des Gesichts, später vielfach gefolgt von Blutandrang zum Kopf; 
ferner wurde über gleichzeitig einsetzende Kopfschmerzen geklagt. Auch Übelkeit und Erbrechen trat gelegentlich auf. Bewusstseinsstörungen in Form typisch hysterischer Anfälle mit Arc de cercle etc. waren unmittelbar nach der Schreckeinwirkung bei 2 Patienten eingetreten und zwar bei den beiden Frauen, die in der Folgezeit ausser den häufig wiederkehrenden Anfällen im übrigen noch alle Zeichen stärkster psychischer Alteration, hochgradige Erregung, Ängstlichkeit, Schreckhaftigkeit und innere Unruhe zeigten, Erscheinungen, die besonders in Fall 16 ("Erschreeken" seitens eines Dritten) sehr ausgesprochenen Charakter trugen. Während der Anfälle, die nur gelegentlich mit völliger Bewusstlosigkeit, meist nur mit Bewusstseinstrübung einhergingen, bestanden vollkommene Verwirrtheit mit Situations- und Personenverkennung sowie Angstvorstellungen mit Anklängen. an paranoide Verfolgungsideen (Angst, geschlagen zu werden etc.). Von den männlichen Patienten, die im allgemeinen weniger prägnante psychische Erscheinungen zeigten als die Frauen, seien folgende Fälle erwähnt:

Fall 3. 37jähriger Bautechniker. Am 27. VII. 1912 mit Fahrrad zu Fall gekommen, sah unmittelbar vor sich Fuhrwerk. Fürchtete, überfahren zu werden. Seitdem "ausserordentlich aufgeregt", "kolossale" Unruhe, Angstgefühl, Schlaflosigkeit, Reizbarkeit, Furcht vor Gerüstesteigen, Schlafstörung mit aufregenden Träumen, Herzklopfen, starkes Schwitzen, zuckendes und stechendes Gefühl im Gehirn, Konzentrationsschwäche, Depression.

Fall 4. 49jähriger Steinbrecher. Anfang Februar 1913 "bei-

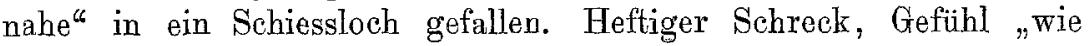
elektrisiert": seitdem allgemeine Unruhe, Aufgeregtheit, Schreckhaftigkeit, Angstgefühl, Missmut, Lebensüberdruss, Abgeschlagenheit, „toll“ im Kopf, starke Schlafstörung, apathisches Wesen.

Fall 9. 28jähriger Arbeiter. Rutschte am 24. XII. 1912 mit $3 \mathrm{~m}$ hoher Leiter aus, konnte sich aber noch festhalten. Vor Schreck "ganz benommen", "total nass geschwitzt". Seitdem Angstgefül, Aufgeregtheit mit Versagen der Stimme, Interesselosigkeit, ziehende Schmerzen in Rücken und Gliedern, zeitweise Schwindelgefühl und Atemnot. Hypochondrische Verstimmung.

Wesentlich ausgeprägter sind im allgemeinen die psychischen Anomalien nach Strassen- und Eisenbahnunfällen, weil hier, worauf ich schon hinwies, die Gewalt des Unfallereignisses vielfach eine weit' intensivere ist und mehr den Charakter des katastrophalen Massenunglücks trägt. So finden wir denn, besonders nach Eisenbahnunfällen, als erste Folgeerscheinungen auf psychischem Gebiet mannigfache Trübungen des Bewusstseins, wie vollkommene Fassungs- 
losigkeit, Verstörtheit, Desorientierung, Verwirrtheit und ähnliche deliriöse Zustände, meist vereint mit Störungen des formalen Gedankenablaufes, sei es im Sinne der Hemmmung, Exaltation oder Inkohärenz. Gelegentlich treten auch Obnmachtsanwandlungen oder Bewusstseinsverlust ein. Dementsprechend sind in schweren Fällen - nur diese habe ich zunächst im Auge - gerade wie nach den grossen Erdbebenund Grubenkatastrophen ausser stuporösen Verwirrtheitszuständen nach Art der Amentia oder Hysterie Zustände hochgradiger Erregang, meist gefolgt von krampfartigen Weinanfällen anzutreffen. Seltener besteht zunächst ausgesprochene Euphorie mit Situationsverkennung. Ich erinnere mich aber an mehrere. Fülle, die anfangs völlig ruhig und gefasst blieben and anderen noch Hilfe leisteten, bis erst nach einigen Stunden die psychische Shockwirkung bei ihnen in hochgradiger Erregung usw. zum Ausbruch kam. Im übrigen trifft man, mag es sich nun um schwere oder leichte Fälle handeln, ausser gelegentlicher Amnesie mit Anklängen zum Korsakowschen Komplex als eines der regelmässigsten, charakteristischsten Symptome Angstzustände an, die bis zu episodisch auftretenden Verfolgungsvorstellungen sich steigern können. Auch sonstige paranoide Wahnideen, besonders an Melancholie erinnernde Kleinheitsideen mit Suicidneigung sowie Halluzinationen kommen vereinzelt vor. Allerdings treten die depressiven Erscheinungen in stärkerer Intensität meist erst allmählich auf, desgleichen hypochondrische Wahnideen, die aber, worauf ich später noch zu sprechen komme, vielfach nicht dem primären Unfallereignis, sondern oft genug dem Entschädigungskamp fe zur Last zu legen sind. Unter den zwangsartigen Angstzuständen sei noch als besonders typisch die sogen. „Eis enbahnfurcht" (Siderodromophobie Riglers) hervorgehoben, die bei fast allen psychisch alterierten Eisenbahnunfallverletzten anzutreffen ist (Eichelberg) und zwar nicht nur bei Passagieren, sondern auch bei Eisenbahnbeamten. So erklärten uns wiederholt an Schreckneurose erkrankte Lokomotivführer, sie seien gern zur Aufnahme jeden Dienstes wieder bereit, nur das Wiederbesteigen der Lokomotive sei ihnen vorderhand unmöglich, da ihnen der Unfall noch allzulebhaft vor Augen stehe. Analoge Beobachtungen habe ich ïbrigens auch bei unfallverletzten Arbeitern gemacht. Noch aus der jüngsten Zeit erinnere ich mich eines Bergmanns, der infolge falscher Signalabgabe mit seinem Förderkorb statt aufwärts nach abwärts gefahren war, vor Furcht und Schrecken, hierbei zu Schaden zu. kommen, an nervösen Störungen erkrankte und seitdem nicht mehr zu bewegen war, die Grube zu befahren.

Eine weitere sehr bemerkenswerte Folge nach Schreckeinwirkungen ist die zum mindesten in den ersten Tagen, meist aber Wochen oder 
Monate hindurch fast ausnahmslos anzutreffende Schlaístörung. Entweder besteht vollkommene Agrypnie oder der Schlaf ist ausserordentlich unruhig und durch schreckhafte Träume, in denen das Unfallereignis meist eine hervorragende Rolle spielt, beeinträchtigt. Auch sonst dominiert, worauf schon Moeli hingewiesen hat, die Erinnerung an den Unfall, der geradezu zwangsartig in der Vorstellungssphäre sich immer wieder reproduziert. Daneben gehören die allgemeine psychische Unruhe, innere Erregtheit und Schreckhaftigkeit mit zu den charakteristischsten psychischen Symptomen. Schon das geringste Geräusch ruft Erregung und Angstgefühl hervor. Daneben entwickelt sich oft im weiteren Verlanfe eine abnorme Reizbarkeit, Launenhaftigkeit, Unverträglichkeit und Neigung zu Zornansbrüchen, kurzum, eine Umprägung der ganzen Persönlichkeit, die aber ebenso wie die hypochondrischen Erscheinungen meist weniger auf die Schreckwirkung als auf sekundäre Momente za beziehen sein dürfte, wenn es auch oft schwer ist, die direkten und indirekten Unfallfolgen bei dem Ineinandergreifen der Erscheinungen auseinanderzuhalten. Einige besonders charakteristische Beispiele für Schreckwirkungen nach Eisenund Strassenbahnunfällen seien kurz erwähnt:

Fall 19. 24 jähriger Kaufmann. Am 17. Dezember 1912 Zugzusammenstoss, ,furchtbarer Knall", keinerlei körperliche Verletzung. Zunächst ,wie benommen", vollkommen verstört, verwirrt, vorübergehende Desorientierung, zu keinem klaren Gedanken fähig; dann „furchtbare Erregung", Zittern am ganzen Körper, Herzklopfen, Kopfschmerzen. Weiterhin Stiche in den Schläfen, Blutandrang zum Kopf mit Schwindelgefühl, starkes Schwitzen, Frösteln, abnorme Sensationen in allen Gliedern, Gehstörung, Magen-Darmbeschwerden, Kariöswerden der Zähne, Kugelgefühl im Hals, schlechter Schlaf mit schreckhaften Träumen, Schreckhaftigkeit, Angstgefühl mit Druck auf der Brust, psychische Depression.

Fall 50. 30 jährige Frau. Am 20. Mai 1913 Strassenbahnzusammenstos3. Keinerlei Verletzung. "Ausserordentlich erschreckt," laut aufgeschrieen, dann ,ganz weg" gewesen; keine genauere Erinnerung an den Unfall mehr vorhanden. Brach in "Weinkrämpfe" aus, sofort „Steifigkeit" und Gefühllosigkeit der ganzen linken Seite. Nach 1/4 Stunde starkes Erbrechen. „Furchtbar aufgeregt", an allen Gliedern gezittert, konnte sich „überhaupt nicht zurechtfinden", anch am nächsten Tage „noch nicht klar“. Hochgradiges Angstgefühl; Ruhelosigkeit, Schreckhaftigkeit, Depression, Neigung zum Weinen, Herzklopfen, starkes Schwilzen, Kopfschmerzen, Schwindelgefühl, schlechter Schlaf mit schreckhaften Träumen, Störungen der Menstruation, Übelkeit, Aufstossen, Sodbrennen, Gefühl, ,als ob sich der Magen berumdrehe“, 
Appetitlosigkeit, Stuhlverstopfung, sehr starker Haarausfall, abnorme Sensationen ("elektrisches Gefühl" und "Nadelstiche") in Händen und Füssen, Frostschauer über den ganzen Körper; bald sei die eine Körperseite oder eine Extremität kalt, während der übrige Körper heiss sei und schwitze.

Auf die bej allen diesen Fällen auf s o matis chem Gebiet erhobenen Befunde werde ich weiterhin zurückzukommen haben, ebenso auf die teilweise schon berührten subjektiven körperlichen Beschwerden. Zunächst möchte ich aber die psychischen Erscheinungen nach Telephonunfällen noch kurz erwähnen. Die meisten unserer Patientinnen (8 von 12) gaben an, sie seien im ersten Augenblick, vielleicht auch einige Minuten hindurch "benommen" oder "betäubt" gewesen. Eine Patientin (Fall 73 unserer Beobachtung) will sogar erst nach $3 / 4$ Tagen wieder völlig klar geworden sein. Wegen des geradezu typischen Falles seien die hauptsächlichsten Daten der Krankengeschichte angefïhrt:

Fall 73. 25 jährige Telephonistin. Schon vor dem Unfall Blutarmat and zeitweise nervöse Beschwerden. Unfall am 3. Juli 1912: Während des Telephonierens plötzlich "starkes Knacken“ im linken $\mathrm{Ohr}$ verspürt (angeblich Fernleitung vom Blitzstrahl getroffen, aber keine Beschädigung der Apparate). Über die weiteren Vorgänge keine Erinnerung mehr. Später wurde ihr gesagt, man habe sie aus dem Saal herausgetragen; sie weiss nur, dass ein Arzt ihr eine Einspritzung gegeben habe. Erst am anderen Morgen wieder bei voller Besinnung. Bemerkte Zuckungen am ganzen Körper; ausserdem Kopfund Rückenschmerzen, Weinkrämpfe, lebhaftes Angstgefühl, unruhiger Schlaf mit schreckhaften Träumen, allgemeine Aufgeregtheit und innere Unruhe.

Eine organische Schädigung war mit an Sicherheit grenzender Wahrscheinlichkeit anszuschlieseen, es handelte sich zweifellos um eine durch starke Knackgeräusche ausgelöste Schreckwirkung bei der ohnehin schon stark nervös disponierten, schwächlichen und blutarmen Patientin. Besondere Hervorhebung verdient vielleicht noch die fast vollkommene Amnesie für die ersten Vorgänge nach dem Unfall.

Eine andere Patientin, Fall 79, die ebenfalls während eines Gewitters einen heftigen Schlag in der Leitung hörte, gab an, sie sei nicht besinnungslos gewesen, habe aber nicht gewusst, „wie ihr zu Mute gewesen sei". Sie sei sofort in Weinen ausgebrochen, habe Kopfschmerzen verspürt und Zuckungen an sich bemerkt. Zu Hause habe sie 3 Tage "wie in einem Dämmerzustande" dagelegen und habe "ganz verwirrt" gesprochen. Im übrigen stellten sich noch eine Reihe 
körperlicher Symptome ein. Auch in Fall 75 (Erschrecken durch starkes Weckgeräusch) trat erst nach einigen Stunden ein tagelang anhaltender "schlafähnlicher" Verwirrtheitszustand auf, nachdem eine hochgradige psychische Erregung vorausgegangen war. Immer aber trugen die Bewusstseinsstörungen, wie anch nach den Erdbeben-, Graben- und Bahnunfällen, einen vorübergehenden, initialen Charakter und dokumentierten damit die unmittelbarste, zunächst in aller Stärke zur Erscheinung kommende Reaktion der Psyche, um allerdings in einzelnen Fällen in Form hysterischer Anfälle gelegentlich wieder aufzutreten. Auch im übrigen deckten sich die psychischen Störungen nach Telephonunfällen mit den bei den übrigen Gruppen auftretenden Erscheinungen. So bestand fast ausnahmslos starkes Angstgefühl, hochgradige Insomnie mit nächtlichem Aufschrecken und ängstigenden Träumen, allgemeine innere Unruhe, ,inneres Beben“, allgemeine Erregtheit und Schreckhaftigkeit. Daneben traten bei $2 / 3$ aller Patientinnen periodisch, ohne irgendwelche besondere Ursache, sehr heftige "Weinkrämpfe" auf, wie überhaupt fast in all en Fällen die depressive Stimmung rorherrschend war. Gradenigo beobachtete nach heftigen Schalleindrücken u. a. Gehörstäuschungen und Halluzinationen. In Fall 72 und 78 unseres Materials fanden sich ausgesprochene Zwangsvorstellungen, besonders Platzangst. Mehrfach wurde auch unbestimmte Angst vor einem drohenden Unglück geäussert. Telephonophobie bestand bei fast sämtlichen Patientinnen. Manche gingen zwar mit festem Willen und guten Vorsätzen wieder an ihre Tätigkeit, waren aber oft durch plötzlich einsetzende Inkohärenz des Gedankenablaufs nicht mehr zur Weiterarbeit imstande. Ihre Gedanken verwirrten sich, die Arbeit schlug ihnen, wie sie sich ausdrückten, ,über dem Kopfe zusammen" und in der Regel stellten sich heftigste Weinattacken ein. Im ganzen stand der gesamte psychische Habitus bei allen nervösen Störungen nach Telephonunfällen im Zeichen mehr oder weniger starker Exaltation, die überhaupt neben den meist lebhaften Angstaffekten und der anfänglichen akuten Bewusstseinsstörung das Hauptcharakteristikum aller S chreckneurosen in psychischer Hinsicht darstellt.

Aber auch in somatischer Beziehung treten bei allen Schreckneurosen ungeachtet ihrer speziellen Ätiologie (Betriebs-, Eisenbahn-, Strassenbahn-, Telephonunfälle) generell immer wieder dieselben Erscheinungen auf und zwar in solch charakteristischen Symptomenkomplexen, dass ihre klinische Sonderstellung gerechtfertigt erscheint. Dass dabei je nach Art und Intensität der psychischen Erschütterung im Einzelfalle Varianten vorkommen und bald diese, bald jene Erscheinung stärker hervortreten kann, ist selbstverständ- 
lich. Auch die individuelle Disposition bedingt, worauf ich weiterhin noch einzugehen habe, gewisse und wichtige Besonderheiten.

Unter den somatischen Erscheinungen stehen in erster Linie zweifellos Symptome von seiten des Herzens und dex Blutgefässe, Symptome, wie sie gelegentlich auch als Neurastheria cordis sive vasomotorica bezeichnet worden sind. Schon Oppenheim hat ihre Häufigkeit bei der "traumatischen Neurose" herrorgehoben, dabei aber anseheinend diejenigen Fälle besonders im Auge gehabt, bei denen der Unfall mit einem psychischen Shock verbunden war, also Fälle, die ins Gebiet der Schreckneurose fallen. Eine genanere Untersuchung ergibt nun, worauf ich schon früher an anderer Stelle hingewiesen habe, dass ansgesprochene Erscheinungeu von seiten des Zirkulationsapparates, seien sie nun subjektiver oder objektiver Natur, bei den Schreckneurosen mit solcher Regelmässigkeit anzutreffen sind (unter 100. Fällen von Schreckneurosen $96 \mathrm{mal}$ ), dass der „vasomotorische" oder "kardiovasknläre Symptomenkomplex" geradezu als Charakteristikum in somatischer Hinsicht angesehen werden muss, obwohl naturgemäss die einzelnen Symptome nicht stets und in allen Fällen in gleicher Ausbildung sich zeigen.

Betrachten wir zunächst die Störungen von seiten des Herzens, so finden wir, dass subjektiv fast immer dieselben Beschwerden vorgebracht werden, und zwar wird vor allem geklagt über Hexzklopfen, Angst- und Beklemmungsgefühl, Schmerzen, Stiche oder sonstige abnorme Sensationen in der Herzgegend, zuweilen mit Ausstrahlen dex Schmerzen in den linken Arm nach Art der Angina pectoris (Thiem beobachtete gelegentlich auch Ausstrahlen in den rechten Arm ohne bestehende Dextrokardie), Klagen, die in der Regel schon unmittelbar nach der Schreckeinwirkung auftauchen und sich auch häufig einige Zeit zu erhalten pflegen. Von unseren 100 Fällen klagten nicht weniger als 70 über Herzbeschwerden, wenn auch im einzelnen meist noch zahlreiche sonstige Klagen bestanden. Noch erheblich lüufiger (etwa 90 Proz.) waren die objektiven Erscheinungen ron seiten des Herzens, Beschleunigung, Irregularität oder Labilität der Herzaktion. Pulszahlen von 140-160 pro Minute waren keine Seltenheit; in der Regel betrug bei ruhigem Verhalten die Pulsfrequenz 100-120, stieg aber bei irgendwelcher körperlichen oder geistigen Anstrengung oder Erregung momentan ganz beträchtlich. Irregularität wurde nur vereinzelt beobachtet und dann auch meist nur vorübergehend nach Aufregungen oder dergl., gelegentlich bei anfallsweisen Attacken von allgemeiner Schwäche, Angstgefühl und Beklemmung, Schweissausbruch und Tachypnoe. Dabei war auffallend, dass sowohl die subjektiven wie objektiven 
Symptome bei den Frauen entschieden ausgeprägter waren als bei den männlichen Patienten. Bernhardt beobachtete unter seinem grossen Material von Telephonistinnen mit Schreckneurosen (zus. 209 Fälle) ebenso wie wir fast stets eine Pulsbeschleunigung. Nur in ganz vereinzelten Füllen erschien das Cor unbeteiligt; statt dessen fanden sich aber dann fast ausnahmslos sonstige Erscheinungen von seiten des Zirkulationsapparates, wie denn ïberhaupt ein inniger Konnex zwischen Herz- und Gefässstörungen besteht.

Als objektive vaskuläre Symptome kommen vor allem in Betracht Dermographie, Cyanose der Hände und Füsse, auf lokaler Asphyxie beruhend, Blutandrang zum Kopf, gelegentlich abwechselnd mit abnormer Blässe, fleckige und streifige Röte im Gesicht oder auch am übrigen Körper, besonders an den Armen, zuweilen mit diffuser oder quaddelartiger ödematöser Schwellung. Auffallend ist auch in manchen Fällen ein marmoriertes Aussehen der Haut. Bei einem Patienten meiner Beobachtung trat plötzlich während des Abendessens innerhalb weniger Minuten eine über den ganzen Körper (Gesicht, Brust, Rücken, Oberarm, Oberschenkel) sowie über die Schleimhäute des Mundes, Rachens und Kehlkopfes ausgebreitete Urticaria ein, die wegen der Mitbeteiligung der Schleimhäute vorübergehend zu starken Erstickungsanfällen führte, sich aber innerhalb einiger Stunden bis auf unerhebliche Reste wieder verlor. Überhaupt unterliegen die vasomotorischen Störungen ausserordentlich starken Schwankungen und sind in hohem Maße abhängig ron psychischen Erregungen. So trat bei einer unserer Patientinnen (Fall 74), einer 25 jährigen Telephonistin, jedesmal im Anschluss an die ärztliche Untersuchung eine von den Schläfen über die Wangen langsam sich ausbreitende ödematöse Schwellung und Rötung ein, die stundenlang bestehen blieb, um dann ziemljch rasch wieder zu verschwinden. Selbst auf der behaarten Kopfhaut wurden gelegentlich derartige von der Patientin selbst als "Beulen" bezeichnete urtikarielle Eruptionen beobachtet.

Subjektiv wird bei bestehenden Gefässstörungen öfters geklagt über ständige oder anfallsweise Kopfschmerzen, Schwindelgefühl, Blutandrang zum Kopf bei gleichzeitig kalten und feuchten Extremitäten, abwechselndes Hitze- und Frostgefühl über den ganzen Körper (vergl. Fall 19 und 50). Dabei stehen jedoch im allgemeinen die Klagen über Kopfschmerz und Schwindelgefühl nicht derart im Vordergrund des gesamten Krankheitsbildes, wie es beispielsweise nach Kopfrerletzungen der Fall ist. Zweifellos sind sie bei den Schreckneurosen aufzufassen als auf allgemeiner Zirkulationsstörung beruhende Symptome, die vielfach überhaupt fehlen und manchen Schwankungen unterworfen sind, während die Kopfbeschwerden nach 
Contusio capitis, Commotio cerebri, Schädelbruch usw. in der Regel den integrierenden Bestandteil des gesamten Krankheitsbildes ausmachen und derart vor allen sonstigen Erscheinungen hervortreten, dass man geradezu von einem ,cerebralen Symptomenkomplex" nach Kopfverletzungen sprechen kann. Handelt es sich doch auch bei letzteren hänfig genug um lokale Reizzustände infolge Blutungen in die Meningen, zuweilen mit folgender chronischer Meningitis serosa, um kapilläre Blutungen, leichte Schädigungen der Hirnsubstanz mit Degenerationsherden, Frschütterung des zentralen Gleichgewichtsapparates usw., also Schädigungen, die schon rein anatomischphysiologisch betrachtet, zum grossen Teil auf vollkommen anderer Grundlage beruhen als die eine allgemeine Alteration des Vasomotoriums darstellenden Gefässstörungen bei Schreckneurosen. Nicht weniger als $1 / 3$ aller Fälle von Schreckneurose klagte überhaupt niemals über Kopfbeschwerden und bei den übrigen handelte es sich häufig mehr um ein eigenartiges Druck- und Bandgefühl als um ausgesprochenen Schmerz, oder der Schmerz war nur unbedeutend, von wechselnder Stärke oder periodischem Auftreten. Mehrfach allerdings bestanden andauernd ganz erhebliche Kopfbeschwerden. Besonders diejenigen Patienten, die an hoehgradjger Agrypnie zu leiden hatten oder bei denen die Zirkulationsstörungen (Blutandrang zum Kopf usw.) einen erheblichen Grad aufwiesen, klagten in der Regel auch über stärkere Kopfschmerzen, Kopfdruck und gelegentlich auch über stärkeres Schwindelgefühl. Klagen über Schwindelerscheinungen wurden aber nur von etwa $1 / 4$ aller Fälle vorgebracht, während sie nach Kopfverletzungen eigentlich niemals fehlen. Dazu kommt, dass nach Kopfverletzungen ausser organischen Schädigungen sehr oft eine als objektives funktionelles Symptom zu betrachtende abnorme Reizbarkeit des Bogengangsystems bei galvanischer Durchströmung oder bei kühlem Ausspritzen der Gehörgänge nachzuweisen ist, was wir unter unseren Schreckneurotikern, abgesehen von den weiterhin za erwähnenden menièreartigen Komplexen nur in den seltensten Fällen beobachten konnten. Auch über Erscheinungen von seiten der höheren Sinnesorgane (Flimmern vor den Augen, leichte Ermüdung beim Lesen, Doppelsehen, Ohrensausen, Beeinträchtigung des Hörvermögens usw.), sehr bänfige Klagen nach Kopftraumen, wurde von den Schreckneurotikern nur ganz vereinzelt geklagt. Meist gingen Flimmern vor den Augen und Schwindelgefühl gleichzeitig einher, ebenso das Ohrensausen, das nur in seltenen Fällen dauernd bestand. Objektiv wurden durch spezialistische Untersuchungen des Sehorgans häufig rom Unfall völlig unabhängige Anomalien des Brechzustandes, besonders Astigmatismus und Hyperopie, bei älteren Individuen Presbyopie und 
beginnende Kataraktbildung festgestellt, Zustände, die bis zum Unfall unbemerkt geblieben waren, um dann infolge erhöhter Selbstbeobachtung erst subjektiv ins Bewusstsein zu treten. Mehrfach waren die Augenbeschwerden als Teilerscheinung des nervösen Allgemeinzustandes anzusehen und gelegentlich fanden sich auch objektive Zeichen eines nervösen Zustandes (Mydriasis spastica, Akkomodationskrampf). Aber nur in einem Falle waren organische, auf den Unfall zu beziehende Schädigungen nachzuweisen (durch Schreck verschlimmerter Diabetes mellitas mit frischen Netzhautblutungen). Auch die spezialistische Untersuchung des Gehör- und GIeichgewichtsapparates ergab nur in einem einzigen Falle eine bis zu einem gewissen Grade als Unfallfolge zu betrachtende organische Schädigung. Es handelte sich um eine 41 jährige, schon vor dem Unfall schwerhörige Frau (Fall 44), die bei Gelegenheit eines Eisenbahnunglücks sich stark erschreckte und die dann in den nächsten Wochen neben sonstigen Erscheinungen (Aufgeregtheit, innere Unruhe, schreckhafte Träume usw.) eine geradezu rapide Abnahme des Hörvermögens bemerkte, die auch von autoritativer Seite festgestellt wurde. Später fand Prof. Eschweiler, der die Patientin mitbegutachtete, eine typische Otosklerose und kam zu dem Ergebnis, dass durch den Unfall sehr wohl eine Verschlimmerung des alten Gehörleidens auf dem Wege vasomotorischer oder trophischer Störungen herbeigeführt sein könne. Im übrigen haben wir aber auch bei Telephonunfällen niemals organische Gehörläsionen beobachtet. Falls nicht die Klagen der Patienten, wie es mehrfach der Fall war, auf alten Mittelohrleiden oder dergl. berubten, waren sie in der Regel als Ausfluss des nervösen Allgemeinzustandes aufzufassen und in der Hauptsache auf abnorme Zirkulationsverhältnisse zurückzuführen. Auch die nach Schreckeinwirkung gelegentlich vorkommenden Anfälle von Pseudomenière (v. Frankl, Böhnig) sind durch vasomotorisch ausgelöste Gefässstörungen im Labyrinth bedingt (v. Krafft-Ebing) und stehen in engstem Zusammenhang mit allgemein nervösen Zirkulationsanomalien. So traten in dem oben beschriebenen Fall 74 gleichzeitig mit den äusserlich sichtbaren Gefässstörungen anfallsweise starke subjektive Beschwerden nach Art des Menièreschen Komplexes ein: Ohrensausen, ziehende Schmerzen im linken Ohr, Hitzegefühl im Kopf, Schwindel, Herzklopfen, Übelkeit, „innere Unruhe und Zittern im ganzen Körper", hochgradige Geräuschempfindlichkeit - Anfälle, die erst nach stundenlangem, völlig ruhigem Verhalten vorübergingen. Auch ähnlich verlaufende migräneartige Komplexe kommen bei Schreckneurosen ziemlich häufig vor.

Was die Klagen über kalte und feuchte Extremitäten anbe- 
trifft, so wurde die objektir oft festzustellende Cyanose (lokale Asphyxie) bereits erwähnt. Häufig findet sich aber anch im Gegenteil eine auffallende Blässe (lokale Synkope) oder abwechselnd bald Blässe, bald Cyanose, besonders an den Fingern, sehr oft verbunden mit Parästhesien, wie Ameisenlaufen, "elektrischem" Gefühl und vor allem "ziehenden" Schmerzen durch den Rücken, die Gliedmassen bis hinein in Fingerspitzen und Zehen. Ob derartige Akroparästhesien durch vasomotorische Störungen (arterielle Krampfzustände bezw. venöse Erschlaffung) bedingt oder ob sie hysterischer Natur sind, ist zwar nicht generell für alle Fälle zu entscheiden. Beim gleichzeitigen Bestehen vasomotorischer Erscheinungen dürften aber die Parästhesien wohl zweifellos mit ersteren in ursächlicher Beziehung stehen. Gelegentlich wird auch nur eine einzige Extremität als "kalt" bezeichnet, während im übrigen Körper ein Wärmegefühl bestehen soll (vergl. Fall 50, bei dem während eines derartigen Zustandes die Finger der rechten Hand auffallend blass waren, während die der linken Hand normale Farbe zeigten). Gelegentlich sind die dauernd vorhandenen oder periodisch auftretenden Verfärbungen derart stark, dass das ganze Bild an die ja auf arteriellen und venösen Gefässkrämpfen beruhende Raynaudsche Erkrankung erinnert, unter deren Gelegenheitsursachen Gemütsbewegungen(Schreck) den ersten Platz einnehmen $(O p p e n h e i m)$ und die symptomatisch als Oedème blea a. a. bei Hysterie ja öfters zur Beobachtung kommt. Gangränöse Erscheinungen haben wir niemals beobachtet, nur gelegentlich trophische Störungen an den Nägeln. Auch das "Hitze"- und "Frostgefiihl" mit seinen zahlreichen Varianten berubt zweifellos auf vasomotorischen. Erscheinungen. Ebenso baben die ja bei Schreekneurosen ausserordentlich häufigen Schlafstörungen zum Teil vasoneurotischen Charakter, desgleichen die später zu erwähnenden Menstruationsanomalien (Bing und Stierlin).

Perkutorisch und röntgenologisch ist bei Mitbeteiligung des Herzens in den nichtkomplizierten Fällen (Fehlen von Arteriosklerose, Nephritiden usw.) in der Regel kein abnormer Befund zu erheben; doch kommen vereinzelt, worauf ich auch schon früher an anderer Stelle hingewiesen habe, Fälle a kuter Herzdilatation nach Schreckeinwirkung vor. Drei einschlägige Fälle unseres Materials können als sichergestellt gelten (Fall 36, 45 und 59); in einem weiteren Falle (81) war die Herzerweiterung möglicherweise auf Arteriosklerose zurückzuführen und älteren Ursprunges; jedenfalls liessen sich die Kriterien einer akuten Entwicklung in letzterem Falle nicht nachweisen, während bei den 3 übrigen Patienten ziemlich inténsive Erscheinungen von seiten des Herzens von Anfang an im Vordergrunde 
der Erkrankung standen. In Fall 45 (56 jührige Frau), der allerdings schon früher vorübergehend Herzstörungen (leichte Herzmuskelschwäche) gezeigt hatte, kam es infolge des Unfallereignisses zu erneutem Auftreten von Herzklopfen, Atemnot und Ohnmachtsgefühl, objektiv ausser Herzdilatation zu kleinem, beschleunigtem Puls und Albuminurie, während in Fall 36 (38 jähriger Mann), der vor dem Unfall auch nach Aussage des Hausarztes nie herzleidend war, ausser Herzstörungen mit Dilatation und Tachykardie zahlreiche vasomotorische Störungen subjektiv and objektiv in Erscheinung traten. Endlich zeigte Fall 59 (29jährige Modistin) bei der einige Wochen nach der Schreckeinwirkung vorgenommenen ersten Untersuchung eine starke Erweiterung des Herzens nach rechts, die aber schon nach 14 Tagen geringer wurde und nach weiteren 2-3 Monaten wieder geschwunden war unter gleichzeitiger Besserung des anfangs kleinen, unregelmässigen und beschleunigten Pulses. Auch in Fall 45 und 36 bildete sich die Dilatation nach wenigen Monaten bei entsprechender Behandlung mit kohlensauren Salzbädern usw. wieder zurück.

Die Beurteilung des Falles 59 stiess übrigens zunächst insofern auf Schwierigkeiten, als die Patientin einen leichten Exophthalmus neben Tremor der Hände, Tachykardie und Hyperidrosis zeigte, Erscheinungen, die jedenfalls den Gedanken an M. Basedow nahelegen mussten. Da aber keine Schilddrüsenveränderung bestand und ausser dem geringfügigen Exophthalmus sonstige Augensymptome fehlten, so erschien uns selbst die Annahme einer "forme fruste" nicht hinreichend begründet, zumal die Hauptsymptome: Tremor, Tachykardie und Hyperidrosis erst als unmittelbare Schreckwirkung aufgetreten waren. Allerdings ist bei allen analogen Fällen unbedingt im Ange zu behalten, dass ,alle auf das sympathische Nervensystem einwirkenden Ereignisse, wie Schreck, Angst" (Thiem), uiberhaupt heftige Gemütsbewegungen bei bestehender Veranlagıng einen plötzlichen Ausbruch des M. Basedow herbeiführen können. Zum Beleg exinnere ich an den von Remlinger mitgeteilten Fall eines türkischen Soldaten, der von einem Hunde angefallen wurde und nach 4-5 Tagen an einer schmerzhaften Schwellung der Schilddrïse, Herzklopfen, Kurzatmigkeit, Pulsbeschleunigung und allgemeinem Zittern erkrankte and bei dem ein rasch verlanfender M. Basedow sich entwickelte. Bei der Identität vieler Einzelsymptome ist die Differentialdiagnose zwischen einer einfachen Schreckneurose und einem durch Schreck ausgelösten und in Entwicklung befindlichen M. Basedow sicher oft recht schwer und erst nach längerer Beobachtung zu entscheiden. Wichtig ist, wie natürlich in allen Fällen, eine sorgfältige Anamnese. So konnten wir bei einer 26 jährigen Telegraphengehilfin einen schon 
Über Schreckneurosen in klinischer und unfallrechtlicher Beziehung. 357

früher vorhandenen. M. Basedow nachweisen, der dureh den Unfall (Erschrecken durch knackende Geräusche) nicht wesentlich verschlimmert worden und auf den der grösste Teil der subjektiven Beschwerden zurückzuführen war, so dass unfallrechtlich Ablehnung des Falles in Frage kam.

Unter den kardiovaskulären Symptomen der Schreckneurose besonders herrorzuheben sind weiterhin Erhöhung und Labilität des Blutdrucks, Erscheinungen, die entsprechend den starken Tonusschwankungen, der leichten Ansprechbarkeit and Labilität des gesamten Zirkulationssystems auf psychische Reize hin in zahlreichen Fällen konstatiert werden konnten. Schon Strauss hat auf die Bedeutung der Blutdruckerhöhung als objektives Symptom bei funktionellen Neurosen hingewiesen, während von anderer Seite (Kühn) bei manchen Formen von Neurasthenie eine erhebliche Herabsetzung des Blutdrucks gefunden wurde. Nach meinen Beobachtungen scheint aber bei Schreckneurosen eine Herabsetzung kaum vorzukommen, während Blutdruckerhöhung sehr häufig anzutreffen ist, sei es als Ausdruck einer konstanten Tonussteigerung im arteriellen System, sei es als periodisch auftretendes Symptom spastischer Gefässkrisen. Überhaupt gehören Schwankungen des an verschiedenen Tagen gemessenen Blutdrucks bei allen funktionell-nervösen Individuen fast zur Regel, schwankt doch selbst bei Normalen der systolische Blutdruck bei geistigen Erregungen usw. nicht selten um 10 bis $20 \mathrm{~mm}$ Quecksilber. So betrug z. B. bei Fall 33 (34 jähriger Kaufmann mit Schreckneurose nach Eisenbahnunfall) der systolische Blatdruck am 24. Juli 170, am 28. Juli 160, am 31. Juli $175 \mathrm{~mm} \mathrm{Hg}$, stets gemessen unter denselben Kautelen und bei ruhigem Verhalten des Patienten. In Fall 9 betrug er am 5. September 120, am 9. Oktober $155 \mathrm{~mm} \mathrm{Hg}$. Wichtig sind die Symptome der Blutdruckerhöhung und -labilität im Krankheitsbilde der Schreckneurose nicht nur bei ihrer erstmaligen positiven Feststellung, sondern vor allem ist auch ihr allmähliches Wiederzurückgehen, ihr regelmässiges Fehlen bei späteren Nachuntersuchungen ein wichtiges Zeichen für ein allgemeines Abllingen des kardiovaskulären Reizzustandes.

Bei 74 von den 80 neu beobachteten Fällen liegen genaue Bestimmungen des systolischen Blutdrucks nach Riva-Rocei vor. Betrachtet man bei jüngeren Leuten, etwa bei Individuen unter 40 Jahren als „normalen" systolischen Blutdruck Werte von 100 bis $140 \mathrm{~mm} \mathrm{Hg}$ and bei älteren Individuen bis zu $150 \mathrm{~mm} \mathrm{Hg}$, lässt man also den "normalen" Werten einen ziemlich weiten Spielraum, so haben wir gefunden, dass "subnormale" Werte (unter $100 \mathrm{~mm} \mathrm{Hg}$ ) überhaupt nicht festzustellen waren - auch Blutdruckzahlen von 
100 bis zu 110 kamen nur in 3 Fällen vor -, dass hingegen abnorm hohe Werte, über 140 bzw. 150 bis zu $200 \mathrm{~mm} \mathrm{Hg}$ und darüber bei nichtw en iger als 29 Schreckneurotikern (=40 Proz.) ermittelt werden konnten (18 Patienten unter und 11 Patienten über 40 Jahren). Der niedrigste Wert war $104 \mathrm{~mm} \mathrm{Hg}$ (Fall 19); 9 Monate früher hatte er $120 \mathrm{~mm} \mathrm{Hg}$ betragen; ausser starker Pulslabilität waren Erscheinungen ron Herzschwäche nicht nachzuweisen, dagegen fand sich eine starke Erschlaffung der Hautgefässe (fast ständige Kopfrötung und andauerndes Schwitzen). Auch in Fall 46 (18 jährige schwächliche, anämische Patientin), der anfangs 130, nach 2 Monaten nur $110 \mathrm{~mm} \mathrm{Hg}$ aufwies, bestand von seiten des Hexzens lediglich eine Beschleunigung und Labilitat der Herzaktion. Dagegen zeigte Fall 65, dessen Blutdruckwert sich ebenfalls der unteren Grenze des Normalen näberte $(105-108 \mathrm{~mm} \mathrm{Hg})$, schon vor dem Unfalle zeitweise eine Debilitas cordis infolge Herzverfettung. Diese 3 Fälle $(19,46,65)$ sind aber auch die einzigen unter unserem Material, bei denen die Blutdruckzahlen sich den "subnormalen" Werten so weit nähern, dass ihnen eine gewisse pathognomonische Bedeutung bei besonderer Würdigung des einzelnen Falles möglicherweise zugesprochen werden könnte.

Demgegenüber kommt den abnorm hohen Blutdruckwerten bei den Schreckneurosen eine ungleich wichtigere diagnostische Stellung zu, wie überhaupt bei funktionellen Unfallneurosen nach meinen Erfahrungen die Blutdrucksteigerung den am hänfigsten anzutreffenden pathologischen Blutdruckbefund darstellt. Allerdings scheint sie bei nervösen Zuständen nach Kopfrerletzungen, allgemeiner Erschütterung usw. bei schätzungsweisem Ermessen weniger häufig vorzukommen als bei den Schreckneurosen. Gerade bei letzteren ist eben, woranf ich weiterhin noch einzugehen habe, der Kernpunkt des ganzen Krankheitsbildes in Reizerscheinungen im vegetativen Nervensystem, speziell im Vasomotorengebiet zu suchen, die naturgemäss sehr leicht zu Erhöhungen des Gefässtonus zu führen vermögen. Übrigens kamen bei Männern nach unserer Beobachtung die Blutdrucksteigerungen bedeutend häufiger vor als bei Franen, wie ein Vergleich der Prozentzahlen eklatant ergibt.

Es wiesen Blutdruckerhöhungen auf:

$$
\text { von } 37 \text { Männern } 20=\text { rund } 50 \text { Proz., }
$$

Die Ursache dürfte zum Teil darin zu suchen sein, dass ein ungleich grösserer Prozentsatz Männer sich bereits in vorgerücktem Alter befand und schon arteriosklerotische Erscheinungen in dem einen und 
anderen Falle sich geltend machten, so dass nicht ausnahmslos in allen Fällen die Blutdruckerhöhung einzig und allein auf Rechnung der Schreckneurose zu setzen war.

Überhaupt sind Erhöhungen des systolischen Blutdrucks natürlich nur dann als objektives funktionell-nervöses Symptom in Anspruch zu nehmen, wenn zuvor alle sonstigen Erkrankungen, die zu Blutdrucksteigerungen führen können, vor allem Arteriosklerose und Nephritiden, mit einiger Sicherheit auszuschliessen sind. Kein Anhalt für das Vorliegen derartiger Komplikationen war unter unseren 29 Fällen mit erhöhtem systolischen Blutdruck zu finden bei 21 Patienten, also bei 72,4 Proz. der Fälle, und zwar bei 15 Männern und 6 Frauen. Im einzelnen waren die Blutdruckwerte folgende:
a) Männer:
b) Frauen:

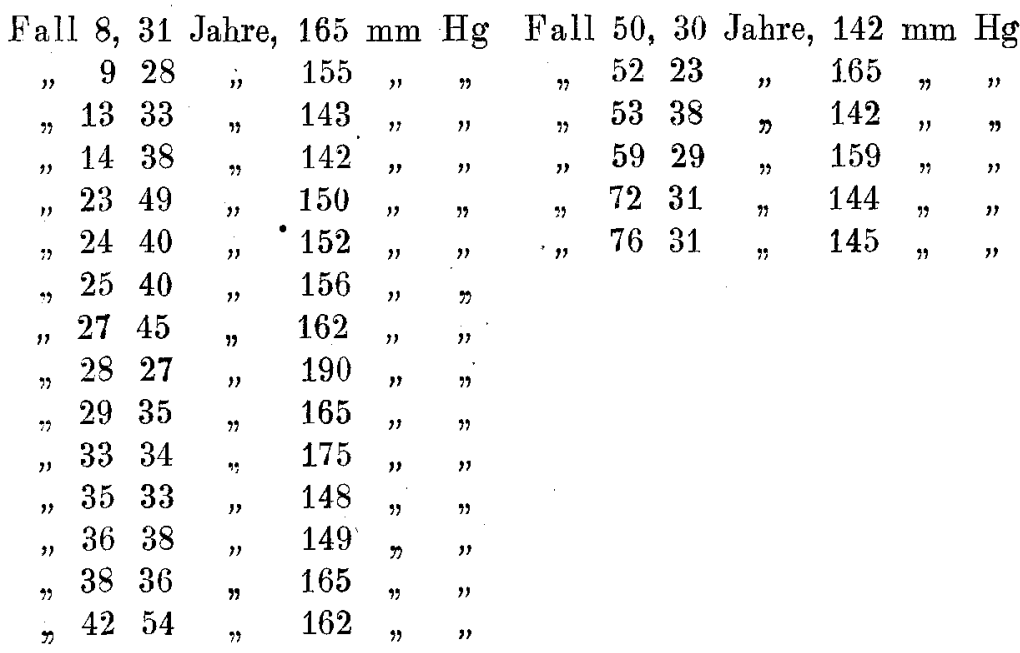

Wir sehen also, dass die Patienten fast durchweg im rüstigsten Alter sich befanden und eine Abhängigkeit vom Alter nicht bestand. Bei allen Patienten ausnahmslos fanden sich weder arteriosklerotische noch nephritische Erscheinungen, dagegen waren stets gleichzeitig noch sonstige kardiovaskuläre Symptome funktioneller Natur festzustellen. Besonders bemerkenswert ist Fall 52 (23jährige Verkäuferin), bei dem sich ausser einer Mitbeteiligung des Respirationssystems (asthmatische Anfälle), des Digestionsapparates (hochgradige Obstipation) und des Urogenitalsystems (Menstruationsanomalien) und neben sonstigen kardiovaskulären Symptomen allnächtlich erfolgende Blntungen aus dem Nasen-Rachenraume bemerkbar machten, für die trotz wiederholter spezialistischer Untersuchung eine sichere Ursache (ein anfängliches Geschwür am Nasenseptum kam rasch zur Ausheilung) 
nicht zu finden war. Vielleicht sind sie mit dem für das Alter der Patientin ausserordentlich hohen Blutdruck (165 mm Hg) in Zusammenhang zu bringen, jedenfalls erscheint mir unter diesen Umständen, obwohl es sick um eine stark hysterische Patientin handelte, der Name „hysterische Blutung nicht am Platze.

Die 8 Fälle von Blutdruckerhöhung mit organischer Komplikation betrafen sämtlich Arteriosklerotiker in vorgerücktem Alter. $\mathrm{Ob}$ und inwieweit bei derartigen Fällen eine bestehende Blutdruckerhöhung der Arteriosklerose bezw. einem funktionell-nervösen Reizzustand zur Last zu legen ist, richtet sich natürlich nach den $\mathrm{Be}$ gleitumständen des einzelnen Falles, insbesondere nach dem frrüheren Zustande des Patienten sowie nach gleichzeitigen kardiovaskulären Symptomen funktjoneller oder organischer Natur. Wichtig ist nicht nur die Beschaffenheit der Arterienwandungen, sondern auch das etwaige Vorliegen eines starken allgemeinnervösen Reizzustandes bezw. einer etwaigen Nieren- und organischen Herzkomplikation (Schrumpfniere, Herzvergrösserung usw.). Je nachdem wird man die Blutdruckerhöhung mehr auf abnorme Gefässinnervationen oder auf organische Ursachen oder auch auf beides zurückführen dürfen, wenn es naturgemäss auch zu allermeist bei Wahrscheinlichkeitsannahmen bleiben muss. So haben wir in Fall 56 (72jährige Frau) bei einer mässig starken Arteriosklerose und gleichzeitigen ausgesprochenen nervösen Reizsymptomen die für Arteriosklerose aussergewöhnlich hohe Blutdrucksteigerung $(210 \mathrm{~mm} \mathrm{Hg})$ teilweise auf funktionelle Einflüsse zurückgeführt und sie damit gleichzeitig in gewissem Grade als kardiovaskuläres Symptom der vorliegenden Schreckneurose mit anerkannt. In anderen Fällen mit weniger starker Blutdruckerhöhung, etwa 160-190 mm Hg, oder geringerer nervöser Erregbarkeit lag es näher, nur die Arteriosklerose als ursächliches Moment heranzuziehen und, falls diese schon vor dem Unfalle in gleicher Intensität bestand, einen Zusammenhang mit den Unfallfolgen abzulehnen. Wir kommen damit zu der weiteren, praktisch sehr wichtigen Frage, ob auch die Arteriosklerose an sich infolge einer stattgehabten Schreckeinwirkung auftreten oder eine bestehende Arteriosklerose vexschlimmert werden kann. Unfallreehtlich ist die Frage der Arteriosklerose ja immer noch eines der umstrittensten und schwierigsten Kapitel, wenn auch nach allen ärztlichen Erfahrungen nicht bezweifelt wird, dass psychische Aufregungen, Sorgen, Kummer, geistige Überanstrengungen die Entwicklung einer Arteriosklerose, besonders einer Koronarsklerose ( $\mathrm{Pawinski}$ ), begünstigen und beschleunigen können. Ich rerweise insbesondere auf die von Oppenheim sowie von Rumpf und Selbach mitgeteilten Fülle, bei denen die 
Herz- und Gefässveränderungen mit grosser Wahrscheinlichkeit auf die durch den Unfall bedingten andauernden seelischen Erregungen zurückzuführen waren, sich also als indirekte Unfallfolgen darstellten. Auch andere Autoren (Watermann, Baum, Külbs, Broadbert, Rivolta) haben analoge Beobachtungen gemacht. Der Rivoltasche Fall (28jähriger Mann mit Depressionsfraktur des rechten Scheitelbeins, 10 Tage bewusstlos, nach 2 Monaten starke Ausdehnung und Schlängelung der Schläfen- und Stirnschlagadern mit bedeutender Wandverdickung, auch Oberarm- und Radialarterien gespannt und gewunden) zeigt allerdings die Besonderheit, dass nach der Art der Verletzung R. zur Annahme einer „direkten Schädigung des vasomotorischen Rindenzentrums" gelangte, während es sich in den übrigen Fällen stets um psychisch bedingte Innervationen des Vasomotorengebietes handelte. Der Endeffelt ist natürlich der gleiche. Ausschlaggebend ist stets eine erhöhte Ansprechbarkeit des Vasomotorenzentrums, eine gesteigerte Innervation der vasomotorischen Fasern des vegetativen Systems und dementsprechend eine aussergewöhnliche Inanspruchnahme des Erfolgorgans, d. h. des gesamten Zirkulationssystems. Kommt es dabei zu dauernder erhöhter Inanspruchnahme, zu ungewöhnlich häufigen Kontraktionen und Erschlaffungen der Gefässwände, so ist, das unterliegt wobl keinem Zweifel, die Möglichkeit einer vorzeitigen Abnutzung gegeben, zumal wenn, wie Kühne zutreffend bemerkt, die erböhte Inanspruchnahme gleichzeitig mit Blutdruckerhöhung einhergeht und damit noch eine weitere Ursache für die Entstehung der Arteriosklerose gegeben wird; ist doch eine ständige arterielle Druckerhöhung sicher imstande, allmählich zu Änderungen der Elastizität und Dehnbarkeit der Blutgefässe zu führen. Kühne ist sogar der Ansicht, dass bei einseitigen vasomotorischen Störungen die arteriosklerotischen Erscheinungen ebenfalls nur einseitig auftreten, eine Angabe, die durch einen jüngst von Rumpf mitgeteilten Fall von umschriebener Arteriosklerose der Arteria profunda cerebri nach Schädelbasisbruch eine gewisse Bestätigung erfährt, obgleich in letzterem Falle die Deutung, weshalb gerade dies eine Gefäss arteriosklerotisch erkrankte, auch nach dem Obduktionsbefunde nicht sicher zu geben war. Unter meinem vorliegeaden Material von Schreckneurosen vermochte ich analoge Fälle nicht festzustellen. Überhaupt ist m. E. das Auftreten von Arteriosklerose als direkte oder indirekte Unfallfolge stets nur als seltene Ausnahme anzusehen. Jedenfalls vermag ich die Angaben von Watermann und Baum, die fast regelmässig bei ihren Unfallverletzten Initialsymptome von Arteriosklerose beobachteten, nicht zu bestätigen. Nicht nur bei unseren Fällen von Schreckneurose, sondern 
auch bei Patienten mit Kopftraumen oder sonstigen Verletzungen haben wir Arteriosklerose nicht häufiger angetroffen als unter den übrigen, nicht unfallverletzten Patienten, so dass der traumatischen Ätiologie der Arteriosklerose m. E. keine besonders hervortretende Bedeutung beigemessen werden kann, es sei denn, dass man die ja bei Schreckneurosen sehr häufig vorhandene Blutdrucksteigerung, für sich allein betrachtet, schon als Initialsymptom von Arteriosklerose unberechtigterweise ansehen würde. Wenn auch gelegentlich, in seltenen Fällen, eine durch andauernde seelische Erregung hervorgerufene Erhöhung und Labilität von Blutdruck und Herztätigkeit infolge einer stärkeren Inansprachnahme und Abnutzung des Herzgefässsystems zu arteriosklerotischen Veränderungen führen mögen, so ist dies doch bei weitem nicht die Regel. Zudem glaube ich, dass auch in derartigen Fällen meist noch sonstige Schädlichkeiten ätiologisch mit in Frage kommen. Für die Praxis der Unfallbegutachtung ergibt sich jedenfalls die Forderung, einen Zusammenhang zwischen Unfall und Arteriosklerose nur dann anzuerkennen, wenn sonstige Schädlichkeiten: Alkohol- und Nikotinmissbranch, Gicht, Diabetes, Lues, Infektionskrankheiten, Heredität mit einiger Sicherbeit als wesentlich mitwirkende Faktoren ausgeschlossen werden können. Nach alledem ist die Gefahr einer nach einer Schreckeinwirkung sich entwickelnden Arteriosklerose als so gering zu betrachten, dass sie praktisch kaum in die Wagschale fällt; liess sich doch unter meinem gesamten Material von Schreckneurosen trotz der Häufigkeit der Blutdrucksteigerung und der-sonstigen kardiovaskulären Symptome auch nicht in einem einzigen Falle mit einiger Wahrschejnlichkeit ein ursächlicher direkter oder indirekter Zusammenhang zwischen Unfall und Arteriosklerose annehmen. Ebenso war Verschlimmerung einer bereits bestehenden Arteriosklerose niemals nachzuweisen oder auch nur als wahrscheinlich anzusehen, obwohl an sich zuzugeben ist, dass beispielsweise bei latenter Gehirnarteriosklerose durch die mit der Schreckeinwirkung verbundene Blutdrucksteigerung die Ausgleichsvorrichtungen im Gehirn (Windscheid) derart gestört werden können, dass nunmehr mit einem Male die ganzen Erscheinungen der Gehirnarteriosklerose zutage treten. Nur in Fall 81 bestanden Zweifel, ob durch die Schreckeinwirkung eine Arteriosklerose verschlimmert worden war; eine vorhandene Herzerweiterung wurde zunächst als indirelste Unfallfolge betrachtet, später ergab die Blutuntersuchung positiven Wassermann und die Röntgendurchleuchtung eine Aortitis ascendens, so dass m. E. die anfängliche Anerkennung der Arteriosklerose als Unfallfolge zu Unrecht erfolgte, zumal, wie schon früher erwähnt, Zeichen einer akuten Herzerweiterung vollkommen fehlten. 
Im Anschluss an die kardiovaskulären Erscheinungen möchte ich noch einen Fall erwähnen, bei dem sich ein abnorm hoher Spinaldruck (280 mm $\mathrm{H}_{2} \mathrm{O}$ im Sitzen mit vornübergebengtem Oberkörper) fand. Allerdings war Patient, bej dem zweifellos eine heftige Schreckeinwirkung stattgefunden hatte, im Zweifel, ob er njcht gleichzeitig auch mit dem Kopfe angeschlagen sei. Im letzteren Falle könnte man an eine chronische Meningitis serosa denken. Aber auch die Möglichkeit, dass einzig und allein die starke psychische Erregung Ursache der Druckerhöhung war, muss offen gelassen werden, ist es doch sehr wohl denkbar, dass bei bestehenden nervösen Zirkulationsstörungen eine vermehrte Exsudation der Plexus chorioidei erfolgt. Besonders bei den Schreckneurotikern mit anhaltenden Kopfbeschwerden ist an die Möglichkeit eines erhöhten Spinaldrucks zui denken. $\mathrm{Ob}$ es sich hier aber um eine häufige oder nur vereinzelte, ausnahmsweise Erscheinung handelt, muss bis zum Vorliegen zablreicherer Beobachtangen natürlich vollkommen unentschieden bleiben.

Neben den Störungen von seiten des Zirkulationssystems spielen bei den Schreckneurosen auf somatischem Gebiete Erscheinungen im Bereiche des Digestionsapparates eine wichtige Rolle. Wenngleich sie keineswegs so häufig und regelmässig anzutreffen sind als Herz- und Gefässsymptome, so finden sie sich doch bei schreckneurosen zweifellos ganz erheblich häufiger als bei Unfallneurosen sonstiger Ätiologie. Unter unseren 80 neu beobachteten Fällen zeigten nicht weniger als $46(=57$ Proz.) ausgesprochene Störungen der MagenDarmtätigkeit nnd zwar 48 Proz. der Männer (19 Fälle) und 67 Proz. der Frauen (27 Fälle). Auch hier traten die krankhaften Erscheinungen bei Patienten aller Kategorien in gleicher. Weise in Erscheinung. Geklagt wurde hauptsächlich über Übelkeit, Brechreiz, Würgen, Erbreehen, Aufstossen, Sodbrennen, Appetitlosigkeit, Magendruck, Schmerzen in der Magengegend, Durchfall, Verstopfung. Übelkeit, Brechreiz, Würgen und Erbrechen traten meist nur als Initialsymptome auf, als direkte, unmittelbare Folge des psychischen Shocks. Öfters wiederkehrende Brechneigung, wie wir sie als cerebralen Reizzustand häufig. nach Kopfverletzungen finden, bestand nur in ganz vereinzelten Fällen. Klagen über Appetitlosigkeit fanden sich fast bei sämmtlichen Patienten; sie sind so allgemein und hängen natürlich von so manchen sonstigen Umständen ab (Schlaflosigkeit, Schmerzen, psychische Verstimmung etc.), dass sie, für sich allein vorkommend, nicht als. "Magensymptome" zu verwerten sind. Grössere Bedeutung in diesem Zusammenhange haben die Klagen über Aufstossen, Sodbrennen, Schmerz und Druck in der Magengegend. Wir haben allerdings. niemals Zeichen einer organischen Erkrankung feststellen können, 
doch liegt nach den Forschungen v. Bergmanns und seiner Sehiiler an und für sich das Auftreten eines Uleus pepticum als Folge psychisch bedingter spasmogener Zustände bei hierzu spezifisch disponierten Individuen immerbin im Bereiche der Möglichkeit. Im wesentlichen beschränken sich aber die Magenerscheinungen bei Sehreckneurosen auf Störungen der Motilität und Sekretion. Ich habe auch in der Literatur keinen Fall auffinden können, in dem ein Uleus ventriculi oder duodeni nach Schreck oder sonstigen psychischen Alterationen aufgetreten und gar als Unfallfolge anerkannt worden wäre. Allerdings sind die Gedankengänge, die die Rolle des vegetativen Nervensystems mehr als bisher in den Vordergrund rücken, noch zu neuartig, als dass sie bereits allgemeine Anerkennung besässen. Sehr verbreitet, besonders unter den Frauen, waren die Klagen über Obstipation, wobei ich besonders hervorhebe, dass nur in ganz vereinzelten Fällen bereits vor dem Unfalle eine Neigung zu Obstipation bestanden haben soll. Vielfach fand" sich abwechselnd Obstipation und Diarrhoe, letztere meist im Anschluss an Aufregungen, dabei gelegentlich von Kolikartigen Schmerzen begleitet. In Fall 52 ergab das Röntgenbild das typische Bild einer spastischen Obstipation. Meist waren die Magen-Darmstörungen von auffallender Abmagerung begleitet, die sich allerdings auch bei Schreckneurosen ohne Digestionserscheinungen zeigte und dann wohl in der Hauptsache auf Schlaflosigkeit bezw. die andauernde Erregung zurückzuführen war. Dass gerade in derartigen Fällen die Möglichkeit latenter tuberkulöser Prozesse zu erwägen ist, ist selbstverständlich.

Als weitere Gruppe vegetativer Störungen nach Schreckeinwirkung sind zu erwähnen Erscheinungen seitens des Respirationsapparates. Ioh sehe hier von den hysterisch bedingten Aphonien, die vereinzelt durch Schreek entstehen können (Bernhardts Material enthält 1 Fall, Förster beobachtete 2 weitere Fälle bei Telephonistinnen), ab, ebenso von den bereits erwähnten urtikariellen Ödemen der oberen Luftwege - alles Erscheinungen, die nach unserer Erfahrung doch nur recht selten zur Beobachtung kommen. Häufiger bei Schreckneurosen sind Anfälle von Atemnot, ähnlich dem Asthma bronchiale nervosum und wie dieses sehr wabrscheinlich auf einer nervös bedingten Erweiterung der Kapillaren mit gleichzeitiger gesteigerter Schleimproduktion beruhend. Also auch hier spielen vasomotorische Störungen mit. Unter unseren 80 neu beobachteten Fällen von Schreckneurose kamen derartige Zustände von ausgesprochener Atemnot bei $12 \mathrm{~Pa}-$ tienten vor. In einem Falle (45) bestand allerdings gleichzeitig eine durch Schreck ansgelöste akute Herzdilatation und in Fall 4 fand sich eine als Alterserscheinung zu betrachtende Arteriosklerose mit. 
Emphysem, so dass diese beidèn Fälle hier natürlich auszuscheiden haben. In den übrigen 10 Fällen kamen zur Erklärung der Atemnot, die wie echtes Asthma bronchiale vielfach des Nachts und unter starkem Angst- und Beklemmungsgefühl auftrat, nur nervöse Einflüsse in Betracht. Besonders bemerkenswert ist Fall 52, in dem die Anfälle von Lufthunger sofort als erste und inmittelbarste Unfallfolge in Erscheinung traten. Es handelte sich um eine 23jährige, bis dahin angeblich gesunde Verkäuferin, die bei einer Zugentgleisung sich aufs heftigste erschreckte, ohne indessen körperlich verletzt zu werden. In ihrer Angst wollte Patientin laut aufschreien, „bekam aber keine Luft". Ein 2. Anfall von Luftmangel trat bei der Weiterreise auf und in den folgenden Tagen nahmen die asthmatischen Anfälle an Häufigkeit und Intensität derart zu, dass nur durch Morphiumgaben Linderung zu erzielen war. 3 Monate nach dem Unfall kam Patientin in unsere Behandlung. Auch jetzt bestanden neben zahlreichen sonstigen Symptomen von Schreckneurose (Aufgeregtheit, Ängstlichkeit, Schreckbaftigkeit, Stimmungswechsel, Schlaflosigkeit, Herzklopfen, Schwitzen, Blutandrang zum Kopf, Obstipation, Menstruationstörungen etc.) noch ausgesprochene Anfälle von Lufthunger, die fast ausnahmslos jede Nacht 1- bis $2 \mathrm{mal}$ auftraten und nur schwer zu bekämpfen waren; eine deutliche Lungenblähung war allerdings, auch bei den analogen übrigen Fällen, nicht festzustellen. Einen ähnlichen Fall von Schreckneurose mit vorwiegenden Atmungsstörungen hat Faust beschrieben.

Häufiger noch als Respirationsanomalien kommen bei Schreckneurosen Störungen im Bereiche des Urogenitalapparates vor und zwar ganz besonders unter den weiblichen Patienten. Hier sind es vor allem Menstruationsanomalien, die, nach unserem Material zu urteilen, mit zu den regelmässigsten Symptomen der Schreckneurose zu rechnen sind. Sehen wir ron den 5 Patientinnen ab, bei denen bereits vor dem Unfall die Menopause eingetreten war, so wurde von 24 unter 35 Patientinnen (=70 Proz.) der Eintritt von Menstruationsanomalien infolge des ausgestandenen Schrecks bebauptet. Dabei wurde, abgesehen von vereinzelten Fällen mit Verzögerung des nächsten Periodeneintritts, zu allermeist versichert, dass noch am Unfalltage selbst oder in der darauf folgenden Nacht die Periode vorzeitig aufgetreten sei. In einem Falle (47jährige Patientin) waren die Regeln bereits 7 Monate ausgeblieben, um am Abend des Unfalltages unter schmerzhaften Erscheinungen und starkem, 8-10 Tage anhaltendem Blutverlust wieder aufzutreten und um in der Folgezeit alle 2--3 Wochen in gleich starker Intensität wiederzukehren. Meist wird jedoch angegeben, die bis dahin normale Periode trete Dentsche Zeitschrift t. Nervenheilkunde. Bd. 53. 
seit dem Unfall in sehr unregelmässigen Intervallen auf, bald vorzeitig, bald verspätet, wobei zu häufiges Auftreten öfters vorzukommen scheint als zu seltenes. Ebenso wird häufiger über starke profuse und langdauernde Blutungen geklagt als über spärliche und kurzdanernde; fast stets werden aber zur Zeit der Periode verstärkte Unterleibs- and Allgemeinbeschwerden vorgebracht, besonders von solchen Patientinnen, bei denen bereits vor dem Unfalle krankhafte Erscheinungen seitens der Unterleibsorgane bestanden (Retroflexio uteri, Stenose des Cervikalkanals etc.). Gelegentlich wird auch, wie in Fall 68 unserer Beobachtung, bei bestehender Veranlagung zu habituellem Abort eine Fehlgeburt durch die psychische Erregung des Schrecks zur Auslösung gebracht.

Bei den Männern sind es besonders Störungen der Potenz, die gelegentlich neben sonstigen Symptomen in Fällen von Sehreckneurose sich bemerkbar machen. Allerdings scheinen durch Schreck bedingte Anomalien in der Sexualsphäre bei Männern nicht derart hänfig vorzukommen, wie beispielsweise postemotionelle Menstruationsstörungen bei Frauen. Zumeist wird geklagt über Erektionsanomalien, gelegentlich aber auch, wenngleich seltener, über Störungen der Ejakulation. Ich hebe diese Störungen im Bereiche der Sexualsphäre vor allem deshalb hervor, weil sie vielfach bei der Krankenexamination keine Berücksichtigung finden und doch andererseits sicher in manchen Fällen eine nicht geringe psychische Rüickwirkung besitzen.

Seitens des uropoëtischen Systems fand sich, abgesehen ron gelegentlich vorhandenem nervös bedingtem Harndrang, in 1 Falle (60) von ausgesprochener Schreckneurose zeitweise eine Spur Albumin im Urin, ohne dass bei der 27jährigen, bis zum Unfall angeblich gesunden Patientin sich irgendwelcher sicherer Hinweis auf ein organisches Herz- oder Nierenleiden (Zylinder etc.) oder eine sonstige Schädlichkeit feststellen liess. $O b$ man aber hier ron einer nervös bedingten Albuminurie sprechen und zur Erklärung etwa funktionell ausgelöste Gefässstörungen in der Niere annehmen darf, erscheint mir nichtsdestoweniger zweifelhaft, wenn ich auch eine derartige Möglichkeit nicht völlig abweisen möchte. Übrigens erwähnt $\mathrm{Ham}$ burger unter den Symptomen der Vasoneurose u. a. auch die lordotische Albuminurie, die er als wabrscheinlich vasomotorisch mitbedingt betrachtet.

Ob durch Schreckeinwirkung auch Störungen der Keimdrïsenfunktionen auftreten können, ist einstweilen noch in rollkommenes Dunkel gehüllt. Besser begründet erscheint die Annahme, dass durch pathologische Zustände des vegetativen Nervensystems, das ja bei Schreckneurosen in ganz hervorragender Weise beteiligt ist, andere 
drüsige Organe, wie Schilddrüse und Pankreas, zu abnormer Funktion veranlasst werden und damit krankhafte Zustände erzeugen, die praktisch erhebliche Bedeutung besitzen. Ich denke hier vor allem an die Beziehungen der Schreckeinwirkung zu dem schon früher erwähnten Morb. Basedow. Nimmt man mit Cassirer an, „dass die Schilddrüsenerkrankung beim Basedow keine primäre Erscheinung ist, sondern nur ein in die Kette des pathologischen Geschehens eingeschobenes Glied darstellt, ihrerseits entstanden auf dem Boden einer Erkrankung des vegetativen Systems", so erscheint das gelegentliche Auftreten eines echten Morb. Basedow nach Schreck einigermassen verständlich, beruht doch die Schreckwirkung, um dies schon jetzt hervorzuheben, auf somatischem Gebiete im wesentlichen auf einer psychogen bedingten Alteration des gesamten vegetativen Systems und stellt doch der Morb. Basedow im Lichte der Cassirerschen Auffassung lediglich eine ,besondere Lokalisation einer allgemeinen Alteration des vegetativen Nervensystems dar ${ }^{4}$, die nur „dureh die Abänderung der Innervationsbedingungen des Thyreoideasekrets von den verwandten Affektionen" (M. Addisonii, Sklerodermie, Myх ödem, A kromegalie) unterschieden ist.

Ähnlich wie beim Morb. Basedow scheinen die Verhältnisse auch bei manchen Formen von Glykosurie bezw. Diabetes mellitus zu liegen. Würde man auch hier die Glykosurie in ihrer Endursache auf Störungen der inneren Sekretion, sei es in Pankreas oder Leber zurückführen, so wäre bei der bestehenden Abhängigkeit der inneren Sekretionsvorgänge vom vegetativen Nervensystem für alle durch Schreck entstandenen oder verschlimmerten Fälle von Glykosurie bezw. Diabetes mellitus der ursächliche Zusammenhang einigermassen plausibel erklärt. Man kann allerdings für manche Fälle auch annehmen, dass die vermittelnde Rolle zum Ausbruch der Zuckerharnruhr das Blutgefässgebiet spielt, auf das der Schreck auf dem Wege der Vasomotoren einwirkt (Thiem). Mag man nun eine direkte Einwirkung auf die innere Sekretion oder vasomotorische Störungen mit indirekter Sekretionsbeeinflussung als Ursache der Zuckerausscheidung annehmen, bei beiden Möglichkeiten kommt man zur Erklärung der Schreckwirkung nicht ohne die Annahme einer Störung im vegetativen Nervensystem aus. In wiefern eine spezifische Disposition hierbei in Frage kommt, wird späterhin zu erörtern sein. - Unter unseren 100 Fällen von Schreckneurose kamen Zuckerausscheidungen $4 \mathrm{mal}$ zur Beobachtung (Fall 39, 40, 41, 42). Die Fälle 39 und 40 betrafen Patienten, bei denen eine Glykosurie vor dem Unfallereignis nicht bestanden haben soll. Sie haben das Gemeinsame, dass die Zuckerausscheidung erst mehrere Monate nach 
dem Unfalle festgestellt wurde und sich in so geringen Grenzen hielt (höchstens bis zu $10 \mathrm{~g}$ pro Tag bei gemischter Kost), dass sie neben den sonstigen Erscheinungen von Schreckneurose mehr einen Nebenbefund darstellte (symptomatische Glykosurie) und keine Neigung zur Verschlimmerung erkennen liess. Ich weise aber ausdrücklich auf die beiden von Lorand mitgeteilten Fälle hin, die 2 weibliche Personen im Alter von 16 resp. 35 Jahren betrafen und die beide innerhalb eines Jahres im Coma diabeticum zngrunde gingen. - In den Fällen 41 und 42 war Verschlimmerung eines schon vorher bestehenden Diabetes mellitus anzunehmen. Beide Male stieg nach der Schreckeinwirkung die Zuckerausscheidung ganz beträchtlich und in Fall 41 wurden, wie bereits früher erwähnt, einige Wochen nach dem Unfall frische Blutungen in die Netzhaut festgestellt.

Auch bei Diabetes insipidus soll gelegentlich eine heftige seelische Erregung als Krankheitsursache in Frage kommen (Thiem). Die von mir beobachteten Fälle von Diabetes insipidus waren allerdings sämtlich nach Kopftraumen entstanden, weshalb ich als Beispiel den Lacombeschen Fall zitiere: Eine 33jäbrige Frau bekam nach Erhalt einer unerwarteten Todesnachricht sofort heftigen Durst und anhaltenden Kopfschmerz; in der folgenden Nacht trank sie bereits sehr grosse Mengen Wasser und zeigte seitdem dauernde Harnvermehrung, die auch 4 Jahre später noch fortbestand. Zweifellos sind aber derartige Fälle von Diabetes insipidus nach Sehreck ausserordentlich selten.

Häufiger als Störungen der inneren Sekretion finden sich nach Schreckeinwirkung Anomalien der oberflächlichen Sekretionsvorgänge. Vor allem trifft man, besonders häufig kombiniert mit vasomotorischen Erscheinungen, bei Schreckneurosen eine auffallende Neigung zur Schweissabsonderung, die am regelmässigsten die Handteller und Achselhöhlen, dann die Fusssohlen und Kopfpartien betrifft und vielfach mit zu den unmittelbarsten Unfallfolgen gehört, wie der schon fruher erwähnte Fall 9 in eklatanter Weise zeigt. Mitunter besteht auch ausgesprochenes Halbseitenschwitzen. (Becker), das ich ebenfalls an mehreren Fällen beobachten konnte. Im Gegensatz zu den sehr häufigen Klagen über Hyperidrosis wird eine abnorme Trockenheit der Haut (Anidrosis) nur in ganz vereinzelten Fällen angegeben. Auch Störungen der Speichelsekretion. habe ich bei Schreckneurose nicht beobachtet. Dagegen stellte sich in einem Falle (49), der eine 20jährige Kontoristin betraf, die bei einem Strassenbabnzusammenstoss sich heftig erschreckt hatte, 8-10 Tage nach dem Unfalle neben sonstigen charakteristischen Erscheinungen (Aufgeregtheit, allgemeine innere Unruhe, Weinkrämpfe, Schlafstörung 
mit Aufsschrecken, Durchfall, Herzklopfen, Zittern und choreatische Muskelunruhe, Menstruationsstörung, zeitweise Kopfschmerzen und Ohnmachtsanfälle) plötzlich eine schmerzhafte Anschwellung und Sekretion der linken Brustdrüse ein, die nach einigen Tagen zurückging, um nach Aufregungen wieder einzusetzen. Eine Abhängigkeit von der Periode wurde nicht bemerkt, anch niemals eine rechtsseitige Absonderung. In einem anderen, schon früher erwähnten Falle (50) wurde behauptet, das früher sehr fettreiche Haar sei schon wenige Tage nach dem Unfalle völlig trocken geworden, gleichzeitig habe ein starker Haarausfall eingesetzt. Es liegt auf der Hand, hier an ein Versiegen der Haarbalgdrüsen zu denken; aber auch trophische Störungen kommen in Betracht. Cassirer hat bereits in seinen klassisehen Arbeiten über die vasomotorisch-trophischen Neurosen darauf hingewiesen, dass zwar der experimentelle Nachweis der Abhängigkeit trophischer Störungen von Läsionen des Nervensystems noch nicht geglückt ist, dass aber andererseits die Erwägung aller pathologischen Erfahrungen es höchstwahrscheinlich macht, dass für die Ernährung der Haut, der Knochen und Gelenke, vielleicht anch der Blutgefässe eine direkte nervöse Regulation vorhanden ist, die zwar im engsten Zusammenhang mit sensiblen und vasomotorischen Erscheinungen verläuft, aber dennoch eine gewisse Selbständigkeit besitzt. Der gewöhnliche Weg der Entstehung trophischer Störungen ist die Alteration des sensibel-vegetativen Reflexmechanismus (Cassirer); dabei handelt es sich im wesentlichen um Reiz-, nicht um Ausfallserscheinungen. Ist diese Theorie begründet, so erscheint damit das so oft bemerkte Auftreten trophischer Störungen nach Schreck hinreichend erklärt. Am meisten von allen trophischen Störungen wird geklagt über Haar a usfall und zwar unter den Frauen scheinbar häufiger als unter den Männern, obgleich ich auch unter den männlichen Patienten einen ausserordentlich instruktiven Fall beobachten konnte, bei dem allerdings ausser dem Schreck noch eine körperliche, aber für die vorliegende Frage völlig belanglose Verletzung stattfand. Es handelte sich um einen 36jährigen Arbeiter, bei dem die Anamnese sonst nichts Bemerkenswertes bot (keine Lues). Unfall am 27. August 1912: Geriet mit der linken Hand in eine Walze, blieb mehrere Minuten in dieser Lage, „lähmender Schreck“ (konnte nicht um Hilfe rufen, keine Schmerzäusserung), furchtbare Aufregung und Angst, der ganze Arm wurde von der weiter laufenden Maschine ausgerissen. Endglieder vom Mittel- und Ringfinger zermalmt - Amputation. Wenige Tage nach dem Unfall allgemeiner Haarausfall (Haupt-, Bart-, Schamhaare usw.), in 4-5 Wochen vollkommen kahl; dann spärliche büschelförmig auftretende Neubildung 
völlig entfärbter (weisser) Haare, später auch stellenweise dunklere Baare. Noch am 17. IV. 14 Kopf haare spärlich, vollkommen weiss mit vereinzelteu dunklen Partien (Bild der Alopecia areata), Barthaare fehlen, Schamhaare äusserst spärlich und auffallend hell; im übrigen Erböhung des systolischen Blutdrucks bei weichen Arterien auf $170 \mathrm{~mm} \mathrm{Hg}$, abnorme Kopfröte beim Bücken, Dermographie, Zittern der Hände und der Zunge, Fehlen der Schleimbautreflexe, Lebhaftigkeit der Fusssohlen-, Knie- und Achillessehnenreflexe; ängstliches, schreckhaftes Wesen. - Auch von mehreren anderen Patienten wurde auffallendes Ergrauen der Haare neben Haarausfall behauptet. Ich erinnere mich auch aus meinem Bekanntenkreise einer 19jährigen Dame, die nach Aufregungen in der Familie in kurzer Zeit stark ergraute. Boissier berichtet über einen 38jährigen Mann, der beim Ersehrecken über den Unfall seines Sohnes ein merkwürdiges „Kältegefühl" und Ziehen im Gesicht und auf dem Kopf verspürte. Am folgenden Tage fielen Kopf-, Bart- und Augenbrauenhaare in Masse aus; nach 8 Tagen war er vollkommen kahl, die Haut an Kopf und Gesicht war völlig blass. Die Haare wuchsen zwar wieder, aber spärlicher und blieben weiss (zit. nach Thiem). Im ganzen gehört aber ein akutes Ansfallen der Haare im Anschluss an emotionelle Ereignisse zu den allergrössten Seltenheiten (Reichardt).

Von sonstigen trophischen Störungen, die wir gelegentlich beobachten konnten, erwähne ich ausser dem schon früher beschriebenen Falle von Otosklerose Wachstumsstörungen der Nägel (Querfurchen usw.) sowie. Kariöswerden der Zähne (beides neben Haarausfall und zahlreichen kardiovaskulären Erscheinungen usw. z. B. in Fall 75 - 28jährige Telegraphistin, durch starkes Weckgeräusch an Schreeknenrose erkrankt). Auch die im Hirnstamm liegenden Zentren der Körpertemperatur können durch affektive Erregungen beeinflusst werden, so dass Temperaturerhöhungen entstehen, ohne dass natürlich die Bezeichnung „hysterisches Fieber“ gerechtfertigt wäre (Reichardt).

Als weitere wichtige Symptomengruppe sind Störungen der Motilität zu erwähnen, die sowohl als motorische Schwäche- und Lähmungs-, wie auch als motorische Reizzustände mannigfacher Art im Bilde der Schreckneurose eine hervorragende Stellung einnehmen. Was zunächst die Schwäche- und Lähmungszustände anbetrifft, so bilden die Klagen über plötzlich einsetzendes Erschlaffungsgefühl, besonders der Beine, eines der unmittelbarsten Schrecksymptome („der Schreck ist ihm in die Glieder gefahren"). Auch im weiteren Verlauf machen vielfach allgemeine Schwächezustände oder Abasien und Astasien, mit Steifigkeit oder schmerzhafter Muskelspannung gelegent- 
lich kombiniert, sich geltend. So war in Fall 19 das Gebvermögen durch starke Unsicherheit und Müdigkeit der Beine mit Schmerzen und "totem Gefühl" stark behindert and bot ein ausgesprochenes Bild hysterischer Abasie; daneben bestanden zahlreiche Störungen im gesamten vegetativen Nervensystem, vor allem kardiovaskuläre Symptome. Auch in Fall 30 spielte im späteren Krankheitsverlauf plötzlich, besonders bei Aufregung eintretendes Schwäche- und Steifigkeitsgefiihl im linken Arm und linken Bein eine grosse Rolle, eine Erscheinung, die bereits in früheren Jahren vorübergehend bestanden und nach der Schreckeinwirkung neben sonstigen Symptomen in verstärkter Intensität wieder aufgetreten war („homologes Rezidiv" Wimmers). Überhaupt sind halbseitige motorische Schwäche- und Lähmungszustände ebenso häufig wie doppelseitige und dabei vielfach kombiniert mit gleichseitiger Anästhesie. So wurde in dem schon mehrfach zitierten Fall 50 unmittelbar nach der Schreckeinwirkung die "ganze linke Seite" völlig bewegungslos, steif und gefühllos; später trat Besserung ein, doch kamen als" neue Erscheinungen Parästhesien, einseitige vasomotorische Störungen, Schweissanomalien usw. hinzu, beim Gehen fiel immer ein zeitweises "Einknicken" und eine gewisse Steifigkeit der linken Seite auf. Daneben stellten sich Zittererscheinungen ein und zwar vom Augenblick des Unfalls an. Überhaupt ist allgemeines oder partielles Zittern ein bei Schreckneurosen sowohl im ersten Beginn als auch im weiteren Verlaufe ausserordentlich häufig anzutreffendes Symptom. Mitunter mag es auf motorischen Reizzuständen beruhen, vielfach scheint es sich aber um psychogen bedingte motorische Schwäche zu handeln, mag es sich nun um Zittern der Hände, der Beine, der geschlossenen oberen Augenlider, der vorgestreckten Zunge oder allgemeines Beben handeln. Fast niemals wird man bei Schreckneurose eines dieser Symptome vermissen. Mitunter treten förmliche Zitteranfälle ein, bei denen sich das Zittern ron anfänglichem „Beben“ einer Extremität zu ausgèsprochenem Schütteln des ganzen Körpers steigert, wie wir es beim hysterischen Schütteltremor sehen. Ja sogar echte Paralysis agitans soll gelegentlich durch Schreck zur Auslösung gelangen. Flatau sah ihre Entwicklung in seinem von mir schon in anderem Zusammenhang erwähnten Falle. Worauf eigentlich die Paralysis agitans, die ich hauptsächlich nur wegen ihrer differentialdiagnostischen Bedeutung berühre, zurückzuführen ist, ist ja immer noch nicht mit Sicherbeit entschieden, Ich möchte aber darauf hinweisen, dass sie u. a. auch als Stoffwechselstörung infolge Schilddrüsenerkrankung angesehen (vergl. Thiem), also in Analogie zum Morb. Basedow gesetzt wird - eine Hypothese, bei der die Auslösung der Paralysis agitans 
durch psychische Erregung auf dem Wege des vegetativen Nervensystems dem Verständnis zweifellos nähergeriückt wäre.

Fibrilläres Zittern, Frostzittern und Muskelwogen sind ebenfalls bei Schreckneurosen häufiger vorkommende, wenn auch weniger charakteristische Erscheinungen. Ebenso wie die vielfach beobachteten Muskelzuckungen deuten sie hin auf motorische Reizzustände. Bekannt ist das häufige Zusammenzucken der Glieder baim Einschlafen. Auch tic-artige Zuckungen im Facialisgebiet oder der Halsmuskulatur kommen gelegentlich im Bilde der Schreckneurose vor; ja sie können unter Umständen dem Krankheitsbilde eine derart prägnante Färbung geben, dass alle übrigen Erscheinungen mehr oder weniger zurücktreten. Typisch ist Fall 73: 25jährige Telegraphengehilfin, nervös disponiert, durch Knacken in der Leitung heftig erschreckt, schrie laut auf, blieb unbeweglich sitzen, wurde zunächst "ganz rot", dann ,leichenblass", alsdann von heftigen Zukkungen befallen, Bewusstseinstrübung. Seitdem neben fixierten Angstaffekten, Weinkrämpfen usw. ständige klonische Zuckungen in der rechtsseitigen mimischen Muskulatur (bei Beklopfen erhöhte Erregbarkeit des Nerv. facialis) sowie klonisch-tonische Kontraktionen des Platysma und der Mm. sternocleidomastoidei, besonders rechterseits. Ausserdem Zittern des rechten Armes, anfallsweise zu Schütteln des ganzen Körpers sich steigernd.

Auch choreatische Störungen der Motilität, gelegentlich mit Übergängen zu Para-, Poly- und Monomyoklonie kommen in vereinzelten Fällen von Schreckneurose vor. So beobachtete Bernhardt unter den Telegraphengehilfinnen mit Schreckneurose einen Fall von typisch choreatischer Bewegungsstörung und unter unserem Material zeigte Fall 49 ausser geradezu klassischen Schrecksymptomen an Chorea minor erinnernde, leicht unkoordinierte Bewegungsunrube der Extremitäten-, Gesichts- und Rumpfmuskulatur, während in F all 57 hemichoreatische Erscheinungen bestanden, die zeitweise derart in den Vordergrund traten, dass das ganze Krankheitsbild als "Motilitätsneurose" imponierte. Auch in Fall 32, der einen 25 jährigen Landwirtseleven betraf, der nach einem Eisenbahnunfall an Schreckneurose mit hochgradiger psychischer Exaltation, Angstzuständen, kardiovaskulären Symptomen, Hyperidrosis, Zitterscheinungen usw. erkrankt.war, fand sich als eines der auffälligsten Symptome eine hochgradige motorische Unruhe mit choreiformen-athetoseartigen Bewegungen, besonders der Hände; daneben bestanden Zuckungen im linken M. pectoralis major und eine Gehstörung mit Nachschleifen des rechten Beines. Becker beschreibt einen Fall „,hysteriseher Schreckneurose" bei einem Soldaten, der in ununterbrochenen tonisch-klo- 
nischen Zuckungen sich befand, die beim Ansprechen und beim Nühern eines Vorgesetzten ,zu ausfahrenden, unkoordinierten Schreck- und Abwebrbewegungen sich verstärkten"; ausserdem bestand "kostale Angstatmung".

Tetanie soll ebenfalls gelegentlich durch Schreck hervorgerufen sein, ob durch Beeinträchtigung der inneren Sekretionsvorgänge (Epithelkörperchen) analog dem Morb. Basedow, bleibe dahingestellt. Mechanische Übererregbarkeit des Nerv. facialis haben wir in mehreren Fällen von Schreckneurose beobachtet, aber niemals Fälle von eigentlicher Tetanie.

Endlich seien als eine der praktisch wichtigsten motorischen Reizerscheinungen die sogen. hysterischen Krampfzustände erwähnt, wie sie in klassischer Form im ,grossen hysterischen Anfall“" uns entgegentreten. Schwere Anfälle mit völliger Bewusstlosigkeit und allen Symptomen starker Hysterie kamen allerdings nur bei 4 (-10 Proz.) unserer Patientinnen (Fall 15, 16, 53, 65) zur Beobachtung, niemals bei Männern. Ein schon früher veröffentlichter Fall (95), der eine von jeher schwächliche, blutarme 34 jäbrige Frau betraf, zeigte häufig wiederkehrende. Anfälle kataleptischen Typs. Kühne berichtet über eine Frau, die beim Ausbruch eines Brandes vor Schreck bysterische Krämpfe und „rote Flecken im Gesicht" bekam, und Paalzow erwähnt das Auftreten gehäufter hysterischer Krampfanfälle bei einem bis dahin anscheinend gesunden Musketier, dem beim Öffnen des Spindes eine Maus ins Gesicht gesprungen war. Auch lokale Crampi, z. B. plötzliche krampfhafte Streckung oder Zusammenkrallung der Finger und Ähnliches fanden sich nur in vereinzelten Fällen. In 2 Fällen (13 nnd 14) bestand eine Mischform von Hystero-Epilepsie. Fall 13 zeigte zunächst rein hysterische Symptome, bis sich schliesslich eine Epilepsie entwickelte, während Fall 14 wahrschainlich schon vor dem Unfalle an Epilepsie litt, bis dann infolge der Schreckwirkung hysterische Anfälle in den Vordergrund traten, die aber mehr und mehr wieder epileptiformen Charakter annahmen. In einem dieser Anfälle, wobei Patient mit dem Gesicht zu Boden fiel, ist er schliesslich zugrunde gegangen. In einem anderen Falle ron Epilepsie trat nach Schreck ein gehäuftes Vorkommen epileptischer Anfälle ein. Aber auch das erste Auftreten von Epilepsie kann durch Schreck hervorgerufen werden, wie Fälle von Dub u. a. beweisen. Selhstredend muss unfallrechtlich stets die Frage sorgfältig erwogen werden, ob nicht schon früher epileptische Anfülle oder Äquivalente bestanden baben und ob nicht durch Alkoholismus oder Lues eine besondere Disposition zu Epilepsie gegeben war (Gordon). Jedenfalls ist ein Zusammenhang zwischen Schreckeinwirkung und Epilepsie nur 
dann als möglich oder wahrscheinlich anzuerkennen, wenn sich die Anfälle in enger zeitlicher Folge an den Unfall angeschlossen haben.

Im Zusammenhang mit den Störungen der Motilität seien sodann die bei Schreckneurose in gleicher Weise wie bei sonstigen nervösen Zuständen ausserordentlich bäufig anzutreffenden Reflexa nomalien erwähnt. Lebhaftigkeit der Knie- und Achillessehnenreflexe sowie der Biceps-, Triceps- und Periosteflexe ist einer der regelmässigsten Befunde, wenn anch die Beinreflexe im allgemeinen viel häufiger erhöht anzutreffen sind ajs die Armreflexe und von den Armreflexen die Periostreflexe ein entschiedenes Überwiegẹn zeigen. Häufig besteht auch Adduktorenreflex bei Beklopfen der Tibia oder der Patella, gelegentlich Andeutung von Fussklonus, seltener von Patellarklonus. Nicht ganz so häufig erhöht wie die Sehnen- und Periostreflexe sind die Fusssohlen-, Kremaster- und Bauchdeckenreflexe. Im allgemeinen zeigten unter unserem Material bei allen diesen Reflexerhöhungen die weiblichen Patienten eine stärkere Beteiligung als die Männer. Noch auffallender trat dies zutage bei den Anomalien der: Schleimhantreflexe (Herabsetzung bzw. Fehlen von Gaumen- und Bindehantreflexen), die an sich ja seltener vorkommen als die vorbesprochenen Reflexanomalien. Unter 80 Füllen waren sie nur bei 25 Patienten (=31 Proz.) festzustellen und unter den 40 Männern fanden sie sich nur in 9 Fällen (=22 Proz.), unter den 40 Frauen hingegen in 16 Fällen $(=40$ Proz.). Wenn natürlich auch den Reflexanomalien bei vereinzeltem Auftreten keine wesentliche pathognomonische Bedeutung beizumessen ist, so können sie doch zweifellos bei gehäuftem Vorkommen (z. B. Lebhaftigkeit aller Sehnenreflexe) oder im Verein mit sonstigen Erscheinungen als objektive Krankheitssymptome verwertet werden. Dabei ist Herabsetzung bzw. Fehlen der Schleimhantreflexe meist einigermassen charakteristisch für Krankheitsformen hysterischen Typs.

Auch die sonst bei Schreckneurosen vorkommenden Störungen a uf sensiblem und sensorischem Gebiet sind zum grossen Teil als hysteriseh, d. h. psychisch bedingt anzusehen. Überhaupt spielen hysterische Momente bei den Schreckneurotikern eive grosse Rolle, fanden sich doch unter unseren 100 Fällen typisch hysterische Erscheinungen, wie Sensibilitätsstörungen, hysterische Druckpunkte, Krampfanfä]le, Fehlen der Schleimhautreflexe, hysterische Lähmungen, Gesichtsfeldeinschränkung, psychische Anomalien hysterischen Typs bei nicht weniger als 53 Proz. - ein Resultat, das in eklatanter Weise auf die starke Beteiligung der Psyche bei Schreckneurosen hinweist: wie sie bei sonstigen Unfallneurosen (Kommotionsneurosen) nach unserer Beobachtung auch nicht annähernd anzutreffen ist. Im Gegenteil sind 
z. B. bei unfallverletzten Arbeitern mit Kommotionsneurosen typisch hysterische Symptome relativ selten. Das Hauptkontingent unter den hysterischen Schreckneurotikern wird von den Frauen gestellt; unter den 53 Patienten fanden sich nur 17 Männer (=32 Proz.) und 36 Frauen ( $=68$ Proz.), oder anders gerechnet, 34 Proz. aller (50) Männer und 72 Proz. aller (50) Frauen wiesen hysterische Stjgmata auf. Unter den Sensibilitätsstörungen fanden sich am häufigsten Hyp- und Analgesien, meist partieller, oft halbseitiger Art. Zuweilen bestand Abstumpfung der gesamten Hautsensibilität. Die Prüfung auf Schmerzempfindung wurde sowohl mit der Nadel als mit dem faradischen Pinsel vorgenommen, Auch Hyperäshesien liessen sich durch die elektrokutane Sensibilitätsprüfung einigermassen genau bestimmen. Hysterogene Druckpunkte (Ovarie, Druckempindlichkeit dér Wirbelsäule, des Nackens usw.) fanden sich in zahlreichen Fällen. Dagegen vermochten wir sensorielle Anästhesien, wie Gesichtsfeldeinschränkung, nur ganz vereinzelt und Fälle von hysterischer Blindheit oder Taubheit, wie sie von Schultze, Riebel u. a. mitgeteilt worden sind, unter dem vorliegenden Material überhaupt nicht zu beobachten. Parästhesien wurden bereits an anderer Stelle erwähnt. Ich brauche daher hier nur hervorzuheben, dass die Mannigfaltigkeit der diesbezüglichen Klagen, besonders bei hysterischen Individuen, eine sehr erhebliche ist, wobei jedoch unbewusste Übertreibung und partielle oder totale Simulation als sehr wesentliche Faktoren mit in Betracht zu ziehen sind.

Dass in vielen Fällen die Abgrenzung von Hysterie und Simu lation kaum oder überhaupt nicht möglich ist, haben schon Schuster u. a. hervorgehoben, bildet doch gerade eine gewisse Sucht zur Übertreibung, zur Ausmalung und Vertiefung der Klagen ein pathognomonisches Merkmal hysterischer Individuen. Im Gegensatz zu früheren Untersuchungen an 500 Unfallpatienten und Invalidenrentenanwärtern, bei denen in 40 Proz. der Fälle bewusste Übertreibung festzustellen war, konnte unter den 80 neu beobachteten Fällen von Schreckneurose nur bei 22 Patienten (= 27 Proz.) partielle Simulation nachgewiesen werden. Vielleicht handelt es sich nur um eine in dem geringeren Material begründete Zufälligkeit, vieilleicht spielt aber auch der Umstand eine Rolle, dass die Schreckneurotiker mit ihren in objektiver Beziehung meist sehr ausgeprägten Symptomenkomplexen (kardiovaskulären Erscheinungen, Sekretionsanomalien usw.) bei den Untersuchern geringerem Skeptizismus begegnen, leichter Anerkennung ihrer Klagen finden und sich daher zur Produzierung sonstiger Störungen weniger veranlasst fühlen als Patienten mit geringem objektiven Befund, die ihren an sich bis zu einem gewissen Grade berechtigten Klagen unter 
allen Umständen, sei es auch unter Zuhilfenahme unlanterer Mittel, Glauben verschaffen wollen. Immerhin ist auch bei den Schreckneurotikern die Zahl der partiellen Simulanten ersichtlich eine nicht. unbedeutende. Bezüglich der Untersuchungsmethoden auf Simulation verweise ich auf die Arbeiten von Becker, Engelen, Erben, Horn, Kirsch, Meunier, Rumpf u. a.

Fassen wir nun zuriuckschauend das klinische Gesamtbild der Schreckneurose nochmals ins Auge, so finden wir, dass auf psychischem Gebiet als immer wiederkehrende charakteristische Symptome anzusehen sind Zustände von allgemeiner Exaltation mit ausgesprochenen Angstaffekten, während auf somatischem Gebiete im Hinblick auf die fast konstant auftretenden kardiovaskulären Erscheinunger, die häufigen Magendarmsympto me, die zahlreichen Sekretionsanomalien, Störungen in der Respirations- und Sexualsphäre sowie die trophiscben Störungen, eine emotionell bedingte allgemeine Alteration, eine Disharmonisierung des gesamten regetativen Nervensystems als unmittelbare Folge starker Schreckeinwirkungen anzunehmen ist. Ja, man kann die Schreckneurose, soweit die rein somatische Seite in Frage kommt, geradezu als die Unfallneurose katexochen des vegetativen Nervensystems bezeichnen, finden wir doch bei keiner anderen Unfallneurose, weder nach Kopfverletzungen, noch nach soustigen lokalen. Traumen oder allgemeiner Erschütterung eine derart regelmässige und intensive Mitbeteiligung vegetativer Systeme. Selbstredend kommen auch bei diesen anderen Unfallneurosen kardiovaskuläre Symptome usw. in vielen Fällen vor, können aber keineswegs als ty pische, für die betr. Neurosenart charakteristische Befunde angesprochen werden. Die Schreckneurose bietet zweifellos ein umschriebenes, einigermassen scharf abzugrenzendes Symptomenbild und stellt eine ausgesprochene Psychoneurose dar. Ganz besonders in den Vordergrund zu stellen sind dabei einerseits die Angstaffekte, andererseits die kardiovaskulären Erscheinungen, kehren sie doch eigentlich ausnahmslos in allen Fällen in konstanter Regelmässigkeit zutage als charakteristischer und durch die spezielle Ätiologie bestimmter Ausdruck der psychogen bedingten allgemeinen Erregung auf psychischem und somatischem Gebiete. Auch Bing und Stierlin heben aus ihrem Material ron psychoneurotischen Störungen nach Eisenbahnkatastrophen als bedeutungsrollste Momente hervor "1. die Psychologie der sogen. Angstneurose, 2. den vasoneurotischen Symptomenkomplex und 3. den Einfluss der definitiven Entschädigung auf die traumatische Neurose". Selbredend können im Einzelfall die Krankheitsbilder trotz ihrer generellen 
Übereinstimmung manche Unterschiede zeigen. Vor allem sind zu unterscheiden die, ,ansgebildeten" und die ,abortiven" Formen von Schreckneurose. Als Beispiele für die ausgebildeten Formen, bei denen das Kranknkeitsbild nach mehrfacher Richtung hin voll entwickelt ist, sei auf die schon früher kurz erwähnten Fälle 19 und 50 verwiesen. Weiterhin sei Fall 75 in extenso wiedergegeben: 28 jährige Telegraphengehilfin, blutarm, z. Z. des Unfalles unwohl. Am 14. V. 1908 heftiger Schreck durch starke Weckgeräusche (mebrmaliges schnelles Drehen der Kurbel): Aufgeregtheit, Zittern, Stechen in den Schläfen, „Gefühl, als ob Sand vor den Augen herunter rieselt", linke Wange soll angeschwollen sein, später die gańze linke Kopfseite. Zu Hause in einen tagelang anhaltenden, schlafähnlichen Zustand verfallen, Schwächegefühl, Herzklopfen. Weiterhin Zunahme der Beschwerden: ziehende Schmerzen im ganzen Körper, besonders in der Herzgegend, Druck in der Magengegend, wechselnder Appetit, Stuhlverstopfung, Kugelgefühl im Hals, Blutandrang zum Kopf bei kühlen Extremitäten, leicht eintretendes Schwitzen, Zittern der Beine bei jeder Anstrengung oder Aufregung, Hinfälligkeit, Haarausfall, Karies der Zähne, Fleckigwerden der Fingernägel, unregelmässige Periode, Gefühl eines nassen, breiten Bandes über dem Rücken, Angstgefühl, Beklemmung, innere Unruhe, schlechter Schlaf mit schreckhaften Träumen, zeitweises Anschwellen der linken Gesichtshälfte. Objektiver Befund (am 10. IX. 1909 und am 4. IX.13 Status idem): Puls 25-26, nach $10 \mathrm{mal}$ Stuhlsteigen $33,30,27,26,28,28$ in je $1 / 4$ Minute, systolischer Blutdruck $135 \mathrm{Hg}$, Dermographie, zeitweise fleckige Gesichtsröte und Anschwellen der linken Wange, Blutandrang zum Kopf, starkes Schwitzen, kühle Extremitäten, Spur Händezittern, Zuckungen im Facialisgebiet, Fehlen der Scbleimhautreflexe, linksseitige Hemianalgesie, Druckpunkte im Nacken, hinter den Ohren und an den Trigeminusaustrittsstellen linkerseits. Psychisch: rascher Stimmungswechsel, Reizbarkeit, Launenhaftigkeit. Hysterische Anfälle mit starker Aufregung, Schwächegefübl und Ohnmachtsanwandlung.

Als ,abortive" Formen sind diejenigen Fälle zu bezeichnen, bei denen nur einzelne charakteristische Symptome psychischer und somatischer Art vorhanden sind. Meist stehen im Vordergrunde der abortiven Formen psychische Frregungs- und Angstzustände einerseits und kardiovaskuläre Störungen andererseits, während von den übrigen typischen Symptomen der Schreckneurose bald diese, bald jene in Erscheinung treten. Derartige rudimentäre Formen lassen also nichtsdestoweniger die Grundzüge, das am meisten Typische und Charakteristische der Schreckneurosen durchweg klar erkennen, selbst wenn sie zunächst anscheinend eine vollkommen einseitige Ausbildung 
zeigen. So treten mitunter die Herzstörungen derart hervor, dass die übrigen Krankheitserscheinungen als nebensächlich betrachtet oder völlig übersehen werden und das Krankheitsbild einfach als "Herzneurose" nach Schreck bezeichnet wird. Aber auch Magendarmerscheinungen, asthmatische Zufälle, Störungen im Urogenitalsystem, Motilitätsstörungen usw. können vor den übrigen Symptomen derart ausgeprägten Charakter zeigen, dass sie gelegentlich zu besonderer Krankheitsbenennung ("Magendarmneurose ", „Motilitätsneurose" usw.) Anlass geben, obwohl es sich im Prinzip nur um Variationen derselben Einwirkung auf das vegetative Nervensystem handelt.

Auf welchen Bahnen und in welcher Art die psychischen Emotionen auf die vegetativen Zentren einwirken, ist noch nicht vollkommen geklärt. Nur die Tatsache an und für sich, dass die Innervationen des regetativen Systems in höchstem Grade unter dem Einflusse rein psychischer Vorgänge, Gemütserschütterungen, Stimmungen und Affekte stehen, ist nach allen Beobachtungen als gesichert anzusehen. Dabei muss die Annahme, dass im Grosshirn selbständige Zentren für die Tätigkeit der Gefässnerven, der Schweissdrüsen, des Magendarmtraktus, der Sexualorgane und für die übrigen vegetativen Funktionen bestehen, wie auch L. R. Müller in seinem vortrefflichen Referate über den "Stand der Lehre rom Sympathicus" (Versammlung Deutscher Nervenärzte, Hamburg 1912) ausführte, als unbewiesen noch durchaus in dubio bleiben. Im übrigen verweise ich auf die experimentellen Untersuchungen von Berger, Weber u. a., wonach die nächste Wirkung des Schrecks anf somatischem Gebiet in einer Reizung der vasomotorischen Zentren der Medulla oblongata mit unmittelbarer starker Kontraktion und, folgender Erschlaffung der Hirngefässe besteht - Erscheinungen, die wegen der mit ihr verbundenen Zirkulationsanomalien (Anämie, Hyperämie) zu Ernährungsstörungen der Ganglienzellen führen (Kühne) und die ganze Hirnrindenfunktion herabsetzen bezw. aufheben können. „Es ist natürlich naheliegend, eine Reihe psychischer Symptome des Schrecks: das anfängliche Abreissen der Gedankenkette und die später auftretenden, sich überstürzenden Vorstellungen auf diese Zirkulationsstörungen zurückzuführen " (Berge r), überhaupt alle Beeinträchtigungen des Bewusstseins, der Apperzeption und Assoziation, der Psychomotilität und Sinnesempfindung. Im übrigen kann die durch äussere Sinneseindrücke oder affektbetonte Vorstellungen erzeugte und von der Rinde ausgehende Reizung der vegetativen Zentren des Hirnstamms eine derart intensive sein, dass in ihrem Gefolge selbst Todesfälle nicht ausgeschlossen sind. Besonders Individuen mit schon bestehenden Kreislaufstörungen, vor allem Arteriosklerose und Herzleiden, 
können bei Alteration der Zentren der Atmung und Herztätigkeit infolge Schreckeinwirkung plötzlich zum Exitus letalis kommen. Dass aber auch bei vorher völlig Gesunden durch starke Gemütserschütterungen ein plötzlicher Tod erfolgen kann, beweist der ron Jasinsky mitgeteilte Fall eines 13 jährigen Mädchens, bei dem die Obduktion als einzigen pathologischen Befund eine aktive Hyperämie des Gehirns und seiner Häute ergab (s. Thiem). In der Begutachtungspraxis spielen derartige Fälle keine besondere Rolle. Ich erinnere jedoch an den Beckerschen Fall, in dem die hochgradige seelische Erregung und Furcht vor einer infolge eines Unfalls notwendig gewordenen Operation den Tod herbeiführie und in dem das Reichsversicherungsamt die Entschädigungspflicht bestätigte.

Gleichzeitig mit dem Grosshirn und den Zentren des Hirnstamms, speziell der Medulla oblongata wird, von diesen ans fortgeleitet, das ganze periphere (= viszerale) Nervensystem in Mitleidenschaft gezogen, vor allem der mit dem Thorakal- und dem oberen Lendenmark in Verbindung stehende Grenzstrang, der Sympathicus j. e. S. (Langley), also das durch Adrenalin erregbare (Hans Horst Meyer) Innervationsgebiet für die glatte Muskulatur (Blutgefässe, Wandungen der Hohlorgane), die Drüsen und das Herz (Edinger). Aber auch das durch die Gifte der Cholingruppe (Pilocarpin, Physostigmin, Muscarin usw.) erregbare, durch Atropin lähmbare und mit seinen Fasern aus dem Mittelhirn und der Medulla oblongata entspringende kranial-autonome System, also das zum Sympathicus antagonistisch wirkende Innervationszentrum für die viszeralen Vagusfasern usw. wird durch weiter geleitete affektive Reize alteriert, ebenso das aus dem Sakralmark hervorgehende sakral-antonome System für die Beckeneingeweide. Als Effekt der Reizeinwirkung treten Tonusschwankungen ein (L. R. Müller) und damit eine völlige oder teilweise Disharmonisierung des regetativen Reflexmechanismus - Störungen der antagonistischen Innervation von kranial- und sakral-autonomem System (= "erweitertem Vagussystem“, Eppinger und Hess) einerseits und sympathischem Grenzstrang andererseits. Im allgemeinen scheinen bei den Schreckneurosen „sympathikotrope "Symptome (Beschleunigung und Labilität des Pulses, Blutdruckerhöhung, Gefässkrämpfe, Schwitzen, Tremor usw.) zu überwiegen, ohne dass man aber einen ,sympathiliotropen" und "vagotropen" Typus stets streng unterseheiden könnte, da vielfach Mischformen zwischen "sympathikasthenischen" und „vagasthenischen" Erscheinungen (v. Bergmann) vorkommen. Zu letzteren wären beispielsweise zu rechnen zahlreiche Magendarmerscheinungen, wie "Magenkrämpfe“, vermehrte Magenmotilität und -sekretion, Ulcus ventriculi und duodeni, spastisehe Obstipation, "Emotionsdiarrhöen“, 
vermehrte Schleimsekretion des Darms u. a. (vergl. auch die schon früher erwähnten Arbeiten von v. Bergmann und Katsch), während. beispielsweise atonische Zustände durch hemmende Einflüsse der sympathischen Nervi splanchnici bedingt sein können. Für den Enddarm tritt an Stelle des Vagus der Nerv. pelvicus, der aus dem sakralautonomen System entspringt. Auch die Genitalien erhalten antagonistische Innervationsimpulse und zwar durch die Rami communicantes lumbales und die Plexus hypogastrici vasokonstriktorische und vom unteren Sakralmark durch die Nerv. pelvici (erigentes) vasodilatatorische Fasern. Störungen in der Sexualsphäre sind daher besonders bei Reizung des Sympathicus sehr naheliegend. Ebenso sind die Erscheinungen von seiten des Respirationssystems, die asthmatischen Zufälle, auf psychogen bedingte Innervationsstörungen im viszeralen Nervensystem (Sympathicus einerseits und Vagus andererseits) zurückzuführen. Besonders hervorheben möchte ich, dass auch motorische Ausfallserscheinungen durch Alteration des sensiblen vasomotorischen Reflexapparates hervorgerufen werden können (Cassirer). Auch auf die engen Beziehungen des vegetativen Nervensystems zu den Drüsen mit innerer Sekretion bezw. zu M. Basedow, Tetanie, Myxödem, Paralysis agitans, Sklerodermie, Diabetes insipidus usw. sei nochmals besonders hingewiesen, desgleichen auf die Anschauung H. H. Meyers, dass die Glykosurie nach Nervenshock als Adrenalindiabetes (sympathisch bedingte Zuckerausschwemmung aus der Leber) zu betrachten sei.

Aber auch die Medulla spinalis kann ebenso wie das Gehirn, um auf letzteres nochmals zurückzukommen, durch Schreckeinwirkungen mittelbar beeinflusst werden und zwar, wie einzelne Autoren mutmassen, in mitunter recht intensiver Weise. So ist Schultze der Ansicht, dass infolge Gefässverengerung nach starkem Schreck unter Umständen grobe anatomische Veränderungen eintreten könnten; ,denn einmal könnten unter dem Einflusse des Schreckes bei einzelnen Menschen die Kontraktionen der Gefässwände länger andauern als bei anderen, so dass ein geradezu tonischer Gefässkrampf mit verhängnisvollen Folgen für die Ernährung der zugehörigen Nervensubstanz einträte, und dann könnten bei manchen dauernd oder zeitweilig gewisse Abschnitte des zentralen Nervensystems gegenüber kurzdauernden Gefässzusammenziehungen trophisch abnorm empfindlich sein." Weiterhin nimmt Kühne an, dass durch krampfartigen Verschluss oder Verengerung der Gefässe im Rückenmark es leicht zu Erweichungsherden, namentlich in der mit besonders feinkalibrigen Gefässen versorgten weissen Substanz kommen könne, und erwähnt dabei die von E. v. Leyden berichteten Fälle aus der Zeit der Belagerung von 
Strassburg, die nach Jahren tödlich endeten und bei der Obduktion schwere myelitische Veränderungen im Rückenmark aufwiesen. Sicherlich sind aber derartige Fälle, falls sie überhaupt vorkommen sollten, ganz ausserordentlich selten; auch müssen selbstredend andere ätiologische Momente (Lues usw.) stets in Rücksicht gezogen werden. Nur in einem einzigen mir nach Lage der Akten bekannten Falle eines 54jährigen Arbeiters, der im Jahre 1907 nach „Verheben“ eine rechtsseitige subkntane Banchdeckenzerreissung erlitt und weiterhin durch die Aufregungen des Prozesses an allgemeinnervösen Erregungszuständen usw. erkrankte, zeigten sich 6-7 Jahre nach dem Unfall neben arteriosklerotischen Veränderungen paraplegische Erscheinungen der Beine, die von mehreren Gutachtern auf eine mit dem Unfall indirekt in Zusammenbang stehende Myelitis chronica bezogen wurden, ob mit Recht, möchte ich allerdings sehr bezweifeln. Eine Sektion wurde leider nicht vorgenommen und die klinischen Symptome waren keineswegs eindeutig. Im allgemeinen dürfen jedenfalls derart weitgehende anatomische Veränderungen des Nervensystems nach Schreckeinwirkung nicht angenommen werden, wenn auch im übrigen die Möglichkeit einer nutritiven, molekularen.Schädigung der Ganglienzellen durch abnorme Reize und stärkere Gefässanomalien durchaus zuzugeben ist. Jedenfalls kann die Ansicht von Oppenheim und Goldscheider, durch beftige Nervenreize könnten dauernde, wenn auch für unsere Hilfsmittel bisher noch nicht nachweisbare Veränderungen der Neurone hervorgerufen werden, eine gewisse Wahrscheinlichkeit für sich in Anspruch nehmen. Ja man ist mit Gold scheider sicher berechtigt, die Frage aufzuwerfen, „ob nicht bei manchen hysterischen Störungen ohne traumatische Antezedentien gleichfolls dauernde funktionelle Zustandsänderungen der Nervenzellen, auf feinen molekularen Alterationen beruhend, anzunehmen sind. Aber dieselben dürften dann nicht durch Hypnose und Autosuggestion, sondern durch das Zusammentreffen von Affektbewegungen und äusseren Eindrüeken und die unmittelbare Wirkung solcher auf die Nervenzellen zu erklären sein".

Der Begriff der Hysterie ist ja trotz der Definitionen von Babinski, Dubois, Strümpell u. a. immer noch nicht als eindeutig umgrenzt anzusehen, wenn auch die Strümpellsche Definition (Störang der Wechselbeziehungen zwischen geistigen und körperlichen Funktionen) mit Recht die weiteste Anerkennung besitzt, ebenso wie die Duboisschen Anschauungen, dass die Hysterie eng gebunden sei an die Mentalität des Individuums und an die Eigentümlichleit seines Charakters, soweit geistige Minderwertigkeit, Psychasthenie, Affektivität, Suggestibilität, Egozentrismus und vor allem die seelische ImDeutsche Zeitschrift f. Nervenheilkunde. Bd.53. 
pressionabilität in Frage kommen, sehr viel Richtiges enthalten. Sicher spielen auch bei einem Teil der Schreckneurotiker typisch hysterische Erscheinungen auf psychischem und somatischem Gebiete eine grosse Rolle, ohne dass man aber berechtigt wäre, das Wesen der Schreckneurose mit Hysterie gleichzusetzen. Die "hysterischen Symptome" bei Schreckneurose sind lediglich ein bei spezifisch disponierten Individuen anzutreffender Nebenbefund and gehören nicht zum eigentlichsten Wesen des Krankheitsbildes. Auch Bonhöffer hat bereits darauf hingewiesen, dass es eine Reihe von Erkrankungen ausserhalb der Hysterie gibt, die durch emotionelle Vorstellungen verursacht werden; z. B. verursache die plötzlich auftretende Vorstellung schwerster Lebensbedrohnng vasomotorische Störungen, die durchaus organischen Gehirnalterationen gleichzusetzen seien. Die sich anschliessende Psychoneurose kann zwar, wie erwähnt, nebenbei hysterische Züge aufweisen, stellt aber ihrem eigentlichen Wesen nach eine psychogen bedingte Alteration des vegetativen Nervensystems, einen Erregungszustand auf psychischem und somatischem Gebiete sui generis dar. Dabei können einzelne Symptome hypochondrischen, neurasthenischen oder - bei besonders Disponierten - hysterischen Charakter tragen, ohne dass aber das Gesamtbild der Schreckneurose in seinen Grundzügen eine Änderung erführe oder zu andersartiger Benennung (,traumatische Neurasthenie" usw.) berechtigte. Es handelt sich eben um ein eigenartiges Gemisch verschiedenwertiger Symptome, unter denen allerdings die neurasthenische Komponente besonders stark hervortritt. $\mathrm{Ob}$ und inwieweit die allgemein als "bysterisch" bezeichneten Erscheinungen abhängig sind von Störungen im regetativen System, bleibe hier unerörtert; dass aber kausale Beziehungen bestehen, erscheint mir zweifelsfrei, wiewohl die Hysterie zunächst als psychische Anomalie zu betrachten ist, die zudem wohl ausnahmslos endogenen Ursprung besitzt. Als angeborene, wenn anch oft latent gebliebene psychische Anomalie ist sie für die Klinik der Schreckneurose insofern von erheblicher Bedeutung, als sie für die posttraumatische Entwicklung psychisch-nervöser Störungen einen ausserordentlich fruchtbaren Boden bildet. Vor allem erscheint die psychische Komponente des Krankheitsbildes der Schreckneurose bei hysterisch Disponierten wesentlich stärker ausgeprägt, wozu dann noch die durch das psychische Trauma ausgelösten hysterischen Stigmata hinzutreten, so dass wir das spezielle Krankheitsbild des „hy sterischen Schreckneurotikers" erhalten, der neben einer Disharmonisierung des vegetativen Nervensystems (eigentliche Schreckwirkung) hysterisehe Symptome auf endogener Veranlagung zeigt. 
Wir kommen damit zur Frage der Disposition bei Schreckneurosen. Aus den Arbeiten von Berger, Weber usw. geht hervor, dass die psychophysische Reaktion auf Schreckeinwirkungen hin als rein automatisch verlaufender physiologischer Vorgang aufzufassen ist, der zunächst keine besondere Disposition vorauszusetzen braucht. Auch Bonhöffer ist der Ansicht, dass die "Alteration des Vasomotoriums" den einzigen bisher beobachteten psychogenen Symptomenkomplex darstellt, der keiner psychopathischen Veranlagung zu bedürfen scheint. Dennoch kann selbstredend - und die klinischen Erfahrungen bestätigen dies vollkommen - eine gegebenenfalls vorhandene, mehr oder weniger grosse individuelle Empfänglichkeit für die Entstehung und Weiterentwicklung des Krankheitsbildes von ąusschlaggebender Bedeutung sein und unter Umständen auch in qualitativer Hinsicht dem ganzen Symptomenkomplex ein spezifisches Gepräge verleihen - eine Anschauung, deren nähere Begrïndung mir auf manche Zusammenhänge posttraumatischer Krankheitsbilder ein interessantes Streiflicht zu werfen scheint. Fassen wir zunächst den Fall ins Auge, dass jedwede disponierenden Momente vollkommen fehlen, dass also keine erbliche Belastung besonders nach psychoneuropathischer Richtung hin besteht, die Gesamtkörper- und Geisteskonstitution eine gesunde ist, komplizierende Erkrankungen (vor allem Herz- und Gefässleiden, Diabetes, Lues) fehlen und keine nervenzerrüttenden Schädlichkeiten (besonders - Alkohol und Nikotin) einwirken, so wird bei einem derartigen nicht disponierten Individuum die Schreckeinwirkung zwar auch in gewissem Grade ihren automatischen Ablauf nehmen, vielleicht auch zu subjektiven und objektiven krankhaften Ausschlägen führen; doch bleibt es im allgemeinen bei episodischen, kurz vorübergehenden, sozusagen physiologischen Schreckreaktionen. Schon früher habe ich an anderer Stelle darauf hingewiesen, dass vollkommen gesunde Individuen gegen nervöse Unfallfolgen einigermassen gefeit sind und etwa doch auftretende Störungen in kurzer Frist meist unschwer überwinden; Voraussetzung ist allerdings, dass keine sekundären schädlichen Momente, vor allem Befürchtungs- und Begehrungsvorstellungen die Heilungsaussichten trüben - ein Punkt, auf den ich weiterhin noch zurückzukommen habe. Interessant nach dieser Richtung hin sind auch die Mitteilungen Placzeks über eine Reibe von Patienten, die ausser körperlichen Verletzungen z. T. sehr starke seelische Erschütterungen erfuhren und dennoch ihre Störungen, da keine Rentenbestrebungen mitspielten, in relativ kurzer Frist überwanden, obwohl es sich grossenteils um ältere Persönlichkeiten handelte. Im allgemeinen sind aber auf psychischem Gebiet rollwertige Menschen, die jedem Ansturm see- 
lischer Erschütterung trotzten, nicht allzuhäufig. Die Zahl der irgendwie zu nervösen Störungen Disponierten und der an nicht-traumatischen Neurosen tatsächlich Kranken ist zweifellos eine ausserordentlich grosse. Jedenfalls spielen unter den zur Beobachtung kommenden Schreckneurosen nachweisbare disponierende Momente eine ganz erhebliche Rolle, ungerechnet die zahlreichen Fälle, deren psychound neuropathische Veranlagung aus irgendwelchen Gründen verborgen bleibt. Dazu kommen diejenigen Individuen, bei denen lebenswichtige Organe (z. B. das Herz) sich schon in krankem, labilem Zustand befinden und deshalb ebenfalls auf psychische Einwirkungen hin leichter und intensiver reagieren (Disposition im weiteren Sinne). Eine ganz hervorragende Rolle, mehr noch als bei Erwachsen, spielt - um dies nebenbei zu erwähnen - die Disposition bei jugendlichen Traumatikern (Hübner); hier stellt die Unfallneurose fast stets "die pathologische Reaktion eines pathologischen Individuums auf den Unfall" (H. Sachs) dar. Unter den 160 früher von mir veröffentlichten Fällen von Unfallneurosen verschiedener Ätiologie war bei 56,5 Proz. eine derartige Disposition zu nervösen Störungen i. w. S. nachzuweisen, unter den darunter befindlichen 16 „reinen" Schreckneurosen bei 75 Proz. der Fälle. Ferner war auffallend, dass ausnahmslos in sämtlich en Fällen, bei denen h ysterisc he Symptome nach Schreckeinwirkung auftraten, bereits vor dem Unfalle eine gewisse Disposition zu nervöser Erkrankung bestand, während bei denjenigen Schreckneurosen, die ohne typisch hysterische Erscheinungen verliefen, nur in 20 Proz. der Fälle eine Disposition sich nachweisen liess.

Unter den 80 neu beobachteten Fällen waren nervös disponierende Momente mit Sicherheit nachzuweisen bei nicht weniger als 64 (=80 Proz). and zwar bei 30 Männern $(=75$ Proz.) und 34 Franen (=85 Proz.). Meine früheren Angaben finden sich also durchaus bestätigt. Es ist hiernach, obwohl an sich die "Schreckreaktion" der Annahme einer besonderen Disposition nicht bedarf, nicht daran zu zweifeln, dass die allermeisten Individuen, die an Schreckneurose erkranken, bereits vor dem Unfalle eine mehr oder weniger hochgradige Veranlagung zu nervösen Störungen besitzen, ja dass sie sich nicht nur aus Veranlagten, sondern zum grossen Teil aus schon vorher tatsächlich kranken, nervösen, blutarmen und heruntergekommenen Individuen rekrutieren. Besonders unter den Frauen finden wir ausserordentlich viele bereits früher schwächliche, anämische und nervöse Patientinnen. Eine familiäre und hereditäre Disposition, deren genaue Feststellung ja immer auf grosse Schwierigkeiten stösst, war nur in einem Teil der Fälle nachzuweisen. Übrigens braucht selbst bei bestehender erblicher Belastung und 
geistiger Minderwertigkeit, worauf auch Gumpertz schon hingewiesen hat, nicht stets und nuter allen Umständen eine allgemeine Neurose nach Unfalleinwirkungen zu folgen, wenn auch die hereditär Belasteten sicher einen grösseren Prozentsatz der Unfallneurotiker, besonders der hysterischen Formen, bilden. Analoges gilt für die uibrigen Arten der Disposition. Zu allermeist wurde von unseren Patienten bei eingehender Examination angegeben, dass schon frïher nervöse Störungen, allerdings nur in geringerem Grade oder vorübergehend bestanden hätten. So hörten wir besonders bei Angehörigen des Fabrikanten- und Kaufmannsstandes häufig von nervöser Abspannung und Überreiztheit, die bereits vor dem Unfalle eine alljährliche Erholungsreise erforderte oder bei Beamten von gelegentlichen nervösen Beschwerden infolge dienstlicher Aufregung und Überanstrengung. Auch frühere Unfälle, die vorübergehend zu nervösen Störungen geführt hatten, z. B. bei mehreren Eisenbahnbeamten, mussten als disponierendes Moment betrachtet werden (Wimmers Rezidive), ebenso vorgeschrittene Arteriosklerose, langwierige Unterleibsleiden, Alkoholismus, Nikotinmissbrauch, Diabetes mellitus, Herzleiden, Lues, vor allem dann, wenn schon vor dem Unfalle, wie es übrigens stets der Fall war, sich die einen oder anderen Störungen nervöser Natur bemerkbar machten. Eine zahlenmässige Angabe über das Vorkommen der verschiedenen disponierenden Momente, wie sie nachstehende Übersicht gewährt, hat natürlich mit Rücksicht auf etwaige Zufälligkeiten an sich nur untergeordnete Bedeutung, lässt aber doch die praktisch wichtigsten Faktoren hervortreten:

\begin{tabular}{|c|c|c|c|}
\hline & Männer & Frauen & Zus. \\
\hline $\begin{array}{l}\text { Hereditäre Belastung, Nerv., Neur- } \\
\text { asthenie, Hysterie; (Epilepsie, } \\
\text { Ischias, spinale Muskelatrophie } \\
\text { je } 1 \text { Fall) . . . . . . . . }\end{array}$ & 14 & 19 & 33 \\
\hline $\begin{array}{l}\text { Frühere Unfälle mit nervösen Stö- } \\
\text { rungen } . \cdot . \cdot . \\
\end{array}$ & 7 & 1 & 8 \\
\hline \multicolumn{4}{|l|}{ Blutarmut und allgemeine Schwäch- } \\
\hline lichkeit . . . . . . . . . . & 2 & 7 & 9 \\
\hline Herz- und Gefüssleiden . . . . & 3 & 3 & 6 \\
\hline Alkohol- und Nikotinmissbrauch & 1 & - & 1 \\
\hline Diabetes mellitus . . . . . . & 3 & - & 3 \\
\hline \multirow{2}{*}{ Unterleibsleiden $\cdot \cdot \cdot \cdot \cdot \cdot \cdot$} & - & 4 & 4 \\
\hline & 30 & 34 & 64 \\
\hline
\end{tabular}

In 24 Fällen kamen mehrere disponierende Momente in Betracht; so lagen z. B. noch bei weiteren 6 Frauen ehronische, vom Unfall 
unabhängige Unterleibsleiden (besonders Endometritis und Dysmenorrhoe) vor, doch habe ich zum besseren Überblick nur die wesentlichsten Formen der Disposition herausgegriffen. Gelegentlich bestand anch neben neuropathischer Disposition (erblicher Belastung) eine alte Lues (Fall 43) oder neben spinaler Muskelatrophie (Fall 7) eine ausgesprochene Arteriosklerose. In 2 Fällen (70 und 75) war die durch Blutarmut und Nervosität gegebene Disposition vorïbergehend dadurch verstärkt, dass der Unfall in die Menstruationsperiode fiel, Patientin sich also in einem Zustande besonders starker Empfänglichkeit gegenüber psychischen Eindrücken befand. In einem anderen Falle (58) fand der Unfall am Tage vor der festgesetzten Hochzeit statt; auch hier war sicherlich eine erhöhte temporäre psychische Erregbarkeit als bestehend anzunehmen. Überhaupt spielen Umstände des täglichen Lebens, der Einfluss ron Verwandten, Bekannten und sonstigen Beratern, die sozialen und wirtschaftlichen Verbältbnisse, Lebensgew ohnheiten, Kriminalität usw. bei der Gestaltung des Krankheitsbildes eine nicht zu unterschätzende Rolle, wie es in gleicher Weise natürlich für sämtliche Unfallneurosen gilt.

Nach alledem kann man der Ansicht von Cramer, Kühne, Reichardt u. a., dass nervöse Störungen nach Tranmen ganz allgemein am weitaus bäufigsten bei Individuen mit einer gewissen nervösen Disposition auftreten, nur beistimmen, mag diese Disposition nun endogener oder erworbener Natur, mag sie begründet sein in einer angeborenen abnormen geistigen Konstitution und Minderwertigkeit, oder sei sie begründet in Ernährungsstörungen, in akquirierten toxischen, infektiösen und vasomotorischen Schädlichkeiten, wie sie besonders durch Alkohol- und Nikotinmissbrauch, Lnes, Arteriosklerose, Diabetes, Inanition, körperliche und geistige Überanstrengungen, Sorgen, Aufregungen usw. verursacht werden. Fehlen jeglicher Disposition ist, zumal wenn man das Unerkanntbleiben einzelner Fälle in Rücksicht zieht, jedenfalls bei Schreckneurosen sicher eine zum mindesten ungewöhnliche Erseheinung.

Sehr wichtig ist nun bei bestehender Disposition ihr spezifischer Einfluss auf das sich entwickelnde Krankheitsbild, ein Gesichtspunkt, der zweifellos eine ganz besondere Hervorhebung verdient. Es genügt, um den auftretenden Schreckeffekt als klinisches Krankheitsbild würdigen zu können, nämlich keineswegs der Umstand, dass überhaupt eine Disposition zu nervösen Störungen vorhanden ist, sondern auch die Art und Intensität der vorliegenden Disposition ist von fundamentaler Bedeutung; denn je nach dem, in welchem spezifisch disponierten Organismus sich der Reflexautomatismus der Schreckeinwirkung ab- 
spielt, wird auch das resultierende Krankheitsbild der Schreckneurose eine spezifische Färbung erhalten, oder es werden sich - in allerdings selteneren Fällen - Krankheitsformen organischer Natur ergeben, die nur noch entferntere, mittelbare Beziehungen zum klinischen Bild der eigentlichen Schreckneurose haben. So ist es keineswegs gleichgültig, ob das psychische Trauma einen Psychonenropathen i. e. S. betrifft oder ein Individuum mit Disposition zu Epilepsie, Chorea, M. Basedowii oder anderen Neurosen, zu Diabetes mellitus, Diabetes insipidus und Arteriosklerose oder endlich einen Herzkranken oder Individuen mit latenter organischer Erkrankung des Zentralnervensystems. Während nämlich der Psychoneuropath i. e. S. mit der typischen Form der Schreckneurose reagieren wird, wird bei Veranlagung zu Diabetes mellitus aussex den sonstigen Erscheinungen der Schreckneurose eine Glykosurie oder Steigerung bestehender Zuckerausscheidung zu erwarten sein, so dass das ganze Krankheitsbild eine spezifische Note erhält und die Glykosurie im Hinblick auf ihre praktische Bedeutung sehr leicht zum Mittelpunkt des ganzen Symptomenkomplexes wird. Ebenso werden der Herzkranke und Arteriosklerotiker in besonders intensiver Weise zu Herz- und Gefässstörungen neigen, und bei Veranlagung zu Ulcus ventriculi wird möglicherweise gerade die Geschwürsbildung durch psychogen bedingte Spasmen ausgelöst und befördert. Jedes Individuum wird eben mit der durch die spezifische Disposition gegebenen vulnerabelsten Seite seines Organismus am leichtesten und intensirsten reagieren. Auch die $\mathrm{Be}$ ziehungen der Schreckeinwirkung zu organischen Nervenleịden, wie Syringomyelie, multipler Sklerose, progressiver Paralyse, fallen unter ähnliche Gesichtspunkte, überhaupt die Beziehungen zu allen Erkrankungen, die durch psychische Einwirkungen und durch Störungen im vegetativen Nervensystem, vor allem durch Gefässstörungen in Mitleidenschaft gezogen werden können. Für alle diese Erkrankungen ist unfallrechtlich die Möglichkeit einer Anslösung oder Verschlimmerung durch psychische Traumen dann anzuerkennen, wenn der Ausbruch der Erkrankung sich in erkennbarer Weise unmittelbar an das Schreckereignis anschliesst. So ist es beispielsweise bei noch latenter progressiver Paralyse durchaus möglich, dass durch stärkere Gefässstörungen im Gehirn (vergl. auch K. Mendel), wie sie ja bei Schreckwirkungen ausnahmslos sich einstellen, die bereits durch die luetische Intoxikation geschädigten Ganglienzellen in ihrer Ernährung und damit in ihrer Leistungstähigkeit derart geschwächt werden, dass der spezifische Prozess zu relativ rascher klinischer Manifestation und Progression gelangt. Allerdings ist gerade bei der progressiven Paralyse, um Fehlschlüsse zu vermeiden, den zeitlichen 
Zusammenhängen grösste Beachtung zuzuwenden. Das Vorhandensein eines vollständigen Krankbeitsbildes wenige Tage nach einem Unfalle spricht ebenso sehr gegen einen ursächlichen Zusammenhang wie ein längeres symptomenfreies Intervall (Hübner, Moser, Kölpin, Schreiber, Weber). Auch muss der psychische Shock ein erheblicher gewesen sein (K. Mendel), wie beispielsweise in den von Kriege, Sprengeler, Witkowski mitgeteilten Füllen (zitiert bei K. Mendel). Kühne sah bei einem 33jährigen Reisenden infolge Schrecks durch Zugzusammenstoss schwere geistige Veränderungen auftreten; etwa $1 / 4 \mathrm{Jahr}$ später war eine ausgesprochene Paralyse festzustellen. In einem anderen Falle zeigten sich nach 1/2 Jahr Symptome von Paralyse; beim Unfalle selbst entstanden zunächst Erregung, Blässe und Zittern am ganzen Körper - also typische Schreckerscheinungen. Darauf aber möchte ich besonders hinweisen, dass neben dem organischen Leiden auch die für Schreckwirkung charakteristischen Symptome funktioneller Natur weiter bestehen können, so dass eine Mischform von progressiver Paralyse und Schreckneurose i. e. S. resultiert, wie es beispielsweise in Fall 34 unseres Materials sich zeigte.

Fall 34. 49jähriger Fabrikant. Anamnese ohne Besonderheiten; Lues negiert. 26.IV.1914 Strassenbahnzusammenstoss, heftige Schreckwirkung: Wie ohnmächtig, "Gitter" vor dem Auge; dann Schmerzen, Stiche und Druck im Kopf, Blatandrang zum Kopf, zeitweise Schwindelanfälle, Herzklopfen, Stiche und Ziehen in der Herzgegend, starkes Schwitzen, Schwäche in den Beinen, Angstgefühl und Schreckhaftigkeit, schlechter Schlaf, Geräuschempfindlichkeit, innere Unruhe, Energielosigkeit, Hang zur Einsamkeit, ïberhaupt auffallende psychische Veränderung, Reizbarkeit, Erregbarkeit, Missmut, Hypochondrie. Befund am 16. VI. 1914: Subjektive Klagen wie zuvor; objektiv mässige Arteriosklerose; Miosis, reflektorische Pupillenstarre, Gesichtsfeldveränderungen, Steigerung der Patellarreflexe, Wassermann im Blut positiv; Pulsbeschleunigung, systolischer Blutdruck $1.60 \mathrm{~mm} \mathrm{Hg}$, starkes Schwitzen, Fehlen der Schleimbautreflexe; psychische Anomalien, vor allem starke Reizbarkeit, Missmut und Hypochondrie.

Wahrscheinlichkeitsdiagnose: Beginnende progressive Paralyse und Schreckneurose mit hysterischen Symptomen. Die Möglichkeit der Auslösung der Paralyse durch den Unfall war zuzugeben; es war anzunehmen, dass die Schreckneurose sich bei einem zu progressiver Paralyse disponierten Individuum entwickelte und dass durch das Auftreten der Schreckneurose gleichzeitig die Bedingungen (Gefässstörungen) zur Auslösung der paralytischen Erkrankung gegeben wurden. Diese konditionale Betrachtungsweise im Sinne Verworns 
vermag ja überhaupt bei allen traumatisch bedingten Erkrankungen sehr zur Klärung an sich schwieriger Zusammenhänge beizutragen. Auch bei den psychoneuropathisch Disponierten i. e. S. kommt es im Einzelfalle immer wieder auf die gerade bei dem betreffenden Individuum vorliegenden Bedingungen an, die in weitesten Grenzen schwanken und damit eine grosse Zahl zwar prinzipiell gleicher, aber doch individuell verschieden gefärbter Krankheitsbilder bedingen können. Gerade die Schreckwirkungen sind ein Beispiel typischer Individualreaktion. So können in seltenen Fällen bei vorliegender spezifischer Disposition auch echte Psychosen zur Auslösung kommen - Dommrich sah nach Schreck Entwicklung einer Dementia praecox und nach Kräpelin schliessen sich auch die einzelnen manischdepressiven Anfälle nicht ganz selten an heftige Gemütsbewegungen an -, ohne dass damit natürlich der Reflexantomatismus der Schreckwirkung an sich eine Änderung erführe und das klinische Bild der Schreckneurose als umschriebener Erkrankungsform beeinträchtigt würde. Es kommen hier eben völlig analoge Momente in Betracht, wie sie oben bei Besprechung dex progressiven Paralyse nach Schreck kurz erörtert wurden. Die Benennung „traumatische Psychose" als selbständiges Krankheitsbild kann natürlich ebensowenig in Frage kommen wie die der "traumatischen Neurose" und wird auch von den meisten Autoren (Hübner usw.) abgelehnt. Dagegen stellt die Schreckneurose zweifellos einen fest umgrenzten Symptomenkomplex von immer wiederkehrenden psychischen und somatischen Erscheinungen dar.

Aber nicht nur die spezifische Disposition des einzelnen Individuums ist für die weitere Gestaltung des Falles von integrierender Bedentung, sondern auch mannigfache Momente sekundärer Natur können den Krankheitsverlauf in weitgehendstem Maße beeinflussen. Auf die durch Milien, soziale Stellung und wirtschaftliche Verhältnisse gegebenen Faktoren, die ja übrigens in gewissem Sinne noch ins Gebiet der primären Disposition fallen, wurde schon kurz hingewiesen. Vor allem aber ist die Art und Weise der Regelung der Entschädigungsansprüche, wie bei allen Unfallneurosen, so auch bei den Schreckneurosen für die Prognose geradezu ausschlaggebend. Auf den Wert der Kapitalabfindung ist ja schon von manchen Seiten mit Nachdruck hingewiesen worden (Wimmer, Nägeli, Billström, Laquer). Ich selbst konnte an einem Material von 173 Fällen nervöser Erkrankungen nach Eisenbahnunfällen mit verschiedener Ätiologie zeigen, dass im allgemeinen nur die Rentenempfänger eine weniger günstige Prognose haben, während bei rascher einmaliger Abfindung in der Regel nach kurzer Zeit, in einigen Monaten, mit- 
unter allerdings auch erst nach 1-2-3 Jahren Heilung, zum mindesten in sozialer, wirtschaftlicher Beziehung, erfolgt (unter 136 Abgefundenen 70 Proz. geheilt, 16 Proz. wesentlich gebessert, 11,8 Proz. unverändert, 2,2 Proz. verschlimmert - demgegenüber unter 172 Rentenempfängern Stursbergs 25, o Proz. geheilt oder gebessert, 64,61 Proz. unverändert, 9,89 Proz. verschlimmert). Dabei fanden sich unter den im 1. Jahre Abgefundenen:

90,1 Proz. Geheilte oder Gebesserte,

9,9 "Unveränderte oder Verschlimmerte,

unter den nach dem 1. Jahr Abgefundenen:

80 Proz. Geheilte oder Gebesserte,

$20 \%$ Unveränderte oder Verschlimmerte,

unter den nach dem 2. Jahr Abgefundenen:

70 Proz. Geheilte oder Gebesserte,

30 "Unveränderte oder Verschlimmerte,

unter den nach dem 3. Jahr Abgefundenen:

55 Proz. Geheilte oder Gebesserte,

$45 "$ Unveränderte oder Verschlimmerte.

Der Wert der möglichst baldigen Abfindung tritt also eklatant zutage.

Bei 49 von den 136 Abgefundenen bestand der Unfall im wesentlichen in einer Schreckeinwirkung, wenn auch in einem grösseren Teil der Fälle noch sonstige ätiologische Momente (Kopfkontusion, sonstige lokale Kontusionen, allgemeine Erschütterung) in Frage kamen. Unter diesen 49 Patienten. waren

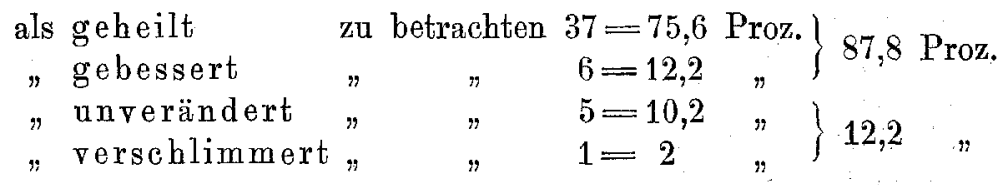

Die Zahl der „reinen" Schreckneurosen, die damals nur 16 (davon 12 geheilt, 2 wesentlich gebessert, 2 unverändert) betrug, beläuft sich, wie schon eingangs erwähnt, mit den neu hinzugekommenen Fällen jetzt auf 100 . Leider war es nicht möglich, über den weiteren Verlauf in sämtlichen Fällen. Auskunft zu erhalten; auch liegt ein grösserer Teil meiner Beobachtungen erst so kurze Zeit zurück, dass sich ein abschliessendes Urteil vielfach noch nicht bilden lässt. Im ganzen lassen sich 3 grosse Gruppen unterscheiden:
1. Abgefundene
35 Fälle.
2. Rentenempfänger 34 ,
3. noch unentschiedene Fälle 31 . 
Von den 35 Abgefundenen, die sämtlich Eisen- und Strassenbahnunfallpatienten betrafen, war in 30 Fällen eine genauere Auskunft über den weiteren Verlauf zu erhalten, wobei besonderer Wert auf die Frage der Wiedererlangung der Erwerbsfähigkeit gelegt wurde. Dabei wurde ermittelt:

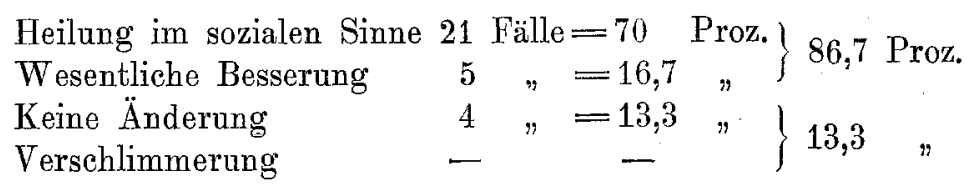

Obwohl in zahlreichen Fällen die Abfindung kaum wenige Monate zurücklag, deckt sich das Ergebnis ersichtlich vollkommen mit unseren früheren Resultaten. Die 4 Fälle $(43,46,85,91)$, in denen trotz der Abfindung angeblich keine Wendung zum Besseren eingetreten ist, betreffen ausnahmslos schwer belastete Individuen: In Fall 43 liegt hereditäre Belastung vor (Mutter seit 24 Jahren wegen Melancholie in der Irrenanstalt); Patientin selbst Iuetisch (Wassermann positiv). In Fall 46 bestand schon vor dem Unfalle bei der sehr zarten, schwächlichen Patientin eine starke hysterische Disposition; weiterhin wirkten ungünstige Familienverhältnisse (Differenzen mit dem Bräutigam, Rückgang des Verlöbnisses usw.) und Prozessaufregungen ein; im ganzen liegt übrigens der Unfall erst $3 \frac{1}{2}$ Jahre, die Abfindung 2 Jahre zurück, so dass immerhin noch eine Besserung zu erwarten steht. Auch in Fall 85 handelte es sich um eine sehr schwächliche, zarte Patientin mit alter Lues, während in Fall 91 bereits vor dem Unfalle ein organisches Herzleiden bestand, das durch die Schreckeinwirkung (Anblick Schwerverletzter) zu vermebrten $\mathrm{Be}$ schwerden führte; daneben bestand Zittern, Kopfröte beim Bücken, lebbafte Reflexe, Angstvorstellungen, Aufgeregtheit, Schlaflosigkeit, Kopfdruck. - Derartige Komplikationen, wie Herzleiden, Lues, sind ebenso wie beispielsweise Arteriosklerose, Diabetes, Alkoholismus und weiter vorgerücktes Alter (etwa über $60 \mathrm{Jahre)}$ natürlich in vielen Fällen für die Prognose von wenig günstiger Bedeutung, wenngleich sie keineswegs in allen Fällen das Abklingen der Unfallfolgen, d. h. der funktionell nervösen Komponente des Krankheitsbildes hintanhalten. Immerhin erfordert die Beurteilung derartig komplizierter Fälle einige Vorsicht and Zurückhaltung. Wesentlich günstiger liegen diejenigen Fälle, bei denen vor dem Unfall Störungen nervöser Natur ohne organische Grundlage bestanden. Hier kommt es in den allermeisten Fällen doch wieder zu wesentlicher Besserung; vielfach klingen die Unfallfolgen nach und nach soweit ab, dass der frühere Zustand wieder erreicht wird, wenigstens hinsichtlich der Erwerbsverhältnisse. Ge- 
wisse Residuen der Schreckwirkung, wie Ängstlichkeit, leichtes Erschrecken, Furcht vor Bahnfahrten usw., bleiben allerdings häufig noch längere Zeit bestehen, ohne aber auf die Erwerbsfähigkeit einen nennenswerten Einfluss auszuüben, gehen ja auch ungezählte nervöse Beamte, Kaufleute usw. in vollem Umfange ihrem Berufe nach.

Ganz erheblich ungünstiger als bei den Abgefundenen waren die Resultate bei den 34 Rentenempfängern, von denen 29 von Berufsgenossenschaften und Behörden gesandte Patienten (darunter 12 Telegraphengehilfinnen) im Arbeiter-, Angestellten- oder Beamtenverhältnis standen, also unfallrechtlich unter analogen Gesichtspunkten zu beurteilen waren; während 5 als Privatpersonen von Versicherungsgesellschaften und Eisenbahnen laufende Entschädigungen nach Massgabe der betr. Versicherungsbedingungen bezw. des Reichshaftpflichtgesetzes bezogen. Diese beiden Kategorien, Arbeiter usw. einerseits, Privatpersonen andererseits, sind unfallrechtlich ja stets ausserordentlich scharf auseinander zu halten. Die Beobachtungsdauer der Fälle erstreckte sich fast durchweg über mehrere Jahre. Dabei ergab sich:

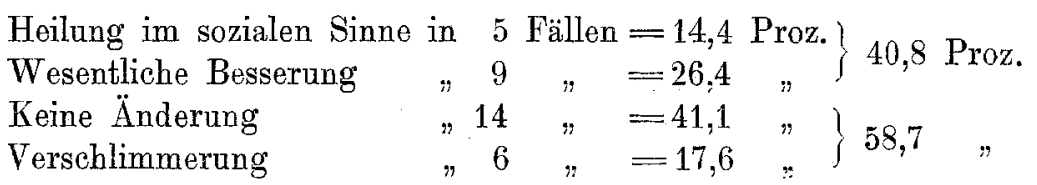

Unter den 8 berufsgenossenschaftlichen Fällen $(3,4,5,6,8$, $9,13,14)$ war nur 2 mal eine derartige wesentliche Besserung zu konstatieren, dass eine Herabsetzung der Rente erfolgen konnte, während in 4 Fällen keinerlei Änderung festzustellen war und 2 mal eine Verschlimmerung konstatiert werden musste. Ebenso ungünstig war der Verlauf bei den 12 Telegraphengehilfin $n$ en, denn nur 2 (71 und 76) vermochten ihre frühere Tätigkeit in vollem Umfange wieder durchzufïhren, während 2 nur in beschränktem Umfange wieder dienstfähig wurden und je 4 keine Änderung bezw. eine Versehlimmerung zeigten, so dass in den meisten Fällen wegen eingetretener Dienstuntauglichkeit eine Pensionierung erfolgen musste. Besonders bemerkenswert sind die beiden verschlimmerten Fälle 70 und 74 , die anfangs beschränkt dienstfähig blieben, nach dem Hinzutritt von. stark ausgesprochenen Rentenbestrebungen aber eine wesentliche Verschlimmerung erfuhren. Noch am günstigsten war der Verlauf bei einigen Eisenbahn- und männlichen Postbeamten, denn 3 wurden völlig wiederhergestellt, 2 zeigten eine wesentliche Besserung und nur 2 blieben unverändert. Unter den Geheilten möchte ich vor allem den bereits früher zitierten Fall 10 hervorheben, bei dem die Schreckneurose innerhalb von 6 Monaten auch in medizinischer Hin- 
sicht als vollkommen abgeklungen zu bezeichnen war, so dass Patient seinem Dienst als Postschaffner wieder ohne irgendwelche Beeinträchtigung nachgehen konnte und keinen Rückfall erlitt. Gerade der Eintritt oder das Ausbleiben derartiger Rückfälle bietet ja einen augenfälligen Maßstab für die wiedererlangte psychische und somatische Widerstandsfähigkeit. Allzu frühe Wiederanfnahme der vollen Berufstätigkeit wirkt zweifellos vielfach ebenso ungünstig wie Mangel jeglicher Betätigung. Leider stösst eine allmähliche Wiederaufnahme des Berufes praktisch oft auf grosse Schwierigkeiten. Wo sie aber durchführbar ist, ist sie meist vòn allergünstigstem Erfolg begleitet.

Die 5 Privatpatienten, die von Versicherungsgesellschaften bzw. Behörden laufende Entschädigungen bezogen, zeigten in 3 Fällen eine wesentliche Besserung, während 1 Fall bisher unverändert blieb und in 1 Falle (22), der einen 55 jährigen Kriminalwachtmeister betraf (Schreckneurose nach Strassenbahnunfall), nach Abschluss des mehrjährigen Prozesses gegen die Versicherungsgesellschaft eine dauernde Dienstunfähigkeit angenommen wurde. Sicher war in diesem Falle die Hauptursache des ungünstigen Verlaufes in den langwierigen Rentenkämpfen zu suchen.

Überhaupt üben gerade Haftpflichtprozesse und alles, was damit zusammenhängt, in der Regel einen ganz ausserordentlich schädlichen Einfluss aus. Nicht nur die Suggestionen Dritter, vor allem sogenannter guter Freunde und Winkeladrokaten, sondern auch die vielfachen Vernehmungen, ärztlichen Untersuchungen und Anwaltsbesprechungen wirken auf die Dauer ungünstig ein. Dazu kommen die eignen übertriebenen Krankheitsvorstellungen, die Angst vor körperlichem Ruin, die Sorge um die Erhaltung der Existenz und zum Teil als Folge dieser Befürchtungsvorstellungen und als eine der schädlichsten Faktoren meist masslose Begehrungsvorstellungen. Gerade letztere werden und m. E. mit Recht von vielen Autoren als eine der wichtigsten Ursachen der sogen. Rentenkampfneurosen betrachtet. Sicher tragen sie ebenso wie die Befürchtungsvorstellungen in stärkstem Maße dazu bei, das ursprïngliche primäre Krankheitsbild nach hypochondrisch-querulatorischer Richtung hin zu modifizieren, wie ich es schon früher an anderer Stelle ausführlich darzulegen Gelegenheit hatte. Damit aber wird die Prognose, je länger ein derartiger Haftpflichtprozess andauert, mehr und mehr nach der ungünstigen Seite hin verschoben (vergl. auch die früher mitgeteilte Tabelle.).

Die Krankheitsvorstellungen nisten sich allmählich derart ein, dass selbst bei später erfolgender Abfindung die Ausheilung mitunter viel längere Zeit in Anspruch nimmt als bei zeitiger Erledigung des 
Falles. Inwieweit hierbei Zustandsänderungen der dauernd gereizten Nervenelemente mitspielen, lässt sich nach dem bisherigen Stande der Wissenschaft natürlich nur vermuten. Wenn aber Wichmann sagt, dass "bei lange Zeit bestehenden hysterischen oder psychogenen Affektionen allmählich or ganische Veränderungen in der Nervensubstanz sich entwickeln, welche nicht mehr zu reparieren sind", so vermag ich dem nicht beizustimmen. Jedenfalls dürften organische Veränderungen in dem bisher üblichen Sinne des Wortes im allgemeinen ausgeschlossen sein. Es ist aber, worauf schon früher hingewiesen, zuzugeben, dass der Zustand gesteigerter Reizbarkeit und Ansprechbarkeit derjenigen Ganglien- und Faserkomplexe, die Träger der auf den Unfall bezüglichen Vorstellungen sind, sehr wahrscheinlich begriindet ist in nutritiven, mit Zirkulationsanomalien einhergehenden Veränderungen, d. h. in einer Änderung im Chemismus des Nervenstoffwechsels (Fr. Schultze) und damit auch in einer Zustandsänderung der Neurone im Goldscheiderschen Sinne.

Dass während der Prozessdauer eine wesentliche Besserung des Gesamtzustandes eintritt, ist geradezu eine Seltenheit, während nach Erledigung des Prozesses oder überhaupt der Entschädigungsfrage vielfach in kurzer Zeit eine fortschreitende T'endenz zur Besserung und Heilung sich zeigt, selbst in solchen Fällen, die vorher einen prognostisch wenig günstigen Eindruck machten. Auch Sachs sah anscheinend schwere und schwerste nervöse Störungen nach Auszahlung der Entsehädigungssumme in kurzer Zeit dauernd verschwinden. Dabei braucht Simulation keineswegs stets eine Rolle zu spielen. Ausschlaggebend ist die endgültige finanzielle Erledigung oder Nichterledigung des Falles und damit der Fortfall bzw. das Weiterbestehen all der Sorgen, Aufregungen, Verdriesslichkeiten usw., die mit der Durchführung eines Rechtsstreites verbunden sind.

So sehen wir, dass unter der 3 . Gruppe, den 31 noch unentschiedenen Fällen unseres Materials nur bei 5 Patienten $(=16,1$ Proz.) durch Heilverfahren usw. eine Besserung erzielt wurde, während 21 Fälle $(=67,8$ Proz.) bisher unverändert geblieben sind und $5(=16,1$ Proz.) eine unverkennbare Verschlimmerung erfahren haben. Es handelte sich durchweg um Eisen- und Strassenbahnunfallpatienten. In 13 Fällen schweben noch Haftpflichtprozesse und unter diesen Patienten konnte im Laufe des Prozessverfahrens bisher nur bei einem einzigen Falle (37) eine wesentliche Besserung und Zunahme der Erwerbsfähigkeit festgestellt werden, während 3 Fälle sich unter dem unverkennbaren Einflusse der Prozessaufregungen usw. verschlimmert baben und die übrigen 9 bisher unverändert geblieben sind. Ersichtlich liegen die Fälle, in denen das Entschädigungsverfahren ebenfalls noch 
unerledigt ist, aber kein Haftpflichtprozess schwebt, noch wesentlich günstiger (unter 18 Fällen 4 mal Besserung, 12 mal keine Änderung, 2 mal Verschlimmerung), wenn auch bisher nicht in einem einzigen Falle eine Heilung im medizinischen oder sozialen Sinne eingetreten ist.

Die unerledigten Fälle sind also im wesentlichen mit den Rentenempfängern auf eine Stufe zu stellen. Hier wie dort zeigen nur ganz vereinzelte Fälle Neigung zur Besserung oder Heilung, während beim Gros der Patienten der Zustand unverändert bleibt. Hier ist es das Bestreben, die einmal erkämpfte Rente möglichst zu erhalten, dort die Sucht, eine möglichst hohe Entschädigung, sei es auch unter langwierigen Prozessen, herauszuschlagen. Allerdings gibt es, das soll keineswegs bestritten werden, sicher zahlreiche Patienten, bei denen die Begehrungsvorstellungen nur eine untergeordnete Rolle spielen, aber sie sind $m$. E. in der Minderheit. Die allermeisten Unfallpatienten gehen mit ihren Ansprüchen weit hinans über das Maß dessen, was ihrer bisherigen Lebensführung und ihrem tatsächlichen Schaden entspricht. Dass die neueren Reichsgerichtsentscheidungen diesem Unfug ganz energiseh entgogenwirken, ist nur zu begrüssen. Das Reichsversicherungsamt hat ja schon vor Jahren die einzig und allein durch die Prozessaufregungen verursachten nerrösen Störungen als nicht entschädigungspflichtig erklärt, während das: Reichsgericht erst in neuerer Zeit dann die Ansprüche unter Annahme konkurrierenden Verschuldens ganz oder teilweise abgewiesen hat, wenn trotz Entgegenkommens des Haftpflichtigen die Forderungen des Patienten ins Masslose gingen, der Kampf um die Entschädigung also ein unberechtigter war. Aber auch die neuerdings immer häufiger geübte Praxis der Gerichte, bei nervösen Unfallfolgen statt einer Daxerrente nur mehr eine fallende, zeitlich begrenzte Rente zuzuerkennen, hat sich den im Laufe der Jahre ja völlig umgewandelten Anschauungen über die Prognose der Unfallneurosen angepasst und bedentet zweifellos einen ganz erheblichen Fortschritt, wird doch damit den tatsächlichen Verhältnissen in gerechter, angemessener Weise Rechnung getragen.

Dass die Erwerbsbeschränkung bei den Unfallneurosen und speziell bei den Schreckneurosen in der ersten Zeit nach dem Unfall eine sehr beträchtliche ist, liegt auf der Hand, sind doch vor allem die psychischen Erscheinungen im Anfange meist sehr ausgesprochen. Unter unseren 100 Fällen bestand zum mindesten im 1. Monat nach dem Unfall vollkommene Erwerbsunfähigkeit bei etwa 70 Proź. Der weitere Verlanf war dann im wesentlichen abhängig von der Handhabung des Entschädigungsverfahrens (Abfindung, Rente, Prozess). 
Im Durchschnitt kann man bei beabsichtigter Kapitalabfindung für mittelschwere, nicht komplizierte Fälle rechnen:

100 Proz. Erwerbsbeschränkung für das 1. halbe Jahr

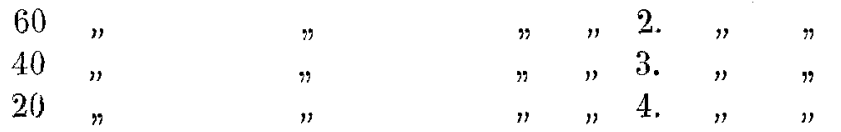

und kann annehmen, dass nach Ablauf von 2, höchstens 3 Jahren erwerbsbeschränkende Unfallfolgen nicht mehr vorliegen. In leichteren Fällen klingen die Unfallfolgen bei frühzeitiger Abfindung schon in wenigen Monaten ab, während bei Patienten mit hochgradigen Störungen and schwerer endogener Veranlagung gelegentlich erst nach 3,4 oder 5 Jahren eine völlige Restitutio ad integrum in wirtschaftlicher Hinsicht eintritt. Auch in veralteten, nicht zur Erledigung gekommenen Fällen (etwa über 2-3 Jahre alt) vergehen, zumal wenn langwierige Prozesse stattgefunden, bis zur Wiederherstellung mitunter noch einige Jahre. Sehwieriger liegt die Beurteilung der Heilungsaussichten bei bestehenden Komplikationen mit schwerer Arteriosklerose (besonders Gehirnarteriosklerose und Angina pectoris), Herzleiden, Alkoholismus, Lues, Diabetes mellitus und sonstigen organischen Störungen. In vielen derartigen Fällen ist, falls das komplizierende Grundleiden nicht selbst durch die Unfalleinwirkung nachweisbar verschlimmert wurde, eine Abfindung unter Annahme einer mehrjährigen, allmählich fallenden Erwerbsbehinderung am Platze. Mitunter empfiehlt sich aber auch ein abwartendes Verhalten, bzw. Rentengewährung, so besonders bei Diabetes mellitus sowie bei posttraumatischer Verschlimmerung des Grundleidens, von dessen Natur im übrigen die Prognosenstellung abhängig ist. Vielfach klingt die nervöse Komponente des Gesamtkrankheitszustandes im Laufe der Jahre wieder ab, wenn auch meist eine etwas längere Zeit dazu erforderlich ist als bei fehlender Komplikation. Dass bei komplizierenden Erkrankungen vor der Anerkennung des ursächlichen Zusammenhanges zwischen Unfall und psychisch-nervösen Störungen aufs sorgfältigste zu prüfen ist, ob diese Störnngen auch tatsächlich mit überwiegender Wahrscheinlichkeit auf den Unfall zuxückzufübren oder ob sie vorher oder später unabhängig von dem Unfall hinzugetretenen sonstigen Erkrankungen zur Last zu legen sind, ist zwar selbstverständlich, dürite aber doch im Hinblick auf die unfallrechtliche, praktische Tragweite nochmals mit Nachdruck hervorzuheben sein. Ebienso muss, wie Reichardt mit Recht betont, genau erwogen werden, ob der Unfall nur eine zufällige Gelegenheitsursache oder eine wesentliche Teilursache fiü den Ausbruch oder die Verschlimmerung der Krankheitserscheinungen darstellte. 
Natürlich können alle derartige Angaben nur als allgemeine Richtlinien betrachtet werden; denn gerade bei den Schreckneurosen ist strengste Individualisierung am Platze. Wir haben aber bei Anwendung obiger Grundsätze zahlreiche Fälle glatt zur Erledignng kommen sehen und haben gefunden, dass der weitere Verlauf zumeist der Abschätzung entsprach, ja dass mitunter die soziale Wiederherstellung noch weit eher eintrat, als angenommen worden war. Auch die Erfahrungen von Hübner, Nägeli u. a. decken sich im wesentlichen mit unseren Anschauungen. In derart günstigem Lichte wie Reichardt, der selbst bei bestehender endogener Veranlagung die Wiederkehr der Erwerbsfähigkeit bereits nach $1 / 4$ bis $1 / 2$ Jahre annimmt, vermag ich allerdings nach unseren eingehenden katamnestischen. Untersuchungen die Prognose nicht zu betrachten. Auch die an sich ausserordentlich wertvollen Angaben von Stierlin, dass die grosse Mehrzahl der Verunglïckten in Messina psychiseh bereits nach einem Monat wieder gesund war und dass nach $1 / 2$ Jahre kein einziger mehr irgend welche psychische oder neurologische Störung zeigte, dürften sich in der Praxis der Unfallbegutachtung, wo noch manche andere indirekt mit dem Unfall zusammenhängende Momente in Betracht kommen, nur teilweise bestätigen. Vor allem kommt es darauf án, ob auch die Erwerbsfähigkeit sich völlig wiederherstellt. Auch wir haben zahlreiche Fälle rasch abklingender Schreckneurose gesehen, andererseits aber auch zahlreiche Patienten, die trotz Abfindung nur allmählich wieder in ibre frühere Tätigkeit sich einzuarbeiten vermochten. Manche waren zu ibrem bisherigen Berufe überhaupt nicht mehr zu brauchen, z. B. Telegraphengehilfinnen, Eisenbahnbeamte usw., konnten sich aber vor und nach auf anderen Gebieten wieder betätigen und sich allmählich eine neve Lebensstellung wieder schaffen. Nach alledem glaube ich vor allzu grossem Optimismus, bzw. übertriebener Schärfe warnen zu müssen; sehr viele Fälle, besonders endogen veranlagte und organisch komplizierte, erfordern sicher bis zur völligen Wjederherstellung längere Zeit.

In schwierigeren Fällen, in denen die Ansichten der Gutachter auseinandergingen oder eine Einigung zwischen Patient und Haftpflichtigem auf Sehwierigkeiten stiess, haben wir mehrfach zur Einberufung eines ärztlichen Schiedsgerichts geraten, dem je ein Vertrauensarzt sowie ein von den Vertrauensärzten zu wählender Obmann angehörte. Ich glaube, dass sich auf diesem Wege manche Prozesse und damit Schädigungen der Patjenten vermeiden lassen. Leider ist die Möglichkeit der Abfindung unfallverletzter Arbeiter bekanntlich nur bei einer Erwerbsbeschränkung bis zu 20 Proz. gestattet. Wenn ich auch der Ansicht bin, dass sich die Erfahrungen, 
die über die Wirkung des Abfindungsverfahrens bei unfallverletzten, nach dem Reichshaftpflichtgesetz und dem BGB. zu entschädigenden Privatpersonen bekannt geworden sind, nicht ohne weiteres auf die staatliche Unfallversicherung übertragen lassen, so glaube ich doch, dass man den Rumpfschen Vorschlag, die Abfindung unfallverletzter Arbeiter schon bei einer Teilrente von $33 \frac{1}{1} 3$ Proz. zu ermöglichen, nur als gerechtfertigt bezeichnen kann. Im übrigen sollte in den Bestimmungen des Reichshaftpflichtgesetzes bzw. des BGB. die Möglichkeit geschaffen werden, nerröse Unfallpatienten durch richterliche Entscheidung auch wider ihren Willen einmalig abzufinden; denn daran ist unter allen Umständen festzuhalten, dass an und für sich die Schreckneurose, trotz ihrer verschieden langen Dauer im Einzelfalle, eine durchaus günstige Prognose besitzt. Hierauf weisen auch diejenigen Fälle mit aller Deutlichkeit hin, bei denen keinerlei Entschädigungsansprüche in Frage kommen, wie z. B. bei den meisten Fällen Stierlins. Auch Döllken hat schon vor Jahren über akut ablaufende Unfallneurosen bei Offizieren, Sportsleuten und Studenten berichtet. Ebenso hebt Reichardt hervor, dass die im Gefolge von Affekten auftretenden körperlichen Störungen, an sich betrachtet, ausnahmslos vorübergehender Natur seien und dass selbst die stärksten, mit stundenlanger Todesangst einhergehenden seelischen Erregungen im allgemeinen keine dauernden körperlichen Veränderungen von erheblicher Bedentung für die Erwerbsfähigkeit zu bewirken vermögen. Dașs die bei Schreckneurosen ja fast stets vorhandenen kardiovaskulären Symptome meist nach und nach verschwinden, konnte ich schon an anderer Stelle (D. m. W. 1914, 2) mitteilen. Genau dasselbe lässt sich von den übrigen somatischen Erscheinungen behaupten. Selbst Symptome, die zunächst einen ungünstigen Eindruck machen, können sich verlieren oder doch wesentlich bessern, wie wir es z. B. bei einigen Fällen von Schreckneurose mit choreatischen Störungen gesehen haben. Hartnäckig ist häufig die Schlafstörung. Auch eine gewisse innere Unruhe, allgemeine Erregtheit, Ängstlichkeit und Schreckhaftigkeit macht sich oft noch längere Zeit bemerkbar, um sich nur ganz allmählich zu verlieren, während die initialen psychischen Symptome, besonders die Verwirrtheitszustände, zumeist in wenigen Stunden in der Hauptsache wieder zurückgehen. Vor allem aber steht fest, dass früher vollkommen gesunde und von endogener nervöser Disposition freie Individuen nur sehr selten an länger dauernden Erscheinungen von Schreckneurose erkranken. Aber auch bei bestehender Veranlagung und vorhandenen Komplikationen pflegt in der Regel ein allmähliches Wiederabklingen der Unfallfolgen einzutreten, vorausgesetzt, dass dieses Ab- 
klingen nicht durch sekundär einwirkende schädliche Momente verzögert wird.

\section{Zusammenfassung.}

1. Die Schreckneurose stellt eine besondere Gruppe der „traumatischen Neurosen" oder Unfallneurosen dar von scharf umschriebener klinischer Selbständigkeit.

2. Sie ist eine ausgesprochene Psychoneurose und als solche charakterisiert auf psychischem Gebiete durch eine allgemeine Exaltation, event. mit vorübergehender Verwirrtheit, und durch fixierte Angstaffekte, auf somatischem Gebiete durch eine Disharmonisierung des vegetativen Nervensystems.

3. Im Vordergrunde der somatischen Erscheinungen stehen vor allem kardiovaskuläre Symptome (vasomotorischer Symptomenkomplex).

4. Die Schreckreaktion erfordert an sich keine besondere Disposition, doch besteht praktisch die grosse Mehrzahl der Schreckneurotiker aus schon vorher kranken, zum mindesten stark disponierten Individuen.

5. Ausschlaggebend für den weiteren Verlauf der Schrecknenrose ist einerseits die spezifische Disposition des Individuums, andererseits die Gestaltung der Entschädigungsfrage.

6. Bei baldiger Kapitalabfindung ist bei mittelschweren, nicht komplizierten Fällen in der Regel in 2 Jahren völlige Wiederherstellung der Erwerbsfähigkeit zu erwarten; Rentengewährung und Prozesse tragen nur dazu bei, das Krankheitsbild zu fixieren und zur Rentenkampfneurose umzugestalten.

7. Nur bei bestehender Komplikation mit schweren organischen Leiden kommt ein abwartendes Verhalten bzw. Rentengewährung in Frage.

8. Die Auslösung bzw. Verschlimmerung von Diabetes mellitus, Diabetes insipidus, M. Basedowii, progressiver Paralyse und von manchen anderen organischen Erkrankungen durch Schreck erfolgt auf dem Wege des vegetativen Nervensystems.

\section{Literatur.}

Babinski, Ma conception de l'hystérie et de l'hypnotisme 1906.

Becker, Lehrb. der ärztl. Sachverständigentätigkeit. Berlin 1907. zig 1908 .

Derselbe, Die Simulation von Krankheiten und ihre Beurteilung. Leip.

Becker, Th., Über nervöse Nachkrankheiten des Mülheimer Eisenbahnunglücks. M. m. W. 1910, 29.

Derselbe, Über Hysterie. D. militärärztl. Zeitschr. 1911, 4. 
Berger, Über die körperlichen Äusserungen psychischer Zustände. Jena 1904 u. 1907.

v. Bergmann, Das spasmogene Cleus pepticum. M. m. W. 1913, 4. Bernhardt, Die Betriebsunfälle der Telephonistinnen. Berlin 1906. Derselbe, Weitere Mitteilungen usw. Berl. kl. W. 1908, 31 u. 32. Nov. 1910.

Billström, Studien über die Prognose traumatischer Neurosen. Hygiea.

Bing u. Stierlin, Beobachtungen über psychonenrotische Störungen infolge der Eisenbahnkatastrophe zu Müllheim i. B. Neur. Zentralbl. 1912, 14.

Biss, Beiträge aus der Praxis usw. Ärztl. Sachv.-Ztg. 1904, 13 v. 14.

Derselbe, Was lehren die Akten der Berufsgen. usw. Ärztl. Sachv.-Ztg. 1910, 22.

Böhnig, Hysterische Unfallerkrankungen bei Telephonistinnen. M. m. W. $1905,16$.

Boissier, Progrès med. 1899.

Bonhöffer, Psychogene Krankheitszustände. Allg. Zeitschr. f. Psychiatrie. 1911, 3.

Breithaupt, Die Reehtsprechung des Reichsversicherungsamts. Berlin 1912. S. 1358 .

Broadbert, Anomalien des Blutdrucks. Wiener med. Presse. 1898.

Cassirer, Die Rolle des vegetativen Nervensystems in der Pathologie der vasomotorisch-trophischen Neurosen. Med. Klin. 1912, 47.

Cramer, Die Begutachtung der nervösen Unfallerkrankungen sowie der nervösen Beamten. D. m. W. 1912, 12.

Döllken, Neurol. Zentralbl. 1906.

Dommrich, Die psych. Zustände, ihre organ. Vermittlung u. ihre Wirkung in Erzeugung körperlicher Krankheiten. 1849 (s. Kühne).

D a b, Über Epilepsie mit besond. Berücks. versicherungsrechtlicher Fragen. Diss. Bonn 1912.

Dubois, Über die Definition der Hysterie. Korrespond.-B]. f. Schweizer Ärzte. 1911, 19.

Edinger, Bau u. Verrichtungen des Nervensystems. Leipzig 1912.

Eichelberg, Zur Kasuistik der als „Eisenbahnfurcht" beschriebenen Unfallneurosen. Diss. Bonn 1905.

Engelen, Simulation und Aggravation neurasthenischer Beschwerden. Ärztl. Sachv.-Ztg. 1911, 8.

Eppinger u. Hess, Die Vagotonie. Berlin 1910 u. Zeitschr. f. klin. Med. 67,68 .

Erben, Über die Neurosen nach Unfällen. Med. Klin. 1910, 32. 1912.

Derselbe, Diagnose der Simulation nervöser Symptome. Berlin u. Wien

Erichsen, On railway and other injuries of the nervous system. London 1866. Deutsch von Kelp, Oldenburg 1868.

Eulenburg, Über Nerven- und Geisteskrankh. nach elektr. Unf. Berl. klin. W. 1905,2 u. 3.

Faust, Therapie der Schreckneurose. Ärztl. Sachr.Ztg. 1913, 16.

Finkelnburg, Erscheinungen von Bulbärparalyse (and Acusticusstörungen) nach Starkstromverletzung. Mon. f. Unf. u. Inv. 1914, 3. 
Flatau, Die Nervenkrankheiten nach Unfällen. Leipzig 1912.

Förster, Unfälle am Telephon wnd deren Verhütung. Berl. klin. W. 1911,37 .

Goldscheider, Die Bedeutung der Reize für Path. u. Ther. im Lichte der Neuroplehre. Leipzig 1898.

Derselbe, Zur Theorie der traumat. Neurosen. Ref. Mon. f. Unf. u. Inv. $1902,7$.

Gordon, Neurological and psychiatric aspects of railway accident cases. Consideration of some medicolegal problems. Medical Record. 24. Oktober 1914.

Gumpertz, Wie wirken Traumen auf die Psyche erblich belasteter und seelisch minderwertiger Personen? D. med. Presse. 1901, 15-17.

Ha mburger, Über den vasoneurotischen Symptomenkomplex bei Kindern. M. m. W. 1911,42 .

Horn, Über nervöse Erkr. nach Eisenbahnunfällen mit besond. Berücksichtigung ihrer Beeinflussung durch Kapitalabfindung bzw. Rentenverfahren. Bonn 1913.

Derselbe, Über Simulation bei Unfallverletzten und Invaliden. Ärztl. Sachv.-Ztg. 1913, 11 u. 12.

Derselbe, Über Herzstörungen nach Unfall. D. m. W. 1914, 2.

Derselbe, Über Nervenleiden nach Unfall und Arteriosklerose usw. Monatsschr. f. Unfallheilkde. u. Invalidenwesen 1915, 1.

Derselbe, Über die neuere Rechtsprechung bei Unfallneurosen. Ärztl. Sachv.-Ztg. 1915. 4 u. 5.

Hübner, Trauma und Neurosen im Kindesalter. Reichsmedizinalanzeiger 1910,20 u. 21.

Derselbe, Lehrb. der forensischen Psyehiatrie. Bonn 1914.

Jakoby, Über die Folgen elektr. Entladungen auf den Menschen, spez. über Telephonunfälle. Diss. Bonn 1912.

Jasinsky, zit. nach Thiem.

Jellinek, Pathol., Ther., Prophylaxe der elektr. Unf. D. m. W. 1907, $10 \mathrm{u} .11$.

Katsch, Pharmakologische Einflüsse auf den Darm. Zeitschr. f. experim. Pathol. u. Therapie, 1913.

Derselbe, Der menschl. Darm bei pharmakol. Beeinfl. seiner Innervation. Fortschr. a. d. Geb. d. Röntgenstrahlen, Bd. 21.

Kölpin, Trauma u. Paralyse. Allg. Zeitschr. f. Psychiatrie, Bd. 63.

Kräpelin, Psychiatrie. Leipzig 1904.

Kühne, Die Bedeutung des Schrecks für die Entstehung ron Nerven- u. Geisteskrankheiten. Neurol. Zentralbl. 1910. S. 1340 usw.

Derselbe in Thiem, Handb. d. Unfallerkrankungen.

Lacombe, De la polydipsie. Thèse. Paris 1841: Zitiert nach Stern, Traumat. Entstehung innerer Krankheiten. Jena 1900.

Langley, Das sympath. u. verwandte nervöse System der Wirbeltiere. Ergebnisse der Physiologie II. 1903.

Laquer, Die Heilbarkeit nervöser Unfallsfolgen. Halle 1912.

Lorand, St. Petersburger m. W. 1903, 22. 1908.

Mendel, K., Der Unfall in der Ätiologie der Nervenkrankheiten. Berlin 
Menier, Verfahren, die Simulanten unter den Unfallkranken zu entdecken. Ref. Mon. f. Unf. u. Inv. 1904, 11.

Merzbacher, Statist. Bemerkungen über Unfallneurosen. Zentralbl. f. N. u. Psych, 1906.

Meyer, Hans H., Stand der Lebre vom Sympathicus. Referat auf dem deutschen Neurologenkongress Hamburg 1912.

Moeli, Über psychische Störungen nach Eisenbahnunfällen. Berl. klin. W. 1881,6 .

Moser, Trauma und Psychose. Ärztl. Sachv.-Ztg. 1903.

Müller, L. R., Stand der Lehre vom Sympathicus. Ref. auf d. d. Neur. Kongr. Hamburg 1912.

Nägeli, Nachuntersuchungen bei traumat. Neurosen. Korresp.-Bl. f. Schweizer Ärzte 1910, 2 u. 3.

Derselbe, Über Rechtsansprüche bei Unfallneurosen. 1913.

Oppenhejm, Die traumatischen Neurosen. Berlin 1889 u. 1892.

Derselbe, Lehrb. der Nervenkrankheiten. 5. Aufl. 1908.

Pawinski, Über den Einfluss der Gemütshewegungen und geistiger Überanstrengung auf das Herz, insbesondere auf die Entstehung der Arteriosklerose. Zeitschr. f. klin. Med. Bd. 79, Heft 1 u. 2.

Pfahl, Erfahrungen über Verletzungen durch Blitz und Elektrizität. D. m. W. $1908,29$. $49-52$.

Placzek, Müssen Unfälle nervöse Folgen haben? Med. Klin. 1913.

Räbinger, Kasuistik der Nervenkrankh. nach elektr. Trauma. D. m. W. $1905,22$.

Reichardt, Bemerkuygen über Unfallbegutachțung. und Gutachterwesen. Jena 1910.

Derselbe, Über die Folgen psychischer Vorgänge auf Körper und Seele. Zeitschr. f. Versicherungsmedizin. 1914, 2 u. 3.

Remlinger, Soc. méd. des hôpit. 9. Nov. 1906; ref. Wien. klin. ther. W. 23. Dez. 1906.

Riebel, Arch. f. Psychiatrie. Bd. XXXI. 1879.

Rigler, Über die Folgen der Verletzungen auf Eisenbahnen. Berlin

Rivolta, Traumat. Arteriosklerose. Il policlinico, März 1907; ref. M. m. W. 1907, 25.

Rumpf, Medizin. Klin. 1912, 45.

Derselbe, im Lehrb. der Arbeiterversicherungsmedizin von Gumprecht u. Pfarrius. Leipzig 1913. 1907, 24.

Derselbe, Über Krankheitssimulation bezw. Dissimulation. D. m. W.

Derselbe, Über funktionelle Erkrankungen des Nervensystems nach Unfällen. Klin.-therapeut. Wochenschr. 1914, 27.

Derselbe, Über Arteriosklerose und Unfall. D. m. W. 1914, 21.

Rumpf u. Horn, Über den Verlauf nervöser Erkrankungen nach Eisenbahnunfälleo. D. Zeitschr. f. Nervenheilkde. 1912.

Rumpf u. Selbach, Mon. f. Unf. u. Inv. 1910, 10 u. 11.

Sachs, Die Unfullneurose. Breslau 1909.

Sachs und Freund, Erk. d. Nerv. nach Unfällen. Berlin 1899. 
Über Schreckneurosen in klinischer und unfallrechtlicher Beziehung. 403

Schmaltz, Zur Kenntnis der Folgen elektrischer Traumen. M. m. W. 1904,29 ,

Schreiber, Ein Beitr. z. Frage des Zusammenhanges zw. progr. Paralyse und Unfall. Diss. Bonn 1914.

Schultze, Fr., Über Neurosen u. Neuropsychosen nach Trauma. Volkmanns Sammlg. klin. Vorträge 1891, 14.

Derselbe; Über Poly-, Para- und Monoklonien und ihre Beziehungen zur Chorea. D. Zeitschr. f. Nervenheilkde. 1898. Bd. 13.

Derselbe, Ein Fall von hysterischer Tanbbeit. D. Ärzte-Ztg. 1901, 4. Schultze u. Stursberg, Erfahrungen über Neurosen nach Unfällen. Wiesbaden 1912. 1910.

Schuster, Drei Vorträge aus dem Gebiete der Unfall-Neurologie. Leipzig

Derselbe, Die Krankheiten der Telephonangestellten. Handb. d. Arbeiterkrankh. von $\mathrm{W}$ eyl.

Stierlin, Über die medizin. Folgezustände der Katastrophe von Courrières usw. Berlin 1909.

Derselbe, Nerröse und psychische Störungen nach Katastrophen. D. m. W. 1911, 44 .

Derselbe, Effet des catastrophes sur le système nerveux. Ann. d'hyg. publ. et de méd. lég. Paris, Juli 1912.

Strauss, Die Blutdruckmessung im Dienste der Diagnostik traumat. Neurasth. u. Hysterien. Neur. Zentral-Bl. 1901, 106.

Strümpell, Über die traumat. Neurosen. Rẹf. a. d. 12. Kongr. f. i. Med. Wiesbaden 1893.

Derselbe, Über die Untersuchung, Beurteilung usw. M. m. W. 1895, 49 d. 50. 1911.

Stursberg, Über die Häufigkeit der Unfallneurosen. Neurol. Zentralbl.

Thiem, Handbuch der Unfallerkrankungen. 2. Aufl 1910.

Veis, Betriebsunfälle am Telephon. M. m. W. 1909, 9.

Wallbaum, Über funkt. nerv. Störungen b. Telephonist. u. elektr. Uñf. D. m. W. 1905, 18 .

Watermann u. Baum, Die Arteriosklerose eine Folge des physischen u. psych. Traumas. Neurol. Zentral-Bl. 1906, 24. 1910.

Weber, E., Der Einfluss psychischer Vorgänge auf den Körper. Berlin

Wichmann, Über Suggestion u. Autosuggestion Verletzter. Mon. f. Unf. u. Inv. 1895.

Wilms, Nerv. Störungen nach Unfällen durch Elektr. Diss. Bonn 1904.

Wimmer, Über die Prognose der traum. Neurose u. ihre Beeinfl. durch die Kapitalabfindung. Zentralbl. f. Nervenh. u. Ps. 1906.

Derselbe, Über Rezidive von traumat. Neurose. D. Z. f. Nervenh. 1913.

Windscheid, Über Hirnerschütterung. D. m. W. 1910, 1. 